Reprod. Nutr. Dévelop., 1984, 24 (5 B), 707-765.

\title{
Motricité de l'intestin grêle : organisation, régulation et fonctions. - Quinze ans de recherches sur les complexes migrants
}

\author{
J.-P. LAPLACE
}

Laboratoire de Physiologie de la Nutrition, I.N.R.A. F-78350 Jouy-en-Josas, France.

Summary. Small intestine motility : its organization, regulation and functions. Fifteen years of research on migrating complexes.

The motility pattern of the small intestine has been widely studied over the past fifteen years since a cyclically recurring and distally migrating sequence of myoelectric and motor events was first discovered. Myoelectric or motor migrating complexes (MMC) are composed of 3 main consecutive phases : quiescence, irregular spiking activity and regular spiking activity. Though specific characteristics have been recorded, this sequence seems to be a common pattern in several species of mammals, despite wide differences in digestive anatomy and physiology and very different food habits. Moreover, the basic pattern has been observed to be able to adapt to the mode of feeding and the food composition. Usually, MMC are initiated on the duodenum, but they may be initiated at any level from wandering sources. The anatomical integrity of the intestinal wall is necessary to regular proximodistal migration of the full sequence. Through the cholinergic network of the plexuses, the intrinsic nervous system plays a determinant role in controlling both the initiation and the migration of MMC. The cyclic recurrence of the full sequence, which seems to be a property of the intrinsic plexuses, can be explained by analogy with relaxation oscillators. Nevertheless, the extrinsic nervous system also plays a role, mainly by modulating the duration and intensity of the irregular spiking activity phase. Such a modulation supports the adaptive changes of MMC to feeding. The significance of several hormones and regulatory peptides has also been considered, as some of them cyclically vary in phase with MMC and, as exogenous peptides, they may affect MMC. However, none of these substances plays any determinant role; they rather serve as feedback regulations coordinating small intestine motility with gastric function and pancreatic and biliary secretion, thus giving rise to the so-called secretory component of MMC. The secretions show a cyclic pattern parallel to the MMC pattern, resulting in a cyclic variation of the $\mathrm{pH}$ of the duodenal contents. Moreover, it now appears that nervous and humoral controls of MMC should not be distinguished. An overall view of the whole control system is even more complicated due to the possible role of the central nervous system and to the ubiquity of several peptides of the brain-gut axis. In spite of extensive data on these mechanisms, there are still several gaps in our knowledge. But the MMC pattern and its related functions obviously support the coordination of the sequential events involved in digestion. As regards specific motor function, MMC control the transit time by setting a cruise rate for the passage of digesta. The passage occurs as separate batches of contents propelled by peristalsis in the segment affected by an irregular spiking activity. However this pattern is also fragile as it may be changed or suppressed by numerous pathological circumstances. 
Introduction.

1. Les grandes caractéristiques des C.M.M.
a) Les observations princeps chez le Chien.
b) Les différences interspécifiques.
c) Variations intra- et inter-individus.
d) Ontogenèse des C.M.M.

2. Influence de l'alimentation sur les C.M.M.
a) Effets de la prise de nourriture.
b) Influence des caractéristiques physico-chimiques de l'aliment.

3. Mécanismes nerveux sous-jacents à l'organisation en C.M.M.
a) Site d'origine et migration proximo-distale des C.M.M.
b) Vers un rôle privilégié du système nerveux intrinsèque.
c) Origine de la périodicité : notion d'horloge interne.
d) Quelle place pour le système nerveux extrinsèque?

4. Influences humorales sur l'organisation en C.M.M.
a) Hypothèses caduques et influences mineures.
b) Le rôle de la motiline.
c) L'intervention de la somatostatine.
d) Recherche d'une signification des modifications humorales.

5. Intégration neuro-humorale et interrelations fonctionnelles.
a) Peptides et milieu endoluminal : la composante sécrétoire des C.M.M. chez l'Homme.
b) Composante sécrétoire des C.M.M. et pH endoluminal chez l'animal.
c) Peptides et système nerveux central.

6. Signification fonctionnelle des C.M.M.
a) Formulation des hypothèses.
b) Transit digestif, rôle des C.M.M.
c) Les C.M.M. et I'absorption intestinale.
d) C.M.M. et physio-pathologie digestive.

\section{Conclusions.}

\section{Introduction.}

Malgré les progrès récents dans le domaine de la physiologie digestive de diverses espèces animales, il reste difficile de fournir un tableau clair des phénomènes qui assurent les diverses fonctions du tube digestif et de ses glandes annexes, qui coordonnent les étapes de la digestion, et qui en permettent la régulation neurohumorale. Même si le champ d'observation est limité au seul intestin grêle, il faut encore considérer comme une vérité présente l'affirmation de Bayliss et Starling (1899) : "On no subject in physiology do we meet with so many discrepancies of fact and opinion as in that of the physiology of the small intestine $"$.

Dans le cas particulier des fonctions motrices de l'intestin grêle, la difficulté tient historiquement (Wingate, 1981) à une confusion latente entretenue, d'une part en raison du postulat selon lequel le transit des digesta résulte de la motricité intestinale, et d'autre part du fait d'une ancienne conception erronnée assimilant 
l'intestin à un réservoir immobile tant que le sujet n'est pas alimenté. La relation globale entre motricité du tube digestif et transit des matériaux alimentaires a fait l'objet précédemment d'une synthèse adoptant le point de vue du nutritionniste (Laplace, 1981). Mais le fonctionnement de l'intestin grêle, en tant qu'organe siège d'une motricité parfaitement organisée, n'est pas encore totalement compris à ce jour. Nous limiterons délibérément le champ de ce mémoire en considérant comme connus tous les phénomènes fondamentaux à l'échelon cellulaire et tissulaire, et en particulier tout ce qui concerne la genèse et la propagation des ondes lentes, la genèse et la propagation apparente des potentiels d'action, la coordination des activités respectives des couches musculaires longitudinale et circulaire, et leur part dans l'élaboration des diverses images électromyographiques et des mouvements correspondants de la paroi intestinale. Ces aspects ont fait l'objet de diverses revues (Bortoff, 1976 ; Laplace et Roman, 1979 ; Becker, Duff et Moody, 1981). Le présent travail est tout entier consacré à l'organisation spatio-temporelle en complexes migrants de la motricité du seul intestin grêle, dont l'étude a été l'un des grands thèmes de recherche en matière de motricité digestive depuis une quinzaine d'années.

Cet intérêt relativement récent pour les complexes migrants ne correspond pas véritablement à une soudaine découverte dans la mesure où bien des informations acquises au tout début du siècle constituent une bonne approximation de ce que nous connaissons à l'heure actuelle (Wingate, 1981). Néanmoins, le concept selon lequel l'intestin est le siège, en situation de jeûne et/ou post-prandiale selon l'espèce animale étudiée, d'une activité motrice périodique organisée ne s'est véritablement imposé que grâce à l'amélioration des techniques d'exploration. Le progrès décisif a été la mise en œuvre d'enregistrements électromyographiques (E.M.G.) continus chez des animaux éveillés. C'est ainsi que nous avons pu décrire l'apparition périodique de quelques 16 épisodes d'intense activité électrique au cours des $24 \mathrm{~h}$ sur l'intestin grêle du mouton (Ruckebusch et Laplace, 1967). L'enregistrement des mécanogrammes a mis en évidence parallèlement l'apparition (15 à 18 fois par $24 \mathrm{~h}$ ) de périodes de segmentation rythmique, d'une durée de $5 \mathrm{~min}$, suivies durant 10 à $20 \mathrm{~min}$ par une période de quiescence, ces séquences survenant de façon cyclique sur un fond d'activité de type péristaltique enregistré simultanément en amont et en aval du segment concerné (Laplace, 1968). La démonstration du fait que cette séquence fait l'objet à la fois d'une migration tout au long de l'intestin grêle et d'une récurrence cyclique est alors apportée par Szurszewski (1969) chez le chien. Dans la mesure où il existe une étroite corrélation entre phénomènes électriques et mécaniques (Laplace et Roman, 1979 ; Wingate, 1981), cette séquence peut être indifféremment connue sous le nom de complexe myoélectrique migrant ou de complexe moteur migrant, désignés par commodité sous l'abréviation C.M.M.

Dès lors, ces C.M.M. peuvent être définis, au-delà de leur migration, par la succession cyclique de trois états d'activité motrice en tout point de l'intestin grêle :

- une période dite de quiescence, au cours de laquelle on n'enregistre pas d'activité mécanique, les ondes lentes constituant la seule activité électrique (pas de potentiel d'action); 
- une période dite d'activité irrégulière (A.I.), caractérisée par une apparition très irrégulière des potentiels d'action sur les ondes lentes, et correspondant au plan mécanique à des contractions locales, ou propagées sur des distances variables ;

- une période dite d'activité régulière (A.R.), coïncidant avec la présence systématique d'une bouffée de potentiels d'action sur chaque onde lente, et donnant une image radiologique de segmentation rythmique.

Nous tenterons ici de rassembler et évaluer les connaissances acquises depuis une quinzaine d'années sur ces C.M.M., en envisageant successivement (i) les particularités éventuelles selon l'espèce animale, et les principaux facteurs de variation, (ii) les mécanismes responsables de cette remarquable organisation spatio-temporelle, et enfin (iii) la signification fonctionnelle de sa présence.

\section{Les grandes caractéristiques des C.M.M.}

\section{a) Les observations princeps chez le chien.}

Les observations initiales (Szurszewski et Code, 1968 ; Szurszewski, 1969) consistent en la description chez le chien à jeun de la migration, du duodénum proximal jusqu'à l'iléon, d'une bande d'intense activité électromyographique, en I'occurrence une A.R. Cette A.R. prend naissance cycliquement au niveau du duodénum, plus rarement au niveau du jéjunum proximal, alors que la précédente atteint l'iléon. Environ $81 \%$ des A.R. migrent effectivement le long de la totalité de l'intestin grêle, tandis que les autres disparaissent progressivement après avoir parcouru quelques $75 \%$ de la longueur de l'organe. Cette migration s'effectue à une vitesse comprise entre 3,5 et $6,2 \mathrm{~cm} \cdot \mathrm{min}^{-1}$ en région proximale, mais seulement de l'ordre de 1,2 à $1,9 \mathrm{~cm} \cdot \mathrm{min}^{-1}$ au niveau distal. Le temps nécessaire à la migration proximo-distale complète d'une A.R. est de 115 à $183 \mathrm{~min}$ pour une longueur totale de l'intestin grêle comprise entre 280 et $420 \mathrm{~cm}$. Enfin, le temps nécessaire pour que la bande d'A.R. franchisse un site d'enregistrement est, quel que soit le segment intestinal considéré, de 5,8 à $7 \mathrm{~min}$. Compte tenu des vitesses de migration indiquées plus haut, ceci implique que la longueur de l'intestin grêle qui est à un instant donné le siège d'une A.R. diminue progressivement : de 25 à $36,5 \mathrm{~cm}$ au niveau du duodénum, elle n'est plus que de 6 à $12 \mathrm{~cm}$ sur l'iléon.

Ces éléments descriptifs ont été confirmés par plusieurs auteurs (Carlson, Bedi et Code, 1972 ; Grivel et Ruckebusch, 1972 ; Code et Marlett, 1975), avec l'affirmation supplémentaire de la migration de toute la séquence de 3 phases (voire 4) et non de la seule A.R. C'est encore dans le cas du chien à jeun que Code et Marlett (1975) ont établi une définition systématique précise des diverses phases des C.M.M. La phase I, de quiescence, est caractérisée comme une période d'absence relative (et non pas totale) de potentiels d'action : de brèves bouffées isolées peuvent être enregistrées, mais leur durée représente au total moins de $5 \%$ de la durée totale de cette période ( 37 à $64 \mathrm{~min}$ ). La phase II, ou phase d'A.l., est identifiée par la présence irrégulière, mais soutenue, de potentiels d'action; ainsi I'A.I. est considérée comme installée lorsque, en $3 \mathrm{~min}, 10 \%$ 
au moins des ondes lentes sont surchargées de potentiels d'action, et s'il ne survient pas d'épisode de plus de $6 \mathrm{~min}$ avec un taux de surcharge des ondes lentes inférieur au seuil de $10 \%$. La durée totale de l'A.l. est variable, de 26 à $62 \mathrm{~min}$, mais dans tous les cas le nombre et l'amplitude des potentiels d'action croissent au cours de son déroulement. La phase III, ou phase d'A.R., est définie non seulement par la surcharge systématique de chaque onde lente par une bouffée de potentiels, mais aussi par le fait que ces bouffées ont une durée maximale, et sont constituées de potentiels d'amplitude maximale. La durée de I'A.R. est de 5,4 à 7,8 min selon Code et Marlett (1975), soient des valeurs pratiquement identiques à celles fournies par Szurszewski (1969). Une phase IV, brève $(2,1$ à 2,4 min) est, en outre, décrite comme occasionnelle par Code et Marlett (1975) ; elle se présente comme un épisode d'A.I. préludant à la réapparition de la phase I. En définitive, la durée totale du cycle complet des C.M.M. chez le chien à jeun est de 90 à $114 \mathrm{~min}$.

\section{b) Les différences interspécifiques}

L'étude des C.M.M., amorcée chez le Chien, s'est très vite étendue à diverses espèces représentant un large éventail de mammifères euthériens (autres carnivores, bovins, ovins, caprins, porcins, équidés, rongeurs et hommel ou métathériens (marsupiaux).

Chez le Veau, les C.M.M. surviennent 27 à 29 fois par 24 heures, soit environ toutes les 40 à $50 \mathrm{~min}$, et la durée respective des 3 principales phases est de 2 à $10 \mathrm{~min}$ pour la quiescence, de 20 à $30 \mathrm{~min}$ pour l'A.l. et de 2 à $3 \mathrm{~min}$ pour l'A.R. (Ruckebusch et Bueno, 1973 ; Dardillat et Marrero, 1977). Dans cette espèce, quelques 70 à $80 \%$ des C.M.M. parcourent la totalité de l'intestin grêle en 150 min, à une vitesse progressivement décroissante $\left(29\right.$ à $7,5 \mathrm{~cm}$. $\left.\min ^{-1}\right)$. Dans l'ensemble, ces caractéristiques ne sont guère modifiées par le sevrage. De la même façon, on peut enregistrer en 24 h sur l'intestin grêle d'un mouton alimenté ad libitum 18 C.M.M. qui migrent en direction aborale à une vitesse moyenne de $23,7 \mathrm{~cm} \cdot \mathrm{min}^{-1}$ (Ruckebusch et Bueno, 1975). La durée des phases de quiescence, d'A.I. et d'A.R. est respectivement de 26,46 et $5 \mathrm{~min}$.

L'intestin grêle du Cheval recevant du fourrage ad libitum est également le siège de C.M.M. dont la récurrence intervient toutes les $90 \mathrm{~min}$ (Ruckebusch, 1973). Les A.R. migrent à raison de 20 à $30 \mathrm{~cm}$. $\min ^{-1}$, et $80 \%$ d'entre elles franchissent le jéjuno-iléon en 60 à $110 \mathrm{~min}$. Chez le lapin alimenté ad libitum, la vitesse de migration comprise entre 10 et $4 \mathrm{~cm}$. min $^{-1}$ permet le franchissement de l'intestin grêle en 90 à 110 min (Grivel et Ruckebusch, 1972) .

Chez le Porc alimenté ad libitum, qu'il s'agisse de porcs miniatures adultes (Ruckebusch et Bueno, 1976) ou de porcs de race Large White en croissance (Laplace, 1978 a), les C.M.M. sont également présents. Ainsi, chez le porc en croissance recevant un régime standard à base de céréales, on enregistre quelques 20 C.M.M. par $24 \mathrm{~h}$ dont $60 \%$ franchissent la totalité de l'intestin grêle. La récurrence des C.M.M. est d'environ $70 \mathrm{~min}$ sur le duodénum, avec des durées moyennes de $13,3-54,0$ et 3,5 min respectivement pour la quiescence, I'A.I. et I'A.R. La vitesse de migration qui atteint en moyenne $29,9 \mathrm{~cm}$. $\mathrm{min}^{-1}$ sur le duo- 
dénum, n'est plus que de 9,7 sur le jéjunum médian et 4,7 sur l'iléon. La longueur du segment affecté par une A.R. décroît de $100-150 \mathrm{~cm}$ en région proximale à 50 $\mathrm{cm}$ au niveau distal.

Chez l'Homme à jeun, des C.M.M. naissent toutes les $110 \mathrm{~min}$, et migrent à une vitesse moyenne décroissante de 12 à $6 \mathrm{~cm} \cdot \min ^{-1}$ au long des $100 \mathrm{~cm}$ proximaux de l'intestin grêle (Fleckenstein et Oigaard, 1977 ; Vantrappen et al., 1977 ; Fleckenstein, 1978). Ils sont aussi présents, quoiqu'avec un intervalle de récurrence plus bref (42 $\mathrm{min}$ ), chez le sujet cholecystectomisé (Stoddard, Smallwood et Duthie, 1978). Les C.M.M. sont aussi présents chez le Rat au cours de la période diurne de repos alimentaire, mais la brièveté des cycles (environ $17 \mathrm{~min}$ ) est remarquable dans cette espèce (Ruckebusch et Ferre, 1973 ; Ruckebusch et Fioramonti, 1975a). De ce fait, les C.M.M. se succèdent 3 à 4 fois par heure, un tiers des A.R. correspondantes disparaissant après avoir franchi, à raison de 2 $\mathrm{cm} \cdot \min ^{-1}$ en moyenne, quelques $60 \%$ de la longueur de l'intestin grêle. Toutefois si le jeûne diurne spontané est prolongé durant $24 \mathrm{~h}$, on assiste à une réduction du nombre de C.M.M. (de 4 à 1,8/h à environ $30 \mathrm{~cm}$ du pylore), à un allongement considérable de la quiescence, et à la disparition des deux tiers des C.M.M. avant migration complète (Bueno, Fioramonti et Ruckebusch, 1977).

Les C.M.M. existent aussi chez un mammifère métathérien tel que le kangourou (Macropus eugenii) (Richardson et Wyburn, 1983). La séquence comporte dans cette espèce environ $30 \mathrm{~min}$ de quiescence, $40 \mathrm{~min}$ d'A.l. et une A.R. durant $5 \mathrm{~min}$. Ces C.M.M. migrent à une vitesse de l'ordre de $5,5 \mathrm{~cm}$. $\mathrm{min}^{-1}$ sur le duodénum et de $1 \mathrm{~cm} \cdot \min ^{-1}$ sur l'iléon. L'intervalle entre deux A.R. consécutives est cependant fort variable, de 42 à 172 min sur le duodénum et de 74 à 258 min sur l'iléon. Il n'existe pas dans cette espèce de différence significative entre sujets à jeun et alimentés, exception faite du nombre de C.M.M. qui font l'objet d'une migration proximo-distale complète : $61 \%$ chez le sujet alimenté, contre $44 \%$ chez le kangourou à jeun. Ceci étant, il est tout à fait remarquable de retrouver une même organisation de la motricité en C.M.M. chez des mammifères euthériens et métathériens qui ont évolué de façon totalement distincte, après avoir divergé voici quelques 120 millions d'années.

D'un rapide examen des caractéristiques de l'organisation de la motricité de l'intestin grêle chez plusieurs espèces de mammifères, on retient en première analyse le fait que les C.M.M. existent dans tous les cas, en dépit d'importantes différences d'anatomie et de physiologie digestives, et d'habitudes alimentaires. Ruckebusch (1981) a souligné la relation linéaire qui existe entre la vitesse moyenne de migration des C.M.M. et la longueur totale de l'intestin grêle, de sorte que le temps nécessaire pour qu'un C.M.M. parcoure toute la longueur de l'organe reste du même ordre de grandeur, quelle que soit l'espèce animale considérée. On peut alors schématiquement classer les différentes espèces en 3 groupes : pour celles dont l'intestin grêle est court (moins de $5 \mathrm{~m}$ ) telles que rat, lapin et chien, la vitesse moyenne de migration est comprise entre 2 et 6 $\mathrm{cm} \cdot \mathrm{min}^{-1}$; pour un intestin grêle de 5 à $20 \mathrm{~m}$ de longueur (homme, porc, veau) cette vitesse oscille entre 8 et $15 \mathrm{~cm} \cdot \min ^{-1}$; enfin dans les espèces à intestin grêle très long $(20$ à $40 \mathrm{~m})$ telles que cheval, bœuf et mouton, la vitesse moyenne atteint 20 à $30 \mathrm{~cm} \cdot \min ^{-1}$. En dépit de ce classement, on peut, toujours schémati- 
quement, admettre que le temps total nécessaire pour la migration proximodistale complète d'un C.M.M., est pour toutes ces espèces compris entre 90 et $150 \mathrm{~min}$, soit de l'ordre de $2 \mathrm{~h}$.

Pourtant cette apparente unité souffre d'au moins une exception connue chez le Chat. En effet, Weisbrodt et Christensen (1972) ont montré I'absence, sur le duodénum et le jéjunum proximal du chat à jeun, des épisodes d'A.R. tels qu'ils sont connus chez le chien. D'une façon générale, chez le chat à jeun les potentiels d'action accompagnent chaque onde lente pendant des périodes de 2 min, séparées par des épisodes de 5 à $20 \mathrm{~min}$ au cours desquels aucun potentiel d'action n'est enregistré. Le taux moyen de surcharge des ondes lentes, pour des enregistrements de 1 à $3 \mathrm{~h}$, est de $25 \%$ pour les $10 \mathrm{~cm}$ proximaux de l'intestin grêle. Par ailleurs si le chat est laissé à jeun durant $18 \mathrm{~h}$ ou plus, une figure électromyographique originale est observée (Weisbrodt et Christensen, 1972). Précédée par une diminution de l'amplitude des ondes lentes, une intense bouffée de potentiels d'action soutenue durant environ $11 \mathrm{~s}$ naît sur le duodénum proximal et migre en direction aborale $\left(5,4 \mathrm{~cm} \cdot \min ^{-1}\right)$; elle est suivie dans $67 \%$ des cas par une propagation apparente en direction orale des ondes lentes durant près de 5 min. Par leur vitesse de migration, ces longues bouffées de potentiels peuvent être assimilées à un phénomène homologue des A.R. chez les autres espèces. Mais même si ce type d'activité survient quelques 11 fois en $25 \mathrm{~h}$ d'enregistrement, Weisbrodt et Christensen (1972) ne décèlent pas une véritable récurrence cyclique, propriété fondamentale des C.M.M. et de leurs A.R. L'existence des longues bouffées de potentiels d'action, et des modifications associées de fréquence, d'amplitude ou de propagation des ondes lentes, a été récemment confirmée (Körner, Altaparmakov et Wienbeck, 1983).

Une étude plus complète de la motricité de l'ensemble de l'intestin grêle chez le chat alimenté ou à jeun a été réalisée par Roche et al. (1982). Chez le chat normalement alimenté, I'activité E.M.G. est analogue à I'A.I. des C.M.M. des autres espèces, avec de brefs épisodes de renforcement des bouffées ou de quiescence ; mais il apparaît aussi sur l'iléon, et lui seul, des phases typiques d'A.R. susceptibles d'une propagation ortho ou antidromique sur une distance de 20 à $30 \mathrm{~cm}$. Par ailleurs, chez le chat à jeun, on retrouve 6 à 18 fois $/ 24$ h les longues $(10 \mathrm{~s}$ à 2 min) bouffées décrites précédemment sur un fond d'A.I. Alors que ces activités particulières sont, après 2 jours de jeûne, 3 fois plus nombreuses en région proximale, elles sont à l'inverse 2 fois plus fréquentes en région distale au quatrième jour, et peuvent disparaître après 5 jours de jeûne. De plus leur propagation normalement orthodromique peut, dans $20 \%$ des cas, devenir antidromique après au moins $72 \mathrm{~h}$ de jeûne. Enfin, les longues bouffées ont une durée qui décroît en région distale, et elles cèdent la place, sur les $10 \mathrm{~cm}$ distaux de l'intestin grêle, à des phases d'A.R. tout comme sur l'iléon du chat alimenté.

Le cas des oiseaux mérite également que I'on s'y arrête, en dépit de leur distance phylogénétique par rapport aux mammifères pris en compte jusqu'ici, et de I'anatomie particulière de leur tube digestif. Ainsi, chez le poulet, Roche (1974) note à côté d'une activité E.M.G. constituée de salves de potentiels isolées, liées à la motricité du gésier et faisant l'objet d'une propagation rapide essentiellement orthodromique, l'existence de salves de potentiels indépendantes de l'activité du 
gésier qui peuvent être soutenues et propagées à faible vitesse sur tout ou partie de l'intestin grêle. Dans un travail ultérieur, l'existence de telles activités, dites " segmentaires à propagation lente », est bien mise en évidence, notamment sur l'anse de Meckel de la poule (Roche et Decerprit, 1977). Ces observations sont appuyées par des travaux réalisés chez le dindon. Dans cette espèce, les activités duodénales s'avèrent étroitement liées à celles des compartiments gastriques (Duke, Kostuch et Evanson, 1975a). Mais une activité particulière est enregistrée sur l'intestin grêle distal (Duke, Kostuch et Evanson, 1975 b) : elle est décrite comme formée de bouffées prolongées de potentiels d'action, soutenues sans interruption durant 4 à 7 min, souvent accompagnée d'une diminution d'amplitude des ondes lentes, et habituellement soumise à une lente migration en direction distale. Cette description rappelle à tous égards celle des longues bouffées caractéristiques de l'intestin grêle du chat. Au plan de la phylogénèse, ces activités particulières de l'intestin grêle distal des oiseaux préfigurent-elles celles qui sont retrouvées sur tout l'intestin grêle du chat chez lequel elles cèdent la place en région distale à d'authentiques A.R. ? En d'autres termes faut-il voir là l'ébauche de ce qui serait devenu chez nombre de mammifères la phase la plus caractéristique des C.M.M. ?

\section{c) Variations intra et inter-individus.}

La reproductibilité de I'organisation de la motricité en C.M.M. est remarquable d'un jour à l'autre chez un même sujet placé dans des conditions stables, tant chez le chien (Code et Marlett, 1975) que chez le porc (Laplace, 1978a) par exemple. Une question fondamentale est cependant de savoir si la présence des C.M.M. est absolument constante chez tous les sujets d'une même espèce. Lorsque certains auteurs ont noté l'absence de C.M.M., chez 1 ou 3 de leurs chiens selon le cas (Szurszewski, 1969 ; Carlson, Bedi et Code, 1972), des phénomènes pathologiques intercurrents en ont été la cause. Chez le Porc, en l'absence de tout désordre clinique, les C.M.M. sont systématiquement enregistrés. II en va de même chez l'Homme comme le montrent les données de manométrie ou de radiotélémétrie (Vantrappen et al., 1977 ; Thompson et al., 1980 ; Kerlin et Phillips, 1982).

Un phénomène particulier peut être à l'origine d'une apparente variabilité. En effet, un C.M.M. peut fort bien prendre naissance sur le duodénum avant que le précédent n'ait atteint l'iléon, et de surcroît un certain pourcentage des C.M.M. n'effectue pas une migration proximo-distale complète. Ceci fait que l'on peut enregistrer, à un instant donné, la présence simultanée de 1 ou 2 C.M.M. sur I'intestin grêle du Chien ou de I'Homme, et de 1 à 3 C.M.M. sur celui d'un Veau ou d'un Porc. De plus des séquences surnuméraires peuvent se développer en n'importe quel point du jéjunum chez le Porc par exemple, et migrer ensuite normalement (Laplace, 1978a).

En dehors de toute anomalie pathologique, et compte tenu de ces phénomènes particuliers mais habituels, il existe une authentique variabilité intra et interindividus. Elle se traduit, notamment chez le Porc, par une certaine irrégularité de la période des C.M.M., d'où résulte un nombre total variable de C.M.M. par 24 h, 
et par des fluctuations de la vitesse de migration des séquences (Laplace, 1978a). Chez le Chien, Scott, El-Sharkawy et Diamant (1983) notent une variabilité importante de la durée des cycles (47 à $172 \mathrm{~min}$ ), et de la valeur moyenne de cette période pour des sujets distincts (73 à $118 \mathrm{~min}$ ). Le temps nécessaire à une migration proximodistale complète varie entre 93 et $175 \mathrm{~min}$, et le temps moyen nécessaire à cette migration chez des animaux distincts est compris entre 98 et 154 min. Toutefois, en dépit de cette variabilité entre chiens et chez un même chien, il existe globalement une bonne relation exponentielle entre la localisation d'une A.R. par exemple et le temps écoulé depuis le début de sa migration. Ceci revient à dire que, pour tout C.M.M., la longueur d'intestin parcourue est proportionnelle au logarithme naturel de la durée de migration (Scott, El-Sharkawy et Diamant, 1983). On peut rapprocher cette formulation de la systématisation proposée par Ruckebusch (1981) qui conduit à admettre comme une estimation très globale, et pour plusieurs espèces animales, un temps de migration de l'ordre de 2 h.

Dans le cas de l'Homme, il y a également une variabilité importante inter et intra-individuelle (Thompson et al., 1980; Kerlin et Phillips, 1982). Elle semble même plus importante que chez le Chien, avec une durée des séquences (intervalle entre 2 A.R.) susceptible de varier entre 15 et $195 \mathrm{~min}$. A noter enfin que diverses situations peuvent affecter le déroulement des C.M.M. En effet, chez l'Homme à jeun, un exercice physique soutenu durant $4 \mathrm{~h}$ (marche) peut abolir complètement ou réduire de moitié le nombre d'A.R. en augmentant considérablement la période (Evans, Foster et Hardcastle, 1984). La gestation est aussi capable d'affecter la régularité des C.M.M. Ainsi chez la rate gestante, il y a modification de la périodicité caractéristique avec des intervalles entre A.R. de l'ordre de 43 min contre 12 à 15 min chez la rate non gravide, et forte augmentation du coefficient de variation de cette période par rapport à celui enregistré pour des femelles castrées ou vides (Scott et al., 1983 a).

\section{d) Ontogenèse des C.M.M.}

L'organisation spatio-temporelle de la motricité de l'intestin grêle apparaît relativement précocement (Bueno et Ruckebusch, 1979). Au cours du dernier tiers de la vie fœetale de l'agneau, des A.R. d'une durée de 3 à $4 \mathrm{~min}$, et se reproduisant à intervalles de 5 à $30 \mathrm{~min}$, constituent le premier signe de motricité jéjunale. Dix jours avant la naissance, l'activité E.M.G. s'organise en phases d'A.I. et d'A.R. avec une récurrence cyclique de l'ordre de $15 \mathrm{~min}$. La fréquence des C.M.M. chute brutalement à la naissance (environ $1 / \mathrm{h}$ ), alors que leur vitesse de migration est multipliée par trois (Bueno et Ruckebusch, 1979). Les C.M.M. sont également présents chez le veau nouveau-né (Ruckebusch, Dardillat et Hatey, 1972). Par contre, chez le chiot, l'activité E.M.G. reste très faible, tant in utero que chez le nouveau né de moins de 15 jours d'âge. Aussi, l'ontogenèse de l'organisation en C.M.M. semble moins liée à l'âge en tant que tel qu'au degré de développement global atteint par le produit in utero ou durant les premiers jours de vie (Ruckebusch, 1981).

Cette relation semble également valable dans le cas du foetus et du nouveau- 
né humain (Wozniak, Fenton et Milla, 1984). L'étude d'enfants prématurés, nés entre 26 et 30 semaines de gestation, montre en effet une évolution en 3 stades de la motricité digestive : activité très irrégulière avec contractions aléatoires entre 26 et 30 semaines d'âge fotal ; groupes de contractions survenant de façon répétitive et régulière entre 30 et 33 semaines; et enfin apparition d'une activité de type C.M.M. entre 33 et 36 semaines. II y a coïncidence constante entre I'apparition de l'organisation en C.M.M. et le début de l'aptitude à têter, ce qui paraît bien témoigner d'une relation avec la maturation neurologique de l'enfant. Chez l'enfant né à terme, les C.M.M. sont bien établis avec une période moyenne de 44 min et une vitesse moyenne de migration de $3 \mathrm{~cm} \cdot \min ^{-1}$ (Wozniak, Fenton et Milla, 1984).

\section{Influence de I'alimentation sur les C.M.M.}

En présentant précédemment les principales caractéristiques des C.M.M. chez différentes espèces animales, nous avons systématiquement noté l'état du sujet - à jeun ou alimenté - . Cette remarque attire l'attention sur I'influence importante de l'alimentation sur les C.M.M.

\section{a) Effets de la prise de nourriture.}

Dès sa première description des C.M.M. chez le chien, Szurszewski (1969) a noté l'absence de ces derniers chez les sujets alimentés $5 \mathrm{~h}$ auparavant. Ce fait a initialement conduit à considérer les C.M.M. comme un phénomène propre à l'état de jeûne. L'interruption des C.M.M. à la suite de la prise d'aliment intervient presque simultanément sur toute la longueur de l'intestin grêle du chien (Code et Marlett, 1975). Elle correspond à I'installation d'une A.l. continue durant 8 à $10 \mathrm{~h}$ après le repas. Même si les caractéristiques quantitatives et qualitatives de l'aliment ont une influence distincte, le stimulus responsable de cette organisation postprandiale particulière paraît être, en première analyse, la présence d'une certaine masse d'aliment dans le tube digestif plus que l'absorption consécutive des nutriments. En effet, la perfusion de secrétagogues (sels biliaires et acide ricinoléique) dans des segments jéjunaux de chiens à jeun, conduisant donc à une augmentation du volume des contenus endoluminaux, entraîne la substitution aux C.M.M. d'une A.I. permanente ; une distension modérée exerce des effets similaires dans le segment affecté par la distension (Da Cunha Melo et al., 1981). L'addition au régime usuel de $30 \mathrm{~g}$ de son de blé, de cellulose ou de gomme arabique, qui entraînent également par leurs propriétés physiques une augmentation du volume des digesta, conduit chez le Chien à accroître de près de $50 \%$ la durée de I'A.I. postprandiale continue sur le duodénum (Bueno et al., 1981). Mais l'argument décisif en faveur d'un rôle de la seule présence de contenus digestifs, pour substituer I'A.I. continue à I'organisation en C.M.M., tient au fait que la nutrition parentérale prolongée ou l'hyperalimentation veineuse sont incapables d'interrompre les C.M.M. chez le Chien, alors que l'A.I. continue réapparaît dès la réalimentation par voie orale (Weisbrodt et al., 1976). 
A I'instar du Chien, les C.M.M. sont suspendus chez l'Homme, même par la seule ingestion de $250 \mathrm{ml}$ de lait (Stoddard, Smallwood et Duthie, 1978) ou d'un petit déjeuner (Hellemans et al., 1977), et l'activité postprandiale s'installe dans les 20 à 40 s qui suivent la prise de lait. La variabilité très importante, signalée pour les caractéristiques des C.M.M., se retrouve également pour la durée de la période postprandiale d'A.I. continue (Thompson et al., 1980). Pour un même repas d'épreuve liquide apportant $600 \mathrm{kcal}$, la durée d'interruption des C.M.M. au profit de l'A.I. continue peut varier entre 2,75 et plus de $10 \mathrm{~h}$ (Kerlin et Phillips, 1982). Il est également possible de distinguer chez le Rat un état postprandial caractérisé par une A.I. continue (Ruckebusch et Ferre, 1973 ; Ruckebusch et Fioramonti, 1975 a). En fait l'intégration des signaux E.M.G. montre qu'en période nocturne de prise d'aliment, les C.M.M. sont encore décelables, mais avec une période de l'ordre de 60 à 80 min (Bueno, Fioramonti et Ruckebusch, 1977). La réapparition des épisodes de quiescence, avec la période diurne de repos alimentaire, accompagne la réduction de l'A.I. et celle de la période des C.M.M. qui revient aux valeurs précédemment mentionnées (15 à $20 \mathrm{~min}$ ). Ainsi, la prise d'aliment conduit à masquer les C.M.M. (Rat) voire à leur substituer complètement (Homme, Chien) une A.I. continue dont l'identité fonctionnelle avec I'A.I. récurrente de la phase II des C.M.M. reste cependant à établir.

A la différence de ces 3 espèces (Chien, Homme et Rat), les C.M.M. surviennent de manière cyclique ininterrompue lors d'alimentation ad libitum chez des espèces aussi diverses que les ruminants (mouton, veau, bovins), le lapin ou le cobaye (Ruckebusch, Bueno et Fioramonti, 1981). Le cas du Veau est quelque peu ambigu dans la mesure où, chez le sujet alimenté au lait, la buvée réduit la fréquence des A.R. ; il peut même $y$ avoir interruption réelle des C.M.M. par une A.l. continue d'autant plus longue que la quantité de lait bue (entre 2 et $8 \mathrm{~kg}$ ) est plus importante (Sissons, 1983). Par contre, après le sevrage, l'ingestion de fourrage reste sans influence (Ruckebusch et Bueno, 1973) à l'instar de tous les ruminants adultes. Chez un autre herbivore, le Cheval, la prise d'aliment réduit le nombre d'A.R. ou les supprime durant 1 à $2 \mathrm{~h}$ sur l'intestin grêle proximal (Ruckebusch, 1973), voire même conduit à une A.I. continue durant plus de $6 \mathrm{~h}$ dans certains cas (Ruckebusch, Bueno et Fioramonti, 1981). A noter enfin que chez le Kangourou, herbivore à estomac multiloculé, les C.M.M. ne sont nullement affectés par la prise de nourriture, à l'instar du Mouton (Richardson et Wyburn, 1983).

Entre les deux situations extrêmes d'interruption systématique plus ou moins prolongée (Chien, Homme et Rat), et de non interruption (ruminants, Lapin, Kangourou) des C.M.M., le Porc fournit un modèle intermédiaire. Alimenté ad libitum, c'est-à-dire effectuant plusieurs petits repas spontanés, cet animal présente une séquence ininterrompue de C.M.M. comme au cours du jeûne (Ruckebusch et Bueno, 1976) ; par contre lorsqu'il reçoit seulement un ou deux repas importants par jour, l'intestin grêle proximal est le siège d'une A.I. continue durant 2 à $3 \mathrm{~h}$ (Ruckebusch et Bueno, 1976 ; Laplace, 1978 a).

Là encore le cas du Chat doit être considéré à part (Roche et al., 1982). Dans la mesure où son intestin n'est à aucun moment le siège de C.M.M., il ne saurait être question d'interruption. On note seulement, lors du repas, une brutale augmentation de l'activité E.M.G. du tiers proximal de l'intestin grêle ; celle du duo- 
dénum reste maximale durant 90 min avant de décroître progressivement en 12 à $16 \mathrm{~h}$. Mais l'autonomie de l'iléon reste entière, quoiqu'on note une certaine désorganisation des A.R. durant 2 à $3 h$, puis une augmentation de leur fréquence pendant toute la période d'activation duodénale. Les effets de la prise d'aliment chez les oiseaux ont été surtout examinés au niveau de l'anse duodénale (Roche, 1974). Chez la poule, la réalimentation après un jeûne prolongé réduit l'activité intestinale parallèlement à une phase transitoire de suralimentation, alors que la pintade est à peu près insensible à de telles influences (Roche, Ruckebusch et Achard, 1983).

En définitive, il apparaît au travers de cet examen comparatif des effets de la prise de nourriture chez diverses espèces animales, même si l'on met à part le cas du Chat et des Oiseaux, que l'organisation en C.M.M. n'est pas l'apanage exc/usif de l'intestin grêle de l'animal à jeun. II semble, au contraire, qu'elle doive être considérée comme une alternance normale de périodes d'activité (A.l. et A.R.) et de quiescence, et qu'elle soit de surcroît adaptable quant à la durée respective des différentes phases, et à l'amplitude des potentiels d'action. Cette adaptation pourrait consister essentiellement en un renforcement de la durée et de l'intensité de la phase d'A.I. aux dépens de la période de quiescence, ce phénomène prenant dans certaines espèces, et/ou dans certaines conditions, une particulière ampleur. En d'autres termes ce renforcement de I'A.I. conduirait à masquer temporairement la périodicité du déroulement des séquences, ce qui peut être aisément observé chez le porc (Laplace, 1978 a). De fait, dans cette espèce, la durée moyenne des phases de quiescence est plus grande et celle des phases d'A.I. plus faible au cours des $12 \mathrm{~h}$ nocturnes sans distribution d'aliment, par rapport aux valeurs pour les $12 \mathrm{~h}$ diurnes incluant les 2 repas quotidiens; il y a également une augméntation de la durée de la quiescence aux dépens de celle de l'A.I. au cours de la migration des C.M.M. en direction aborale, ce qui suggère bien un rôle de l'importance de la masse de digesta présents dans la lumière à l'égard du déterminisme de la durée relative des phases (Laplace, 1978 a).

De même que la description initiale de l'organisation régulière en C.M.M. a dû être nuancée par l'importance de la variabilité inter et intra individuelle, le caractère absolu de la suspension des C.M.M. au profit d'une A.I. continue postprandiale, chez l'Homme ou le Chien, doit également être nuancé. Nous avons déjà noté que, chez I'Homme, la durée de l'A.l. varie dans un rapport de 1 à 3 pour un même repas d'épreuve de $600 \mathrm{kcal}$ (Kerlin et Phillips, 1982). II apparaît aussi, chez des sujets recevant leurs 3 repas quotidiens usuels, et libres d'ingérer en outre quelques " en cas ", que l'organisation en C.M.M. typique d'une situation de jeûne peut fort bien être enregistrée par épisodes durant la journée malgré ces multiples prises de nourriture (Thompson et al., 1981). Il en va de même chez le chien libre d'effectuer de multiples repas au cours de la journée (Crenner et al., 1984). On note également que l'ingestion de $200 \mathrm{~g}$ de foie par un Chien peut suspendre les C.M.M. duodénaux sans affecter ceux d'une anse jéjunale isolée, cependant que, chez un chien à jeûn, la perfusion de chyme duodénal dans l'anse isolée peut suspendre les C.M.M. à la fois dans l'anse et dans l'intestin en place privé d'aliment (Heppell et al., 1983). Cette dualité de réponse soulève diverses questions quant aux mécanismes mis en jeu, et que nous envisagerons plus loin. 
Enfin, lors d'alimentation entérale par perfusion d'un liquide nutritif complexe équilibré chez le Chien, la suspension des C.M.M. au profit d'une A.I. continue est bien observée ; mais si l'alimentation entérale est poursuivie au long cours, les C.M.M. réapparaissent progressivement malgré la présence de contenus digestifs (Crenner et al., 1983). La suspension des C.M.M. par la prise de nourriture, dans les espèces où le phénomène est observé, n'a donc pas un caractère absolu. Par ailleurs, cette réapparition des C.M.M. malgré l'alimentation entérale survient d'autant plus tardivement que l'apport quotidien d'énergie est plus important (Crenner et al., 1983), ce qui conduit à examiner l'influence de la nature des contenus digestifs.

\section{b) Influence des caractéristiques physico-chimiques de l'aliment.}

La faculté d'adaptation de l'organisation de la motricité en C.M.M. est encore étayée par le fait que les effets de la prise d'aliment diffèrent non seulement en fonction de la charge calorique, mais aussi selon la nature des matériaux ingérés. Déjà Code et Marlett (1975) ont noté que l'ingestion de lait suscite une A.l. postprandiale continue durant 2,5 à $4 \mathrm{~h}$ chez le Chien alors que le même volume de $\mathrm{NaCl}$ n'affecte pas les C.M.M. Chez le Rat, une solution de $\mathrm{NaCl}$ est susceptible ou non d'induire une A.I. continue de type postprandial selon sa concentration (Ruckebusch et Fioramonti, 1975a). Par rapport à l'absorption de liquide, I'ingestion d'aliment solide suscite une A.I. continue plus importante (Grivel et Ruckebusch, 1972), et la durée d'interruption du déroulement normal des C.M.M. chez le Chien augmente avec I'accroissement de la teneur en matière sèche de I'aliment (Ruckebusch, Bueno et Fioramonti, 1981).

Si l'on examine séparément l'effet des diverses catégories de substances nutritives, il apparaît que les matières azotées, sous forme de protéines de lait ou de peptides, ont une action plus faible que des glucides tels que le glucose ou le saccharose ; ce sont les lipides et en particulier les triglycérides à chaîne moyenne qui induisent l'interruption la plus longue de l'organisation en C.M.M. chez le Chien (De Wever et al., 1978 ; Schang et al., 1978). La quantité de matériaux alimentaires nécessaire pour susciter l'interruption des C.M.M. est supérieure à celle requise pour stimuler la sécrétion pancréatique (Weisbrodt et al., 1975b), mais le site de stimulation n'est pas nécessairement proximal. En effet la perfusion, directement dans l'iléon, d'huile d'arachide mélangée à de la bile et du suc pancréatique, entraîne également l'apparition de l'A.I. continue postprandiale sur l'intestin grêle proximal du chien (De Wever et al., 1980). Enfin, la perfusion intra-jéjunale de lipides est moins efficace que la perfusion intra-duodénale, si de la bile n'est pas ajoutée au perfusat (Schang et al., 1980), ce qui indique que la lipolyse est un préalable nécessaire au plein effet des lipides. L'apport jéjunal direct de lipides entraîne en effet une suspension plus brève des C.M.M. que l'apport duodénal de la même quantité, et parallèlement une moindre absorption des lipides ; ces deux effets sont pleinement corrigés par addition de bile au perfusat lipidique jéjunal, ce qui conduit Schang et al. (1981b) à suggérer que la durée d'interruption des C.M.M. dépend plus de la quantité de lipides absorbée que de la quantité administrée. Quoi qu'il en soit, ces éléments montrent que la durée postprandiale de suspension des C.M.M. au profit d'une A.I. continue dépend, non seulement de 
la masse de digesta et de la charge calorique qu'ils représentent, mais aussi de la nature des nutriments apportés.

Indépendamment de ces effets différenciés des divers principes nutritifs à l'égard de la durée de l'A.l. postprandiale continue, il convient également de prendre en considération l'intensité de l'activité contractile (Schang et al., 1978). A valeur énergétique égale, les lipides entraînent l'A.l. postprandiale la plus longue, mais aussi celle dont I'intensité est la plus faible. Cet effet modérateur des lipides vis-à-vis de l'intensité de l'A.l. disparaît lorsqu'ils sont associés à des peptides ou à des glucides, alors qu'il y a une certaine additivité dès durées d'interruption des C.M.M. du fait de ces divers nutriments lorsqu'ils sont associés. Enfin, l'intensité de I'A.I. continue induite par les lipides est indépendante de la charge calorique apportée sous cette forme. Par conséquent, l'effet exercé sur l'intensité de l'A.I. postprandiale est dépendant de la nature des nutriments, plus exclusivement que sa durée qui dépend à la fois de la charge calorique globale et de la nature des nutriments qui la constituent. D'évidence, la complexité et la sensibilité des mécanismes sous-jacents sont grandes, puisqu'il existe tout à la fois des différences d'effets selon la nature des nutriments, la charge calorique, mais aussi le site intestinal concerné (Heppell et al., 1983). La perfusion d'anses jéjunales chez le Chien avec une solution glucosée induit une suspension des C.M.M. duodénaux dans 54 ou $83 \%$ des essais selon la quantité de glucose (respectivement 300 et $600 \mathrm{mM}$ ) ; la suspension des C.M.M. n'est obtenue que dans 33 et $66 \%$ des essais respectivement, pour les mêmes quantités perfusées dans des anses iléales (Schang et al., 1981a).

Un autre aspect de la faculté d'adaptation des C.M.M. a été observé chez le porc recevant un régime semi-purifié hautement digestible (Laplace, 1978a). Par rapport à une situation d'ingestion d'aliment standard à base de céréales, le nombre de C.M.M. enregistrés en 24 h est réduit sur le duodénum, et leur migration proximo-distale est à la fois beaucoup plus lente et moins régulière, avec augmentation du nombre de C.M.M. qui s'effacent avant d'atteindre l'iléon. Enfin, même s'il est d'évidence plus spectaculaire d'étudier les effets de l'alimentation chez des espèces telles que le Chien qui exhibe nettement une organisation postprandiale en A.I. continue, il est aussi possible d'observer les signes d'une adaptation à la nature de l'alimentation chez des espèces dont l'organisation en C.M.M. est stable. Par exemple, chez le Mouton, la distribution quotidienne unique d'une ration à base de céréales broyées et agglomérées au lieu du fourrage usuel entraîne une augmentation de la durée des phases d'A.I. et un raccourcissement du cycle des C.M.M. (Bueno, Weekes et Ruckebusch, 1977). Par conséquent, il s'avère nécessaire d'admettre que l'organisation de la motricité de l'intestin grêle en C.M.M. constitue pour beaucoup de mammifères une norme commune, susceptible $\mathrm{d}^{\prime}$ adaptations diverses à la grande variété des aliments et des habitudes alimentaires des diverses espèces.

\section{Mécanismes nerveux sous-jacents à l'organisation en C.M.M.}

L'existence même de cette organisation remarquable par sa récurrence cyclique, sa migration, et ses possibilités apparentes d'adaptation relativement diffé- 
renciées, soulève nombre de questions quant aux mécanismes qui la contrôlent dans son ensemble.

\section{a) Site d'origine et migration proximo-distale des C.M.M.}

Diverses observations, tendant à préciser le site d'origine de la séquence d'une part, et la nature de la coordination qui permet sa migration proximo-distale régulière d'autre part, conduisent à formuler des hypothèses quant aux mécanismes nerveux sous-jacents. La première question est de savoir si les C.M.M. se forment sur le duodénum, ou s'ils ne constituent que la propagation à l'intestin grêle d'un phénomène né en un site plus proximal. Effectivement, une organisation cyclique de la motricité du sphincter œsophagien inférieur et de l'estomac existe par exemple chez le Chien (Code et Marlett, 1975 ; Itoh et al., 1978a et d), avec apparente migration des séquences sur l'intestin grêle sous la forme de C.M.M. Mais des C.M.M. peuvent également naître en divers points de l'intestin grêle (Vantrappen et al., 1977 ; Laplace, 1978a ; Kerlin et Phillips, 1982).

Un certain nombre d'éléments semblent en faveur d'un site gastrique d'origine des C.M.M. : des poches antrales isolées conservent, chez le chien à jeûn, une organisation cyclique de leur motricité (Itoh et al., 1978b) ; le court-circuit ou la résection du tiers distal de l'intestin grêle n'affecte nullement la récurrence périodique de l'activité cyclique gastrique (Takeuchi et al., 1980). Face à ces faits, d'autres observations suggèrent que les C.M.M. sont fondamentalement une organisation propre à l'intestin grêle : chez le Mouton, le développement d'une A.R. sur le duodénum, succédant à une série de 8 à 12 fortes bouffées de potentiels qui correspondent à l'évacuation du bulbe duodénal, est concomitant d'une suspension de l'activité antrale (Ruckebusch et Bueno, 1977a) ; il en va de même chez le Porc lorsqu'une A.R. prend naissance sur le duodénum (Ruckebusch et Bueno, 1976 ; Laplace, 1978a). Cette quiescence antrale, qui pourrait être simplement induite par la voie d'un réflexe entéro-gastrique, tend à donner une image trompeuse de périodicité à l'activité gastrique du Mouton et du Porc. Mais même le Chien, pour lequel l'existence d'une activité cyclique gastrique est bien établie en situation de jeûne, est susceptible de présenter des A.R. duodénales de 8 à $10 \mathrm{~h}$ après le repas alors que l'activité antrale est encore continue (Ruckebusch, 1976). La simple observation des relations temporelles entre les activités des territoires concernés ne permet donc pas de conclure dans un sens ou dans l'autre. La démonstration du fait que les C.M.M. prennent effectivement origine en un site intestinal proximal a été apportée chez le Chien. En effet les C.M.M., et en particulier leur phase la plus remarquable d'A.R., se développent toujours sur le duodénum après anastomose antro-jéjunale ou après gastrectomie (Bueno, Rayner et Ruckebusch, 1981). Par conséquent, un estomac intact fonctionnel n'est nullement nécessaire à la naissance des C.M.M. sur le duodénum. On peut ainsi admettre qu'ils prennent effectivement origine sur le duodénum proximal, chez des espèces aussi différentes que le Mouton et le Chien. Cependant, estomac et duodénum ne sont pas au plan fonctionnel des structures complètement indépendantes. En effet, chez l'Homme, I'ablation de l'antre gastrique, associée à une gastrojéjunostomie, entraîne une augmentation importante de la fréquence des A.R. sur l'anse intestinale efférente (Bortolotti et al., 1983). En somme, il existe- 
rait en permanence une inhibition exercée par l'antre gastrique sur la fréquence intestinale propre de récurrence des C.M.M. Ces éléments suggèrent donc que les C.M.M. sont une organisation exclusivement intestinale soumise à des influences extérieures.

La seconde question tient à la nature de la coordination qui permet la migration proximo-distale régulière des C.M.M. nés au niveau duodénal. L'observation initiale, chez des chiens préparés avec une fistule de Thiry-Vella, de la propagation des C.M.M. sur le segment proximal, puis sur l'anse isolée, et enfin en séquence sur le segment distal, a d'abord conduit à suspecter l'intervention d'un contrôle nerveux extrinsèque dans cette propagation coordonnée (Carlson, Bedi et Code, 1972). Néanmoins la complexité des phénomènes est rapidement apparue. Chez le Mouton, la migration des A.R. subit un retard au niveau du site de transsection intestinale, et seulement $30 \%$ d'entre elles passent effectivement sur l'anse isolée, puis sur l'intestin en aval de l'anastomose de restauration de la continuité (Grivel et Ruckebusch, 1972). La réalisation de 2 transsections simples conduit à des phénomènes analogues, d'effacement de certains C.M.M. et de retard de migration, avec cumul des retards à chaque anastomose (Bueno, Praddaude et Ruckebusch, 1979). Non seulement tous les C.M.M. n'effectuent pas une migration proximo-distale complète, mais des C.M.M. se forment de novo sur l'anse et/ou en aval de l'anastomose chez le Chien porteur d'une fistule de Thiry-Vella (Bueno, Praddaude et Ruckebusch, 1979 ; Ormsbee et al., 1981). II en résulte un nombre de C.M.M. plus élevé au total sur l'intestin grêle distal que sur le territoire situé en amont de l'anastomose. Tous ces phénomènes de retard de migration, d'effacement de C.M.M. et de formation de novo de nouveaux C.M.M., observés chez le Mouton ou le Chien, sont également retrouvés chez le Porc, lors de transsection simple, et lors de construction d'une fistule de Thiry-Vella (Laplace, 1980). L'autonomie relative apparente dans certaines situations, des segments intestinaux les uns par rapport aux autres, est encore étayée par d'autres observations. La perfusion d'une anse intestinale isolée par des digesta ou une solution glucosée conduit, selon les cas et le segment concerné, à des effets variables : apparition d'une A.I. continue sur l'anse perfusée avec persistance ou non de l'organisation en C.M.M. sur l'intestin en place (Eeckhout et al., 1980 ; Schang et al., 1981 a ; Heppell et al., 1983).

Au-delà de ces divers phénomènes observés à court terme, il apparaît que, 3 mois après la construction d'une anse isolée, la propagation des C.M.M. sur l'intestin anastomosé en place est redevenue normale et que les C.M.M. de l'anse isolée sont complètement indépendants (Pearce et Wingate, 1980). II s'avère donc que les C.M.M. ne sont pas nécessairement organisés en un site unique duodénal, mais qu'ils peuvent réellement naître en tout point de l'intestin grêle. L'intégrité de la paroi intestinale, c'est-à-dire la continuité des plexus nerveux intrinsèques et éventuellement des couches musculaires, pourrait assurer la propagation normale des C.M.M. Dans ce sens, la restauration probable des plexus nerveux au-delà de 3 mois après l'intervention plaide en faveur d'un rôle important de l'innervation intrinsèque dans le déclenchement et la propagation des C.M.M. L'utilisation d'un principe expérimental analogue, par la réalisation chez le Chien de 3 transsections suivies de réanastomose de façon à partager l'intestin grêle en 
4 segments égaux déconnectés les uns des autres par les sites de transsection, permet de relier les phénomènes du déclenchement des C.M.M. d'une part, et de leur migration d'autre part (Sarna, Condon et Cowles, 1983a). II apparaît qu'initialement chacun des 4 territoires produit des C.M.M. totalement indépendants de ceux des autres ; puis une récupération survient 45 à 60 jours après l'opération, et enfin la migration proximo-distale des C.M.M. est complètement restaurée en 98 à 108 jours. Par conséquent, au cours de la période initiale, chaque territoire intestinal est capable de déclencher des C.M.M. pour son propre compte. Ceci signifie donc que les C.M.M. sont, certes, une organisation exc/usivement intestinale, mais qu'il n'y a pas dans l'absolu de site unique privilégié de naissance de ces C.M.M. I/ apparaît aussi que l'existence, sur un intestin intact, d'un site origine préférentiel - duodénal - avec migration proximo-distale régulière, repose sur l'intégrité anatomique de la paroi. C'est désigner a priori, dans la mesure où une telle organisation ne saurait être exclusivement myogène, l'intervention des plexus nerveux intrinsèques comme support du mécanisme de formation et de la migration proximo-distale des C.M.M.

\section{b) Vers un rôle privilégié du système nerveux intrinsèque.}

Avant de rechercher les arguments à l'appui de l'hypothèse d'un rôle essentiel de l'innervation intrinsèque à l'égard de la genèse et de la migration des C.M.M., et en particulier de la phase d'A.R., il convient de s'interroger sur le rôle potentiel du système nerveux extrinsèque. Du reste cette question a été, historiquement, envisagée la première (sans doute pour des raisons d'ordre méthodologique), suscitant diverses expériences de vagotomies et de sympathectomies, chez le Mouton (Ruckebusch et Bueno, 1975) et chez le Chien (Marik et Code, 1975 ; Weisbrodt et al., 1975a). L'activité continue enregistrée en réponse à un repas de viande est amoindrie à la suite d'une vagotomie (Marik et Code, 1975 ; Weisbrodt et al., 1975a ; Reverdin et al., 1980). Il y a également une grande irrégularité de la période des C.M.M. avec une variabilité importante de la durée de chacune des phases qui les constituent selon Marik et Code (1975). Mais la réduction globale de l'incidence des C.M.M. chez le chien vagotomisé, notée par ces auteurs, est contestée tant chez le Mouton (Ruckebusch et Bueno, 1975) que chez le Chien (Weisbrodt et al., 1975a ; Reverdin et al., 1980).

Au-delà de ces controverses, une étude des conséquences de la vagotomie chez le Chien (Ruckebusch et Bueno, 1977b) conduit à observer que l'interruption postprandiale de la périodicité des C.M.M. est différée d'environ $60 \mathrm{~min}$, et que la durée de la présence de l'activité continue postprandiale est réduite. De tels effets pourraient n'être que le résultat d'une modification par la vagotomie du rythme d'évacuation gastrique donc de la quantité de digesta déversés dans le duodénum et de la chronologie de leur arrivée. En fait, l'effet principal de la vagotomie consisterait en une réduction de la durée de l'A.I. postprandiale continue chez le Chien et en une réduction de la durée des phases d'A.I. des C.M.M. chez le Mouton (Ruckebusch et Bueno, 1977b). Or la seule modification expérimentale du débit de digesta dans l'intestin - augmentation par introduction de digesta additionnels ou réduction par dérivation extra-corporelle - induit chez le Mouton une 
variation de même sens de la durée des phases d'A.I., effet qui persiste chez le sujet vagotomisé en dépit d'une moindre réactivité de la préparation (Ruckebusch et Bueno, 1977b). L'hypothèse d'une influence indirecte de la vagotomie trouve donc là une confirmation, accordant du même coup un rôle prépondérant dans la régulation de I'A.I. à des réflexes locaux mis en jeu par la présence des digesta. Ainsi le nerf vague assurerait-il tout au plus un ajustement et/ou renforcement local de la réponse. Par ailleurs, la splanchnicectomie réduit simplement l'incidence des C.M.M. chez le Mouton (Ruckebusch et Bueno, 1975) ; les C.M.M. persistent chez le Chien après ganglionectomie coeliaque ou mésentérique supérieure, en dépit d'une certaine variabilité de leur période (Marlett et Code, 1979). Au total, les expériences de section nerveuse ne permettent donc pas de mettre en évidence un rôle important de l'innervation extrinsèque. Elles suggèrent tout au plus que celle-ci pourrait jouer un rôle modulateur, notamment à l'égard de l'organisation postprandiale. Mais il paraît nécessaire d'exclure une hypothétique intervention de l'innervation extrinsèque dans la genèse et la migration des C.M.M.

Compte tenu de ce qui précède, on est donc fondé à rechercher les éléments directs en faveur du rôle exclusif du système nerveux intrinsèque, notamment au travers d'une approche pharmacologique. Le blocage des récepteurs muscariniques et nicotiniques chez le Chien conduit à conclure qu'une bonne régularité des C.M.M. requiert une libération d'acétylcholine au niveau du muscle lisse (muscarinique), mais aussi probablement au niveau des ganglions (nicotiniques) des plexus intrapariétaux et/ou des ganglions sympathiques prévertébraux et paravertébraux (Ormsbee, Telford et Mason, 1979). L'incertitude demeure donc, du fait de l'implication de récepteurs nicotiniques qui laisse subsister le doute sur une possible intervention de l'innervation extrinsèque cholinergique. Mais cette éventualité concorde mal avec les observations relatives au peu d'effet des sections nerveuses extrinsèques (vagotomies notamment). Du reste, d'autres mécanismes (nerveux non vagaux, ou humoraux) pourraient être responsables d'une libération préganglionnaire d'acétylcholine associée au déclenchement et à la propagation des C.M.M. (Ormsbee, Telford et Mason, 1979). De fait, les résultats de ces auteurs peuvent être considérés comme en faveur de la mise en jeu du système nerveux intrinsèque.

La mise en œuvre d'injections intra-artérielles à un niveau périphérique très localisé, de façon à n'irriguer que des segments intestinaux de 3 à $5 \mathrm{~cm}$ au plus, a conduit Sarna et al. (1981) à affirmer l'élaboration des mécanismes de propagation des C.M.M. au sein même des plexus intrinsèques. Lorsqu'une A.R. est déclenchée en un site, l'activité contractile en ce site fournirait un stimulus qui, par l'intermédiaire des plexus, déclencherait les contractions d'A.R. un peu plus en aval. En effet, la perfusion intra-artérielle locale d'atropine, et celle d'hexaméthonium, sont capables, chacune séparément, de bloquer la propagation de l'A.R. Par conséquent les ganglions concernés (récepteurs nicotiniques bloqués par l'hexaméthonium) et le muscle lisse (récepteurs muscariniques bloqués par l'atropine) seraient disposés " en série " dans le circuit intrinsèque mis en jeu, un circuit direct de ganglion à ganglion (par des interneurones) paraissant peu probable. La transmission distale de l'excitation (propagation des C.M.M.) pourrait 
s'effectuer à partir de mécanorécepteurs activés par la contraction et articulés sur un ganglion distal ; en d'autres termes ces mécano-récepteurs pourraient fournir, par l'intermédiaire d'interneurones, l'excitation proximo-distale responsable de la propagation des C.M.M. L'injection locale de tétrodotoxine, qui bloque la conduction nerveuse, interrompt également la migration distale des A.R. en supprimant la transmission de cette excitation proximo-distale. En somme, la migration des C.M.M., et notamment des A.R. lorsqu'elles sont déclenchées en un site proximal, s'effectuerait " en cascade " dans la conception de Sarna et al. (1981).

Le travail de El-Sharkawy, Markus et Diamant (1982) confirme les effets de l'atropine et de l'hexaméthonium établis précédemment. Les éléments de certitude peuvent donc être résumés comme suit : (i) l'atropine peut bloquer la migration en cours des C.M.M. et le déclenchement de nouveaux C.M.M. Par conséquent l'activation de récepteurs cholinergiques muscariniques est responsable du déclenchement des phases actives des C.M.M. (A.I. et A.R.) à tous les étages du viscère. Le blocage ganglionnaire par l'hexaméthonium a des effets largement analogues à ceux de l'atropine. II y a donc activité cyclique d'éléments cholinergiques préganglionnaires articulés par des synapses nicotiniques sur les neurones cholinergiques postganglionnaires. Hors de ces faits on ne peut trancher entre deux hypothèses, également plausibles quant à l'origine de ces éléments préganglionnaires : S'agit-il de fibres d'origine extrinsèque, ou de connections constituées par des interneurones du plexus myentérique ? Cette seconde hypothèse paraît cependant la plus probable, qu'il s'agisse de connections interganglionnaires ou du système " en cascade " suggéré par Sarna et al. (1981). Enfin, à côté de ce rôle essentiel du système cholinergique, on peut envisager que le système adrénergique soit responsable de l'inhibition durant les phases de quiescence, mais cette hypothèse doit être rejetée puisque le blocage distinct ou simultané des récepteurs $\alpha$ et $\beta$ n'affecte nullement les épisodes de repos (El-Sharkawy, Markus et Diamant, 1982), ce qui est en accord avec les résultats des sections des voies nerveuses adrénergiques précédemment évoquées. Toutefois, ceci n'exclut nullement une intervention du système adrénergique, qui serait capable d'exercer un certain degré d'inhibition sur les phases actives (A.I. et A.R.), donc de moduler I'intensité de l'excitation cholinergique et d'affecter la durée respective de ces phases (El-Sharkawy, Markus et Diamant, 1982 ; Altaparmakov et Wienbeck, 1983).

En définitive, lorsqu'on cherche à identifier le support de la genèse et de la migration des C.M.M., il ne s'avère pas possible de reconnaître un rôle véritable au système nerveux extrinsèque, hors le fait que le système adrénergique intervient au plus comme modulateur dans le fonctionnement normal. Par contre, il paraît évident que le système nerveux intrinsèque, i.e. les plexus intrapariétaux, joue un rôle privilégié dans la mesure où il constitue le support cholinergique indispensable à l'accomplissement des C.M.M. En toute rigueur, I'analyse pharmacologique ne peut trancher entre une activation cyclique extrinsèque et la totale autonomie d'une activation cyclique intrinsèque par des interneurones. Mais, même si - hypothèse probable - les deux systèmes coexistent, on retiendra que l'intégrité des plexus nerveux intrinsèques est essentielle au déclenchement et à la migration des C.M.M. La preuve directe éclatante en est apportée par les conséquences de la destruction des neurones du plexus myentérique après 
application de chlorure de benzalkonium sur la séreuse (Fox, Epstein et Bass, 1984): cette destruction, contrôlée par l'histologie et l'immunohistochimie, entraîne au niveau de la zone traitée une quasi-absence de potentiels d'action et l'interruption des C.M.M.

\section{c) Origine de la périodicité : notion d'horloge interne.}

S'il est donc acquis que c'est au niveau des plexus intrapariétaux que sont accomplies la formation et la migration des C.M.M., la question reste posée de savoir quel est le mécanisme responsable du déclenchement périodique des états successifs d'activité intestinale. L'étude de ce problème a bénéficié des travaux conduits sur les effets des alcaloïdes morphiniques et le rôle des opioïdes endogènes - endorphines et enképhalines - à l'égard du fonctionnement du tube digestif (Rozé et Dubrasquet, 1983). Au-delà de l'observation fort ancienne de la constipation due aux opiacés, on sait aujourd'hui que leurs effets tiennent à l'existence de sites de liaison de haute affinité tant dans le tissu cérébral que dans le tissu musculaire lisse du tube digestif. Ainsi, la morphine ralentit considérablement le transit chez le rat en affectant la faculté de propulsion de l'intestin grêle (Fiocchi et al., 1982). Les effets des enképhalines sur l'intestin de chien isolé et perfusé in situ sont en partie liés à un effet direct sur le muscle lisse (Burks et al., 1982). L'inhibition du transit digestif induite chez le Rat par la morphine est complètement évitée par l'administration préalable d'un antagoniste à action périphérique sélective ( $N$-méthyl-Naloxone), ce qui plaide en faveur d'un site d'action intestinal des opiacés (Bianchi et al., 1983). Or, chez le Rat éveillé et en situation de jeûne, la morphine abolit les périodes d'A.I. sans affecter les A.R. ; chez le sujet alimenté, I'A.I. continue postprandiale est abolie au profit de la restauration des C.M.M. et des A.R. typiques de l'état de jeûne (Hutton, Dean et Wingate, 1983).

En plus de cette restauration de l'activité cyclique chez le sujet alimenté, la morphine est capable de provoquer l'apparition d'A.R. surnuméraires. Son injection intramusculaire chez l'Homme induit dans un délai moyen de 4 min une A.R. prématurée par rapport au cycle normal, et d'une durée généralement supérieure à celle d'une A.R. spontanée (Waterfall, 1983). On peut concevoir que la morphine simule l'effet d'un opioïde endogène responsable de la libération d'acétylcholine au niveau de récepteurs muscariniques et, par là même, l'effet déclenchant d'une A.R. Mais l'étude électrophysiologique de Wood (1980), fondée sur l'enregistrement intracellulaire de l'activité des neurones du plexus myentérique, montre que la morphine supprime l'excitabilité des seuls neurones de type 1 ou $\mathrm{S}$. II est donc également plausible que les effets, spasmogène et constipant, de la morphine résultent de la suppression de l'excitabilité de neurones inhibiteurs intrinsèques. Quelles que soient les modalités exactes d'action de la morphine, directes ou indirectes par levée d'inhibition, un élément important ici est que le déclenchement d'une A.R. surnuméraire par la morphine n'est pas affecté par la vagotomie tronculaire ou de branche. Ceci indique une fois de plus, que non seulement le site de déclenchement de la séquence des C.M.M. est intestinal, mais aussi que ce déclenchement est sous un contrôle entièrement local, échappant à un contrôle extrinsèque parasympathique (Waterfall, 1983). 
Le travail récent de Sarna, Northcott et Belbeck (1982), confirmant chez le Chien l'absence d'influence de la vagotomie, éclaire le mécanisme d'action de la morphine en mettant en évidence les caractéristiques d'oscillateur des C.M.M. Divers oscillateurs, ou horloges biologiques, se comportent comme des oscillateurs de relaxation. Un tel système se caractérise par l'augmentation progressive de la décharge jusqu'à un niveau seuil correspondant à la décharge maximale de l'oscillateur. II y a alors relaxation avec chute de la décharge au niveau le plus bas, puis à nouveau augmentation graduelle, etc... Dans ce système, un stimulus exogène appliqué lors de la décharge maximale de l'oscillateur reste sans effet, alors que s'il est appliqué à un autre moment du cycle il peut relever le niveau de décharge jusqu'à la valeur seuil, induisant ainsi prématurément la décharge maximale. II semble parfaitement plausible que l'activité nerveuse intrinsèque puisse ainsi osciller et donc affecter le niveau de décharge - manifesté par la plus ou moins grande intensité d'une activité de potentiels d'action du muscle lisse intestinal. Ainsi la décharge maximale est-elle représentée par I'A.R. Or il apparaît effectivement que la morphine exogène, injectée lors de la décharge maximale, n'affecte en aucune façon l'A.R. spontanée. Puis, correspondant à la phase de quiescence, existe une période réfractaire absolue durant laquelle la décharge de potentiels étant minimale, le stimulus exogène - la morphine - est incapable même à dose supra maximale de relever le niveau de décharge suffisamment pour atteindre la valeur seuil, et ne peut donc déclencher l'A.R. Suit enfin, approximativement durant la phase d'A.I., une période réfractaire relative durant laquelle les doses de morphine nécessaires pour atteindre le seuil, et donc déclencher prématurément I'A.R., sont de plus en plus faibles, ce qui témoigne de l'élévation spontanée progressive de la décharge non stimulée. A noter enfin que la vagotomie n'affecte pas plus les limites des périodes réfractaires que les effets de la morphine.

On peut donc aisément concevoir que la libération d'acétylcholine, médiateur clef au niveau des récepteurs muscariniques, soit pilotée du fait de cette propriété d'oscillateur de relaxation des plexus nerveux intrinsèques. Ceci signifie que les C.M.M. et leurs phases successives, dans leurs caractéristiques de durée et d'intensité, sont déterminés localement, au niveau de l'intestin grêle lui-même, sous le contrôle d'une véritable horloge biologique nerveuse intrinsèque. Nous avons noté plus haut que chaque territoire intestinal est capable de déclencher des C.M.M. pour son propre compte, et de se comporter comme un oscillateur indépendant. Mais dans un intestin intact, les oscillateurs régionaux sont couplés par l'intermédiaire des neurones intrinsèques de sorte que les oscillateurs proximaux pilotent les oscillateurs distaux. En somme chaque territoire dispose de son horloge intrinsèque, mais le couplage des différentes horloges assure la coordination de la migration des C.M.M. Les plexus nerveux intrinsèques sont donc tout à la fois l'origine et le support de l'organisation en C.M.M., dans ses caractéristiques fondamentales de récurrence cyclique sur le duodénum proximal et de migration proximo-distale coordonnée. Enfin si I'on ne peut exclure totalement la possibilité additionnelle d'une activation cyclique extrinsèque, se superposant à l'indispensable activation intrinsèque, il se pourrait qu'existe, à côté des horloges intrinsèques couplées, une horloge centrale. 


\section{d) Quelle place pour le système nerveux extrinsèque?}

L'incertitude qui subsiste quant à l'éventuelle possibilité d'ingérence du système nerveux extrinsèque dans le fonctionnement normal de l'intestin grêle amène à rechercher les situations révélant son rôle, relativement à celui, fondamental, du système nerveux intrinsèque. Il est acquis que lorsqu'un C.M.M. démarre en un site, sa propagation est assurée par excitation proximo-distale dans le réseau neuronal cholinergique des plexus. Une telle conception est encore appuyée de façon éclatante par les résultats d'expériences d'autotransplantation de jéjuno-iléon chez le Chien (Sarr et Kelly, 1981) ou de jéjunum proximal chez le porc (Aeberhard, Magnenat et Zimmermann, 1980). Elle est également en accord complet avec les conclusions qui peuvent être tirées de l'étude de la migration de C.M.M. sur des anses isolées (fistule de Thiry-Vella) réalisées à partir de segments d'intestin préalablement soumis à dénervation extrinsèque totale (ltoh, Aizawa et Takeuchi, 1981). Avant construction de l'anse isolée, les C.M.M. migrent normalement au travers du segment dénervé en place. Après réalisation de l'anse isolée, les C.M.M. ne passent pas sur celle-ci mais migrent directement de l'intestin proximal à l'intestin distal au travers de l'anastomose ; par contre des A.R. surviennent et migrent de façon totalement indépendante sur cette anse. Ceci ne fait donc que confirmer que le processus d'excitation et inhibition réciproque qui soustend la migration des C.M.M., élaboré dans le réseau neuronal des plexus, est capable de fonctionner parfaitement en dehors de toute influence nerveuse extrinsèque. En dépit de cette certitude, le rôle du système nerveux extrinsèque n'est pas nul, dans la mesure où celui-ci paraît effectivement capable d'intervenir dans la coordination temporelle des C.M.M. entre segments distants de l'intestin grêle, dans la fréquence de leur récurrence et la durée des phases qui les constituent (Hall, El-Sharkawy et Diamant, 1982 ; Heppell, Kelly et Sarr, 1983), et dans le phénomène d'interruption apparente postprandiale de l'organisation en C.M.M. (Sarr et Kelly, 1981).

Chez le Chien à jeun, pour lequel est bien établie l'existence d'une organisation motrice cyclique affectant de façon séquentielle le sphincter œsophagien inférieur, l'estomac, puis l'intestin grêle, le blocage vagosympathique bilatéral extemporané par refroidissement d'anses nerveuses sous-cutanées (Hall, ElSharkawy et Diamant, 1982) conduit à plusieurs observations. D'une part, la pression dans le sphincter œsophagien inférieur décroît et l'activité contractile gastrique disparaît, ce qui signifie que l'activité cyclique de ces territoires requiert impérativement l'intégrité fonctionnelle de l'innervation extrinsèque vagosympathique. $D^{\prime}$ autre part, le blocage extemporané par le froid n'interrompt pas le déroulement en cours d'un C.M.M. parcourant le duodéno-jéjunum, et n'empêche pas la récurrence des C.M.M. ultérieurs dont la périodicité n'est pas altérée. Par conséquent, l'activité cyclique du territoire gastrique est étroitement tributaire de l'intégrité nerveuse extrinsèque. Ce fait est en accord avec l'enregistrement de décharges efférentes vagales survenant au même rythme que l'activité cyclique gastrique (Miolan et Roman, 1978) et donc susceptibles d'en constituer la commande extrinsèque. A l'opposé, les C.M.M. de l'intestin grêle persistent, ce qui vient renforcer le fait, précédemment établi, qu'il s'agit bien d'une organisation exclusive- 
ment intestinale élaborée au niveau des plexus intrapariétaux. Cependant, au-delà de cette affirmation de la préservation du cycle des C.M.M. duodénaux, essentiellement fondée sur la récurrence normale de la phase d'A.R., le refroidissement vagosympathique extemporané (Hall, El-Sharkawy et Diamant, 1982) montre que, au total, la période active des C.M.M. (A.I. + A.R.) est abrégée avec absence des épisodes transitoires de repos et de contractions renforcées. Cette particularité conduit donc à nuancer les affirmations précédentes. En réalité, seule la phase d'A.R. caractéristique serait exclusivement tributaire de l'intégrité des plexus intramuraux ; par contre, le déroulement normal de la phase d'A.I. pourrait nécessiter en outre l'intégrité de l'innervation extrinsèque. On notera que cette conception concorde avec les effets de la vagotomie chez le Chien ou le Mouton, qui consistent essentiellement en une réduction des phases d'A.l. (Ruckebusch et Bueno, 1977b).

En somme, ce qui caractérise le plus authentiquement les C.M.M. intestinaux, c'est-à-dire la récurrence cyclique et la migration de la phase d'A.R., est le fait exclusif des plexus nerveux intrinsèques. Lors de l'A.I., le système nerveux extrinsèque interviendrait pour moduler ou renforcer l'activité intestinale, et probablement pour l'ajuster en fonction des afférences mises en jeu par les digesta présents dans la lumière. Cette dualité est compatible avec le fonctionnement des plexus intrinsèques sur le mode d'un oscillateur de relaxation. On conçoit qu'une influence extrinsèque puisse affecter le niveau de décharge de l'oscillateur au cours de la période réfractaire relative correspondant à la phase d'A.I., et qu'elle soit inopérante lors de la phase d'A.R., lorsque la décharge de l'oscillateur est maximale. En définitive, s'il y a fondamentalement à l'origine des C.M.M. une activation cyclique intrinsèque (interneurones des plexus), il y a aussi possibilité d'activation intercurrente d'origine extrinsèque, non cyclique par elle-même.

Cette place qui peut être accordée au système nerveux extrinsèque pour moduler la phase d'A.I. des C.M.M. pourrait constituer le support de la faculté d'adaptation des C.M.M. à la prise de nourriture. C'est ce que suggère l'étude de Diamant et al. (1980) chez le chien alimenté : dans cette situation, le blocage vagosympathique extemporané, par refroidissement $d^{\prime}$ une anse nerveuse souscutanée, abolit l'organisation postprandiale préexistante au profit d'un retour d'A.R. périodiques ; I'A.I. continue reparaît dès le réchauffement de la préparation. Au demeurant, le seul repas fictif est capable de retarder ou perturber la récurrence normale des C.M.M., tant chez l'Homme qui mastique puis recrache l'aliment, que chez le Chien porteur d'une canule gastrique ouverte (Defilippi et Valenzuela, 1981 ; Ruckebusch et Bueno, 1977b). La non-distribution du repas à un Porc accoutumé à un horaire précis d'alimentation suffit à perturber, durant environ $2 \mathrm{~h}$, la régularité de récurrence des C.M.M. sur le duodénum (Laplace, données non publiées). Tous ces éléments conduisent donc à reconnaître au système nerveux extrinsèque, notamment vagal, un rôle particulier dans le contrôle des modifications postprandiales de l'organisation en C.M.M., c'est-à-dire de leur faculté d'adaptation à l'arrivée plus ou moins massive des digesta.

Plus encore que le repas fictif, quelques situations particulières viennent témoigner de la capacité d'intervention du système nerveux central dans le fonctionnement normal de l'intestin grêle. Chez l'Homme, une agression mentale, 
prolongée ou intermittente, est capable d'inhiber fortement, voire de supprimer, l'organisation en C.M.M. sur le duodéno-jéjunum (McRae et al., 1982 ; Valori et al., 1983). Le vertige ou l'état nauséeux induit par une stimulation thermique indirecte et unilatérale du labyrinthe (irrigation de l'oreille externe par de l'eau glacée) peut conduire chez l'Homme alimenté à une modification de l'activité duodénale postprandiale qui tend à reproduire l'activité de jeûne malgré la présence d'aliments dans le tube digestif (Thompson, Richelson et Malagelada, 1982). Enfin, toujours chez l'Homme, une analyse spectrale de la périodicité des changements d'état de sommeil, des mouvements corporels au cours du sommeil et de l'activité contractile duodénale (C.M.M.) montre une cohérence significative qui plaide en faveur de l'existence d'un oscillateur, probablement central, qui influencerait plusieurs fonctions végétatives, dont les C.M.M. intestinaux (Finch et al., 1982).

\section{Influences humorales sur I'organisation en C.M.M.}

L'intervention, dans le contrôle des C.M.M., d'influences humorales (hormones, peptides dits régulateurs, opioïdes endogènes) doit également être envisagée. Le cas des peptides est particulièrement complexe dans la mesure où certaines de ces substances sont identifiées aussi bien dans les cellules endocrines de l'épithélium du tube digestif que dans diverses structures nerveuses tant périphériques que centrales (Dockray et Gregory, 1980). Aussi, quatre modes d'action distincts peuvent être postulés :

- endocrine, après déversement dans le courant sanguin pour agir sur des cellules cibles éloignées ;

- paracrine, avec libération locale pour action sur des cellules cibles adjacentes après diffusion limitée ;

- neurocrine de type neuro-médiateur, avec libération au niveau de surfaces synaptiques ;

- neurocrine de type neuro-modulateur, c'est-à-dire affectant les caractéristiques de la membrane des neurones sans assurer une quelconque médiation.

Si complexe que soit la physiologie des peptides, il existe divers arguments à l'appui de leur intervention dans la régulation de la motricité digestive, liés à la fois à leur présence, pour certains d'entre eux, dans les plexus intrinsèques, et à leur capacité de modifier des organisations telles que les C.M.M. intestinaux, lors d'administration de peptide exogène.

\section{a) Hypothèses caduques et influences mineures.}

C'est initialement pour tenter d'identifier une éventuelle médiation humorale de l'interruption postprandiale des C.M.M., au profit d'une A.I. continue, qu'a été entrepris ce type d'études. Un effet (endocrine) de l'insuline a été envisagé chez le Chien et le Mouton (Bueno et Ruckebusch, 1975 ; Ruckebusch et Fioramonti, $1975 b)$. On note chez le Rat Zucker hyperinsulinémique une réponse exagérée à la prise de nourriture (Ruckebusch et Weekes, 1976). Chez le Chien, les C.M.M. sont remplacés par une A.I. continue après injection d'insuline exogène ou perfusion de $\mathrm{D}$-glucose, de L-leucine ou de L-arginine, alors que à l'inverse la réponse 
à la prise de nourriture est réduite chez le Chien en diabète alloxanique (Bueno et Ruckebusch, 1976). La récurrence et l'intensité des C.M.M. sont réduites chez le Mouton en diabète alloxanique, mais l'injection d'insuline exogène permet de restaurer I'organisation normale des C.M.M. (Bueno et Ruckebusch, 1976). Chez le Rat également, lors de diabète induit par la streptozotocine, il y a diminution de la fréquence des C.M.M. avec perturbation des phases d'A.R. (Pascaud et al., 1982).

Cependant, l'étude chez le Chien de la corrélation entre la durée de l'A.I. continue postprandiale induite par divers types d'aliments (protéines de lait, saccharose, huile d'arachide, triglycérides à chaîne moyenne), et les taux d'insuline plasmatique, ne permet pas d'étayer valablement l'hypothèse d'un rôle physiologique de l'insuline dans le déterminisme de l'interruption postprandiale des C.M.M. (Eeckhout et al., 1978). En fait, le taux d'insuline plasmatique chez le Porc s'avère être le plus faible durant la phase de quiescence des C.M.M. et le plus élevé au cours de I'A.I. juste avant le déclenchement de I'A.R. Ceci suggère que, loin d'être une conséquence des variations de la sécrétion d'insuline, les C.M.M. pourraient en fait influencer l'absorption du glucose et, de ce fait, la production d'insuline (Rayner et Weekes, 1978). Une confirmation supplémentaire de cet enchaînement est fournie par l'observation que l'insuline exogène n'interrompt les C.M.M. chez le porc à jeun que dans la mesure où une hypoglycémie est induite (Rayner, Weekes et Bruce, 1981). Par conséquent, l'insuline ne semble pas être responsable de la substitution aux C.M.M. d'une A.I. continue de type postprandial.

Divers peptides gastrointestinaux, tels que la gastrine, la cholécystokinine, la sécrétine et le polypeptide pancréatique, ont été suspectés de jouer un rôle particulier compte tenu de leur importance dans la physiologie du carrefour gastroduodénal. II a été ainsi envisagé que la gastrine (Weisbrodt et al., 1974 ; Wingate et al., 1975 ; Marik et Code, 1975) et la cholécystokinine (Mukhopadhyay et al., 1977) pourraient être responsables, au moins en partie, de l'interruption postprandiale des C.M.M. chez le Chien. Ces deux peptides réduisent en effet l'incidence des C.M.M. chez le sujet à jeun mais ne les abolissent véritablement qu'au niveau de l'intestin grêle proximal (Wingate et al., 1978). Chez le Rat, la perfusion endoveineuse de cholécystokinine peut, à l'instar de la prise d'aliment, substituer à l'activité périodique une A.I. continue durant 2 à $3 \mathrm{~h}$; il en va de même durant 30 min après injection sous-cutanée de pentagastrine (Hutton et Wingate, 1984). La sécrétine est capable de réduire la fréquence des A.R. duodénales (Dimagno et al., 1981) ou de diminuer l'incidence des potentiels d'action sur le duodénojéjunum sans affecter notablement la périodicité des C.M.M. (Wingate et al., 1978). Mais il s'avère peu probable que ces divers peptides soient, dans les conditions physiologiques, responsables de l'instauration de l'A.I. postprandiale, que ce soit seuls (Eeckhout et al., 1978 ; Lee, Kim et Chey, 1980) ou en association (Wingate et al., 1978 ; Lee, Kim et Chey, 1980). En effet, l'organisation de l'activité myoélectrique induite par ces peptides n'est pas véritablement semblable à celle qui est consécutive au repas (Wingate et al., 1978).

En ce qui concerne le po/ypeptide pancréatique, les résultats, obtenus dans 3 espèces différentes, ne sont guère convergents. Chez l'Homme à jeun des varia- 
tions cycliques du taux plasmatique de ce peptide ont été décrites, avec un maximum en fin d'A.I., immédiatement avant l'apparition de l'A.R. enregistrée par manométrie sur le duodénum descendant (Janssens et al., 1982). A la suite de la prise d'aliment, on observe à la fois une forte augmentation de la concentration du polypeptide pancréatique et I'A.I. continue postprandiale. Mais la perfusion de polypeptide non spécifique (bovin), pour créer chez le sujet à jeun une concentration plasmatique supérieure aux valeurs postprandiales, n'affecte pas la récurrence des A.R. La perfusion de polypeptide pancréatique (bovin également) chez le Porc ou le Chien à jeun, augmente considérablement - et de façon variable selon la dose - la fréquence des C.M.M., ce qui conduit Bueno et al. (1982) à reconnaître à ce peptide une fonction régulatrice de leur périodicité. L'existence de variations cycliques, analogues à celles décrites chez l'Homme à jeun (pic en fin d'A.I.) a été décrite chez le Chien à jeun (Hall et al., 1983). Dans cette espèce, la perfusion de polypeptide pancréatique porcin, à des doses reproduisant les plus fortes concentrations de jeûne, reste sans effet sur le déroulement des A.R. A une dose 4 fois plus élevée, reproduisant les concentrations plasmatiques postprandiales, elle induit, même lors de blocage bilatéral de la conduction dans les nerfs vagues par le froid, une inhibition spécifique des A.R. duodéno-jéjunales ; ceci signifie que, pendant toute la durée de la perfusion, les phases de quiescence et d'A.I. sont régulièrement observées, la phase d'A.R. étant remplacée soit par un épisode de quiescence, soit par une prolongation de l'A.I. La réapparition de I'A.R. survient dans les $10 \mathrm{~min}$ qui suivent l'arrêt de la perfusion. Aussi Hall et al. (1983) suggèrent que le polypeptide pancréatique n'interviendrait ni dans le contrôle de la périodicité des C.M.M. à jeun, ni dans l'établissement de l'A.I. continue postprandiale. Mais ce peptide pourrait éventuellement jouer un rôle dans l'inhibition postprandiale de la phase $d^{\prime} A . R$. En réalité, les discordances relevées sont trop importantes pour qu'un véritable crédit soit accordé aux hypothèses d'un rôle physiologique du polypeptide pancréatique, du moins sur la base d'expériences de perfusion d'un peptide non spécifique dans tous les cas. A noter enfin que la perfusion endoveineuse de peptide $Y Y$, résidu de 36 acides aminés présentant des analogies structurales avec le polypeptide pancréatique, abolit la migration des A.R. en direction aborale sur le jéjunum de Rat, mais n'affecte pas leur récurrence sur le duodénum (Al-Saffar et Tatemoto, 1984).

La neurotensine, probable neurotransmetteur au niveau du système nerveux intrinsèque de l'intestin, est un peptide dont le seul facteur de libération connu est le repas, et en particulier les graisses, et qui s'avère également capable d'affecter l'activité intestinale. La perfusion endoveineuse de $\left(\mathrm{Gln}^{4}\right)$-neurotensine modifie le transit intestinal du chyme chez le Rat, d'un mode interdigestif en un mode typiquement postprandial (Wilen, Gustavsson et Jung, 1982). Elle conduit également, dans cette même espèce, à substituer à l'organisation en C.M.M. une A.I. continue de type postprandial (Al-Saffar et Rosell, 1981). De même chez l'Homme la perfusion de $\left(\mathrm{Gln}^{4}\right)$-neurotensine induit une $\mathrm{A}$.I. continue analogue à celle consécutive à l'ingestion de graisses (Thor et al., 1982). Bien que ces éléments suggèrent un rôle de la neurotensine dans l'instauration de l'A.I. continue postprandiale, on note que, chez le Rat, la réponse à la neurotensine est indifférente à la vagotomie alors que la réponse à un repas de graisses requiert l'intégrité vagale 
(Wilen, Gustavsson et Jung, 1982). La réponse à ces 2 stimulus n'est pas non plus identique chez l'Homme dans la mesure où, après perfusion endoveineuse de neurotensine, les A.R. restent présentes dans un fond d'A.I. continue, alors qu'après instillation d'oléate dans le duodénum les A.R. sont totalement abolies (Thor et al., 1984). La neurotensine ne saurait donc être considérée comme le responsable principal de l'activité postprandiale.

La substance $P$, autre neurotransmetteur probable, présente entre autres localisations dans les neurones des plexus myentériques, pourrait également être impliquée dans un contrôle neuroendocrinien de l'activité intestinale (Thor, Sendur et Konturek, 1982). La perfusion endoveineuse de doses faibles 10,25 à $1 \mathrm{nmol} . \mathrm{kg}^{-1} \cdot \mathrm{h}^{-1}$ ) entraîne chez le Chien à jeun une augmentation de la fréquence des C.M.M. avec renforcement des phases d'A.I. et d'A.R., notamment au niveau du duodénum. A dose plus élevée, la substance $P$ peut conduire à l'apparition d'une activité de type A.l. postprandiale. Enfin, ces effets de la substance $P$ sont bloqués par l'atropine ou par la pirenzépine ce qui témoigne d'une médiation de ces effets par une libération d'acétylcholine au niveau du muscle lisse (Thor, Sendur et Konturek, 1982).

Le peptide intestinal vasoactif (ou V.I.P.), autre peptide abondant en particulier dans les neurones des plexus intrapariétaux de l'intestin, constitue également un très probable neurotransmetteur et/ou neuromodulateur (Fahrenkrug, 1979; Gaginella, O'Dorisio et Hubel, 1981), susceptible d'affecter I'ensemble du système digestif et de ses glandes annexes. II n'est cependant pas évident que son action soit exclusivement de type neurocrine, c'est-à-dire locale. Le V.I.P. est en effet présent dans le plasma à des concentrations non négligeables, notamment dans le sang portal (Schaffalitzky de Muckadell et al., 1977). La stimulation électrique des nerfs vagues entraîne une augmentation des concentrations plasmatiques du V.I.P. chez le porc anesthésié, même après atropinisation (Schaffalitzky de Muckadell, Fahrenkrug et Holst, 1977). La perfusion intraduodénale d'acide chlorhydrique ou de graisses entraîne également une élévation du taux plasmatique de V.I.P. ; cette réponse n'est modifiée ni par la vagotomie, ni par le blocage ganglionnaire à l'hexaméthonium à une dose qui abolit pourtant la réponse à la stimulation vagale (Schaffalitzky de Muckadell et al., 1977). Mais on ne dispose guère d'information quant aux effets du V.I.P. sur l'activité du muscle lisse, hors le travail de Morgan, Schmalz et Szurszewski (1978) qui met en évidence les effets inhibiteurs du V.I.P. sur les activités mécaniques et électriques du muscle lisse antral. On peut néanmoins concevoir que le V.I.P. ait un rôle particulier d'inhibiteur, à l'intérieur du réseau neuronal des plexus, dans le cadre du système d'excitation et inhibition réciproque qui sous-tend la migration des C.M.M.

Au total, il n'existe pas, pour toutes les substances prises en compte ici, d'éléments véritablement convaincants en faveur d'un rôle déterminant particulier dans des conditions réellement physiologiques. Outre les suspicions du fait des doses utilisées, des voies d'administration qui ne sont pas nécessairement les voies normales d'action et des problèmes de spécificité d'espèce pour certains fragments des molécules concernées, il faut aussi se rappeler que nombre de ces peptides sont " libérés" plus ou moins simultanément, par exemple lors d'un repas, ce qui rend encore plus difficile l'évaluation de leur rôle. 


\section{b) Le rôle de la motiline.}

La motiline est capable d'induire une augmentation dose-dépendante de l'activité de potentiels d'action sur une préparation isolée et perfusée de duodénum de Chien (Green et al., 1976). Lorsqu'elle est perfusée chez le Chien à jeun, elle induit l'apparition d'A.R. typiques, propagées en direction aborale, mais survenant prématurément et donc intercalées dans la séquence normale des C.M.M. (Wingate et al., 1975, 1976). La perfusion endoveineuse de motiline exogène est par contre incapable, même à dose élevée, de modifier l'organisation postprandiale chez le Chien alimenté, alors qu'elle induit une activité périodique analogue aux C.M.M. spontanés chez le sujet à jeun (Itoh et al., 1976). Toutefois, la 13Nlè-motiline qui est capable d'induire un C.M.M. chez le Chien à jeun, ne peut déclencher ce même phénomène ou affecter la fréquence des C.M.M. spontanés chez le Porc à jeun (Bueno et al., 1982). L'hypothèse a néanmoins été envisagée, dès 1976, que les C.M.M. pourraient être, au moins en partie, contrôlés par le taux de motiline circulante.

Cette hypothèse a été d'abord confortée par l'observation, chez le Chien, d'une augmentation parallèle du taux de motiline plasmatique et du taux de surcharge des ondes lentes par des bouffées de potentiels d'action (Lee et al., 1977). Chez le chien à jeun depuis $17 \mathrm{~h}$, le taux plasmatique de motiline atteint un maximum concomitant de l'épisode cyclique d'activité antrale, peu avant le déclenchement d'une A.R. sur l'intestin proximal (Itoh et al., 1978c). Pour Lee et al. (1978), le pic de concentration de la motiline dans le plasma coïncide avec le déclenchement d'une A.R. sur le duodénum du chien à jeun, cependant que le taux le plus faible est observé au cours de la phase de quiescence. Des concentrations très faibles de motiline sont également enregistrées tout au long du déroulement de la période d'A.I. postprandiale continue (Itoh et al., 1978c). On note, par ailleurs, que l'augmentation cyclique de la motilinémie chez le sujet à jeun est bloquée par l'atropinisation au même titre que le déroulement de l'A.R. (Lee et al., 1977). De plus, sous perfusion de pentagastrine, la motiline n'a pas d'effet sur l'activité de potentiels d'action (Wingate et al., 1976, 1977), et les bandes d'A.R. spontanées ou induites par la motiline exogène sont inhibées par la perfusion endoveineuse de gastrine (ltoh et al., 1976). Toutefois, à côté de cet ensemble d'éléments favorables à un rôle particulier de la motiline, il s'avère que des pics peuvent survenir en l'absence de déclenchement d'une A.R. sur le duodénum, et inversement que des A.R. peuvent survenir alors que les taux de motiline plasmatique sont au plus bas. En dépit du parallélisme, force est donc d'admettre que les pics de la motilinémie ne sont probablement ni nécessaires, ni suffisants pour déclencher une A.R. (Fox, Track et Daniel, 1981).

Dans le cas de l'Homme, l'existence d'importantes variations inter et intra individuelles des taux de motiline plasmatique est très vite apparue (Vantrappen et al., 1978b). Quoique la plupart des C.M.M. duodénaux semblent contemporains de variations cycliques du taux plasmatique de motiline, il existe chez l'Homme, comme chez le Chien, des A.R. sans pic de motiline associé et inversement (Vantrappen et al., 1978a). Cependant, l'existence effective d'une étroite relation statistique entre le déroulement des A.R. sur le duodénum et les pics de motilinémie 
chez I'Homme à jeun a été finalement établie (Vantrappen et al., 1979 ; Peeters, Vantrappen et Janssens, 1980b ; You, Chey et Lee, 1980). Le taux de motiline est au plus bas au début de la phase de quiescence ; il augmente progressivement durant le déroulement de I'A.I. pour atteindre un pic à la fin de cette dernière, immédiatement avant le déclenchement de l'A.R., et décroît à nouveau au cours de celle-ci. Il existe néanmoins là encore des observations divergentes. Certains auteurs ont constaté un défaut total de corrélation entre les C.M.M. spontanés et l'évolution du taux de motiline endogène (Lux et al., 1978), ou encore une élévation significative, mais inattendue, de ce taux à la suite de l'ingestion d'un repas d'épreuve au cours de la période réfractaire consécutive à une A.R. (Christofides et al., 1981).

La controverse s'est également développée autour des résultats enregistrés chez le Porc. II n'y a pas libération de motiline à la suite du repas (Modlin, Mitznegg et Bloom, 1978). Selon Bloom et al. (1982), il y aurait une variation cyclique de la motilinémie, associée aux C.M.M. duodéno-jéjunaux chez le Porc à jeun : la concentration plasmatique de la motiline passerait par un maximum environ $6 \mathrm{~min}$ avant l'apparition de l'A.R. sur le duodénum. Mais aucune relation n'est identifiée par d'autres auteurs (Borody et al., 1981). De plus, la motiline naturelle exogène ou la 13-Nle-motiline synthétique ne déclenchent pas l'apparition d'A.R. surnuméraires dans cette espèce (Borody et al., 1981). Toutefois, il existe également chez le Porc de très importantes variations inter et intra indiviquelles du taux de motiline plasmatique, et les contradictions relevées ci-dessus s'avèrent être la conséquence d'inégales durées de jeûne (Cuber, Laplace et Chayvialle, 1984) : en fait, chez le Porc à jeun depuis $24 \mathrm{~h}$, il existe bien des variations cycliques de la motilinémie, concomitantes des C.M.M. sur le duodénum proximal. Le tableau obtenu chez le Porc à jeun est tout à fait semblable à celui décrit pour l'Homme par You, Chey et Lee (1980).

\section{c) L'intervention de la somatostatine.}

La somatostatine est un tétradécapeptide, initialement connu comme facteur inhibiteur de la libération d'hormone de croissance, et présent à la fois dans des cellules de type endocrine-paracrine et dans le système nerveux central (hypothalamus notamment) et périphérique (plexus myentérique). A des concentrations analogues à celles nécessaires pour supprimer la libération d'hormone de croissance, la somatostatine supprime l'activité spontanée des neurones myentériques et la libération d'acétylcholine par les plexus myentériques soumis à stimulation électrique. Lorsqu'on l'utilise par la voie endoveineuse, chez le Chien à jeun, la somatostatine exogène est capable d'augmenter la fréquence des C.M.M. Son administration chez le sujet alimenté conduit à substituer à l'A.I. continue postprandiale une organisation en C.M.M. analogue à celle enregistrée en situation de jeûne (Thor et al., 1978). Par contre, chez le Porc, à la dose qui accroît la fréquence des C.M.M. chez le Chien, elle inhibe la survenue des potentiels d'action duodénaux, et interrompt les C.M.M. (Bueno et al., 1982). La somatostatine exogène est encore capable d'induire des A.R. surnuméraires chez l'Homme, de façon analogue à l'effet de la motiline exogène quoique le déclenchement de 
I'A.R. soit plus précoce (Lux et al., 1980b). Enfin, le démarrage d'une A.R. spontanée sur le duodénum proximal de l'Homme s'accompagne d'un pic de somatostatine (Peeters, Janssens et Vantrappen, 1983).

Cependant, on note aussi que chez l'Homme la perfusion de somatostatine exogène entraîne tout à la fois une abolition de I'A.I., une fréquence accrue d'apparition des A.R., et parallèlement une diminution des taux plasmatiques de motiline et de polypeptide pancréatique (Peeters, Janssens et Vantrappen, 1983). Chez l'Homme, la perfusion de polypeptide pancréatique bovin entraîne un abaissement du taux plasmatique de motiline, alors que les A.R. sont préservées (Janssens et al., 1982). De façon contradictoire avec certaines des données précitées, les cycles spontanés des C.M.M. et les pics cycliques de motilinémie qui leur sont associés, peuvent être supprimés chez le Chien à jeun par la somatostatine exogène ; celle-ci peut retarder également le déclenchement des A.R. induites par la motiline exogène et supprimer leur migration, mais est capable d'induire des A.R. ectopiques et propagées en direction aborale en dépit de taux faibles de motiline (Ormsbee, Koehler et Telford, 1978 ; Poitras et al., 1980). Les effets inhibiteurs de la somatostatine, à l'égard des C.M.M. spontanés et des pics associés de motiline, sont cohérents avec l'abaissement du taux de motiline plasmatique enregistré lors de perfusion endoveineuse de glucose ou d'acides aminés chez le Chien (Mori et al., 1981). Chez l'Homme, la valeur de la motilinémie semble également varier selon la nature des nutriments, aussi bien en situation d'alimentation orale que de nutrition parentérale : ainsi la motilinémie augmente avec les lipides et baisse avec le glucose ou les acides aminés (Bloom et al., 1978 ; Christofides et al., 1979).

En définitive, il apparaît là encore une profusion d'informations, avec nombre de contradictions pour autant que permette d'en juger la diversité des espèces et des conditions expérimentales exactes mises en œuvre. II reste que la motiline, secondairement la somatostatine et éventuellement le polypeptide pancréatique, apparaissent comme les plus susceptibles de jouer un rôle véritable dans la mesure où leurs concentrations plasmatiques présentent des variations cycliques spontanées concomitantes des C.M.M., au moins dans certaines espèces.

\section{d) Recherche d'une signification des modifications humorales.}

Les peptides candidats à un rôle effectif dans le déroulement physiologique des C.M.M. sont donc peu nombreux. Mais la signification exacte des fluctuations ou effets enregistrés n'est pas évidente. La recherche d'une analogie entre les actions respectives de la morphine et de la motiline doit être écartée. II n'y a, en effet, pas identité complète des effets sur les C.M.M. de ces 2 substances (Sarna, Condon et Cowles, 1983b) et s'il est plausible que les opioïdes endogènes jouent un rôle quelconque dans le déclenchement des C.M.M. duodénaux, il semble bien que, de toute façon, la motiline n'agisse pas par l'intermédiaire des récepteurs aux opiacés (Telford et Szurszewski, 1983). Ceci étant, l'existence de variations cycliques des concentrations plasmatiques de la motiline, de la somatostatine et du polypeptide pancréatique, signalée chez l'Homme, le Chien et le Porc (Itoh et al., 1978c ; Vantrappen et al., 1978b, 1979 ; Keane et al., 1980a ; 
Lux et al., 1980a ; Janssens et al., 1982 ; Bloom et al., 1982 ; Cuber, Laplace et Chayvialle, 1984 ; Hall et al., 1983 ; Peeters, Janssens et Vantrappen, 1983) plaide en faveur d'une fonction physiologique de ces peptides en relation avec les C.M.M. On peut envisager trois hypothèses : (i) ces peptides jouent effectivement un rôle causal, individuellement ou collectivement, à l'égard des C.M.M. ; (ii) leurs fluctuations ne sont qu'une conséquence des phénomènes responsables des C.M.M., mais ils jouent néanmoins un rôle effectif pour synchroniser d'autres phénomènes physiologiques avec les C.M.M. ; (iii) ils interviennent comme des modulateurs potentiels, mais leurs co'ncentrations plasmatiques n'ont pas nécessairement grande signification.

Des variations cycliques de la somatostatinémie d'une part, et une accélération de la fréquence des A.R. lors de perfusion de somatostatine d'autre part, ont été précédemment notées. Or, la perfusion de motiline entraîne chez l'Homme à la fois une A.R. et un pic de somatostatine, ce qui conduit Peeters, Vantrappen et Janssens (1983a) à conclure que la motiline pourrait déclencher les A.R. par l'intermédiaire de la somatostatine. Ceci reviendrait à accorder à ces 2 peptides un rôle effectif dans le déclenchement des A.R. Pourtant, la somatostatine exogène peut dans certains cas induire des A.R. ou accélérer leur fréquence chez le Chien ou l'Homme tout en abaissant la motilinémie. Konturek (1984) obtient chez le Chien la suppression des fluctuations cycliques de la motiline en l'absence de toute influence sur le déclenchement et la propagation des C.M.M. Nous avons aussi noté que le polypeptide pancréatique n'affecte pas les C.M.M. dans la plupart des cas, ce que confirme Konturek (1984) qui note parallèlement la réduction des variations cycliques de la motilinémie. Enfin, l'immunoneutralisation de la motiline par des anticorps spécifiques réduit les concentrations de motiline circulante pour plusieurs jours, alors que les C.M.M. réapparaissent au bout de quelques heures sur l'intestin grêle proximal, de façon tout à fait normale (Konturek, 1984). Ces éléments conduisent donc à minimiser le rôle déterminant que l'on a voulu un temps faire jouer à certains peptides, et à la motiline notamment.

Dans le cas particulier de l'Homme (Janssens, Vantrappen et Peeters, 1983), sous perfusion combinée de polypeptide pancréatique et de 13-Nle-motiline, $90 \%$ des A.R. prennent origine sur l'estomac; mais sous perfusion de polypeptide pancréatique seul, toutes les A.R. naissent sur l'intestin grêle alors que la motilinémie est abaissée. Ces observations suggèrent que la motiline pourrait avoir un rôle essentiel pour réguler l'activité périodique de l'estomac, mais pas celle de I'intestin grêle. II est vrai que cette conception serait compatible avec la présence d'une plus grande densité de récepteurs à la motiline sur le muscle lisse antral que sur le muscle lisse duodénal (Bormans et al., 1983). Mais ce fait n'a été jusqu'ici mis en évidence que chez le Lapin. De plus, il a été précédemment noté que l'activité gastrique n'est organisée de façon cyclique véritable que chez l'Homme et le Chien. Aussi, compte tenu des relations temporelles entre C.M.M. duodénaux et variations cycliques de la concentration plasmatique des divers peptides, il paraît difficile d'accorder à ces derniers un rôle causal individuel ou collectif, y compris pour la motiline vis-à-vis de l'activité gastrique. En somme la première hypothèse peut être écartée et, dans la mesure où les concentrations plasmatiques des peptides concernés ont une réelle signification physiologique, il serait 
plus vraisemblable de postuler leur rôle comme agents d'une coordination entre organes ou fonctions.

L'examen des fluctuations de la motilinémie chez le Porc à jeun et alimenté, donc en situation physiologique hors de toute perfusion de peptide exogène, conduit à constater que les variations cycliques de la motilinémie enregistrées à jeun sont totalement absentes durant l'A.I. continue postprandiale. Mais on note aussi que la réapparition, au-delà de 2 à 3 heures après le repas, de C.M.M. typiques avec des A.R. bien individualisées, précède la réapparition de variations cycliques, initialement de faible amplitude, de la motiline (Cuber, Laplace et Chayvialle, 1984). Cette chronologie conduit donc à envisager que la libération de motiline soit plutôt une conséquence qu'une cause des A.R. C'est également à cette conclusion qu'amène le travail de Sarna et al. (1983) chez le Chien : toutes les A.R., spontanées ou induites par la morphine, sont accompagnées d'un pic de motiline. La morphine peut, même en situation postprandiale ou sous perfusion de somatostatine, déclencher une A.R. qui migre en direction aborale, par contre, dans ces deux mêmes situations, la motiline est incapable de déclencher une A.R. II semble donc bien que la motiline endogène ne soit nullement le déclencheur des A.R., mais qu'à l'inverse elle soit libérée du fait de l'activation, spontanée ou suscitée par la morphine. Il existe cependant des différences régionales au long de I'intestin dans la mesure où une relation C.M.M.-libération de motiline existe bien au niveau proximal alors que des territoires plus distaux sont moins concernés par les variations des peptides (Sarna et al., 1983 ; Konturek, 1984). Ceci peut rendre compte du fait que des A.R. ectopiques naissant sur le jéjunum ne sont pas associées à un pic de motiline. Aussi, la motiline libérée lors du déclenchement de I'A.R., pourrait-elle jouer un rôle particulier dans la physiologie du carrefour gastro-duodénal, par exemple pour assurer une coordination entre phénomènes moteurs et secrétoires, aspect sur lequel nous reviendrons. Toutefois, si cette seconde hypothèse paraît bien devoir être retenue, le mécanisme par lequel la motiline est libérée reste obscur. L'effet mécanique de la contraction est envisageable au même titre que l'intervention d'un relais nerveux activé par des récepteurs sensibles par exemple à la contraction (Sarna et al., 1983).

La relation entre activité nerveuse et libération de motiline constitue la troisième hypothèse, dans la mesure où ce peptide pourrait renforcer ou moduler l'action des oscillateurs intrinsèques qui constituent I'horloge interne des plexus. La motiline exogène, susceptible d'induire des A.R. surnuméraires sur l'intestin grêle proximal, retarde au contraire le déclenchement des A.R. spontanées d'une anse jéjunale isolée chez le Chien (Pinnington et Wingate, 1983). La perfusion de motiline exogène, capable d'accroître la fréquence des A.R. dans des proportions considérables (période 3 fois plus brève) n'affecte pas la période des A.R. d'un segment jéjunal autotransplanté, donc privé d'innervation extrinsèque (Sarr, Kelly et Go, 1983). L'utilisation combinée d'agonistes et d'antagonistes du système cholinergique et de stimulations nerveuses, soit des vagues, soit des nerfs duodénaux intrinsèques (par stimulation de champ) conduit Fox et al. (1983) à conclure que l'augmentation des taux de motiline endogène, liée au passage de l'A.R. sur le duodénum, pourrait résulter des effets combinés d'une augmentation de l'activité vagale et de l'activité motrice duodénale. Deux types de libération de motiline 
pourraient en fait exister, l'un indépendant de la motricité duodénale mais relevant d'une activation nerveuse vagale, l'autre étroitement corrélé avec l'augmentation de motricité duodénale. Enfin, Hall, Diamant et Greenberg (1983) parviennent à la conclusion que, chez le Chien, la phase d'A.I. des C.M.M. et la libération concomitante de motiline sont dépendantes de l'intégrité vagale, alors que I'A.R. dépendrait d'une innervation cholinergique non vagale. Cette conception concorde bien avec le partage établi plus haut entre les rôles respectifs des plexus nerveux intrinsèques d'une part, et de l'innervation extrinsèque d'autre part.

En définitive, la motiline et probablement quelques autres peptides sont sans doute mis en jeu sous un double contrôle nerveux intrinsèque et extrinsèque, pour contribuer à moduler la chronologie des C.M.M. et aoordonner la motricité avec d'autres phénomènes physiologiques. I/ paraît certain qu'aucun des peptides étudiés ne sert de déclencheur (rôle réservé à l'horloge intrinsèque) mais qu'ils peuvent servir de facteurs de rétroaction positive ou négative selon le cas (Konturek, 1984). De même, aucun de ces peptides ne peut, par lui-même, être responsable de l'organisation postprandiale de la motricité qui est plus certainement le résultat de la combinaison d'actions humorales multiples et de l'activité nerveuse particulière suscitée par tous les facteurs physiques et chimiques qu'implique la présence d'aliment dans le tube digestif.

\section{Intégration neuro-hormonale et interrelations fonctionnelles.}

Les mécanismes nerveux et les influences humorales impliqués dans le contrôle des C.M.M. ont été jusqu'ici envisagés de façon distincte. Pourtant il faut d'évidence rejeter un tel partage simple des rôles, et accepter une conception intégrée dans laquelle l'horloge biologique des plexus nerveux intrinsèques peut voir son action modulée ou affectée par des influences nerveuses extrinsèques et des influences humorales. De plus, le fonctionnement remarquable de la motricité de l'intestin grêle ne saurait être complètement indépendant d'un certain nombre d'autres fonctions digestives. Mais dans cette intégration fonctionnelle, on ne peut a priori savoir si les fluctuations de la libération de peptides associées aux C.M.M. sont l'instrument d'une coordination imposée à d'autres fonctions, ou si ces fluctuations sont la résultante de la périodicité d'autres fonctions qui moduleraient l'activité du grêle par l'intermédiaire de la libération de peptides.

a) Peptides et milieu endoluminal: la composante sécrétoire des C.M.M. chez l'Homme.

Si I'on s'interroge sur les facteurs qui pourraient être responsables de la libération cyclique de peptides à partir des cellules endocrines de l'épithélium intestinal, une hypothèse consiste à accorder un rôle aux conditions de milieu régnant dans l'intestin, et au premier chef au $\mathrm{pH}$ endoluminal qui peut être considéré comme la résultante $d^{\prime}$ actions diverses : pouvoir tampon des matériaux alimentaires, sécrétion acide gastrique, sécrétions biliaire et pancréatique. La seule augmentation du débit acide basal sous l'influence d'un repas fictif conduit à un allongement de la période des C.M.M. (Peeters, Vantrappen et Janssens, 1983b).

Chez l'Homme, le débit acide gastrique s'avère supérieur de $78 \%$, et le débit 
de pepsine supérieur de $61 \%$, au cours des 30 min qui précèdent le déclenchement d'une A.R. spontanée par rapport aux $30 \mathrm{~min}$ consécutives au déroulement de cette activité (Vantrappen, Peeters et Janssens, 1979a et b). Parallèlement, la concentration de bicarbonate dans les contenus duodénaux est supérieure de $136 \%$, et celle d'amylase plus élevée de $38 \%$, au cours des $30 \mathrm{~min}$ qui suivent le déroulement d'une A.R. par rapport aux 30 min qui précèdent son déclenchement, ce qui témoigne donc d'une importante variation de la sécrétion pancréatique (Vantrappen, Peeters et Janssens, 1979a et b). La sécrétion biliaire présente également des fluctuations. Le débit d'acides biliaires au cours des 30 min précédant I'apparition de I'A.R. est en effet égal à $374 \%$ par rapport au débit durant les 30 min consécutives (Peeters, Vantrappen et Janssens, 1980a). L'exacte chronologie des phénomènes diffère légèrement selon les auteurs, mais il semble que chez l'Homme le déclenchement d'une A.R. sur le duodénum soit associé à la transition entre une vague acide d'origine gastrique et une vague alcaline d'origine biliaire et pancréatique (Lux et al., 1980c). Cet ensemble de fluctuations est dénommé composante sécrétoire des C.M.M.

En ce qui concerne plus particulièrement la sécrétion pancréatique, son pouvoir de neutralisation des contenus acides déversés dans le duodénum est considérable. Toute variation de cette sécrétion peut donc affecter fortement le $\mathrm{pH}$ intraduodénal. Tel est le cas chez l'Homme atteint d'insuffisance pancréatique dont les contenus duodénaux s'avèrent significativement plus acides, tant à jeun que chez le sujet alimenté (Dutta, Russel et Iber, 1979a et b). L'association de débits maximaux de trypsine pancréatique et d'acides biliaires avec la fin d'A.I. et I'A.R. est confirmée chez l'Homme à jeun par Owyang, Achem-Karam et Vinik (1983). Mais ces auteurs montrent, en dépit de fortes variations inter- et intraindividuelles, que le polypeptide pancréatique présente une concentration faible durant la quiescence, augmente durant la phase d'A.I. pour atteindre un maximum au début de l'A.R. et chuter ensuite rapidement. Or, la perfusion intraduodénale de sécrétion pancréatico-biliaire, intervenant $30 \mathrm{~min}$ après une A.R., stimule fortement la libération de polypeptide pancréatique (concentration triplée par rapport à la valeur basale en $10 \mathrm{~min}$ ), lorsque sont reproduites les concentrations intraduodénales de trypsine et acides biliaires usuelles en fin d'A.I.-début d'A.R. (Owyang, Achem-Karam et Vinik, 1983). La fluctuation cyclique des sécrétions pancréatique et biliaire pourrait donc être responsable des pics périodiques de polypeptide pancréatique enregistrés dans le plasma en relation avec les C.M.M.

Diverses informations complètent ces résultats en soulignant le rôle de la bile. Chez l'Homme, en période interdigestive nocturne, il existe des variations cycliques concomitantes du taux plasmatique de polypeptide pancréatique et des acides biliaires primaires conjugués présents dans le sang (Baldi et al., 1984). Les pics simultanés sont enregistrés en fin d'A.I. Les forts débits pancréatico-biliaires enregistrés à ce moment du cycle des C.M.M. pourraient donc être à l'origine d'un phénomène de rétroaction par l'intermédiaire du polypeptide pancréatique. L'action de celui-ci se traduirait, dans les instants qui suivent, c'est-à-dire durant I'A.R., par la chute des débits sécrétoires pancréatiques. Par ailleurs, s'il existe une coordination chez le sujet alimenté entre évacuation gastrique et vidange vésiculaire (Lawson et al., 1983), il y a également des épisodes de vidange vésicu- 
laire périodiques chez l'Homme à jeun qui surviennent toujours durant l'A.I. duodénale et le plus souvent à la fin de cette période (Kraglund et al., 1983). II y a aussi une variation cyclique, liée aux C.M.M., de l'excrétion d'acides biliaires dans le duodénum, du fait de contractions phasiques du sphincter d'Oddi surimposées à son activité tonique (Scott et al., 1983b). Enfin, il apparaît chez l'Homme à jeun une relation temporelle entre les vidanges vésiculaires partielles et les fluctuations de la motilinémie, le début de la vidange vésiculaire précédant régulièrement le pic de motiline plasmatique (Svenberg et al., 1982).

En ce qui concerne les mécanismes qui sous-tendent cette coordination temporelle des phénomènes moteurs et sécrétoires, il faut noter que l'atropine par voie endoveineuse abolit à la fois le débit biliaire vésiculaire périodique et les fluctuations de la motilinémie (Svenberg et al., 1982). Ceci ne permet pas d'établir de relation causale dans un sens ou dans l'autre, mais dénote l'intervention d'une médiation cholinergique. Par ailleurs, le mécanisme par lequel la sécrétion pancréatico-biliaire induit une élévation du taux de polypeptide pancréatique, reste également obscur. Toutefois, il semble que la sécrétion de ce peptide soit soumise à une régulation cholinergique (Schwartz et al., 1978), et que les fluctuations cycliques de sa concentration plasmatique soient abolies lors de blocage de l'activité vagale (Greenberg et al., 1980). II est donc plausible que la sécrétion pancréatico-biliaire déversée dans le duodénum suscite un réflexe entéropancréatique cholinergique qui soit à l'origine de la libération de polypeptide pancréatique (Owyang, Achem-Karam et Vinik, 1983). Mais un mécanisme humoral sous dépendance cholinergique peut être également en cause puisque la sécrétion pancréatico-biliaire déversée dans le duodénum stimule aussi la libération de motiline chez I'Homme (Owyang, Funakoshi et Vinik, 1983), et que la perfusion de motiline peut induire un pic plasmatique de polypeptide pancréatique (Janssens $e t$ al., 1982).

Si I'on rapproche tous ces éléments, réunis chez l'Homme, de l'analyse faite au chapitre précédent de la signification des modifications humorales par rapport au rôle respectif des systèmes nerveux intrinsèque et extrinsèque, on peut proposer une ébauche du puzzle de facteurs responsables de la coordination des fonctions motrices et sécrétoires convergeant au carrefour gastro-duodénal : le déclenchement périodique des A.R. et la récurrence des C.M.M. sont liés à l'horloge interne des plexus ; l'ajustement de l'A.I. et la libération croissante concomitante de motiline impliquent l'intervention du système extrinsèque vagal ; cette libération de motiline sous contrôle cholinergique est assortie d'une libération de polypeptide pancréatique et de somatostatine. II y aurait donc plusieurs boucles de régulation par rétroaction impliquant par exemple motiline et polypeptide pancréatique d'une part et sécrétions biliaire et pancréatique d'autre part. Ces boucles de régulation seraient synchronisées par le fait que la motiline serait libérée périodiquement à la fois sous contrôle vagal et sous l'effet mécanique du déroulement de l'A.R. dont I'horloge primaire est intrinsèque.

\section{b) Composante sécrétoire des C.M.M. et pH endoluminal chez l'animal.}

L'existence d'une composante sécrétoire des C.M.M. est également établie chez le chien à jeun. On constate en effet une augmentation significative des 
débits de lipase et de bilirubine, des volumes sécrétés dans le duodénum, et des pressions dans le canal pancréatique au cours de l'A.R. duodénale, avec un rapide retour aux valeurs basales après l'achèvement de I'A.R. en ce site (Dimagno et al., 1979). Les débits de trypsine et de bicarbonates pancréatiques sont les plus faibles pendant la phase de quiescence, alors que le débit de trypsine atteint un maximum durant I'A.I. et celui de bicarbonate durant I'A.R. (Keane et al., 1980b). L'étude du pH intraduodénal chez le Chien conduit Itoh, Honda et Aizawa (1980) à décrire 3 périodes consécutives : I'une de faible acidité (entre 7 et 4) se prolonge durant environ $9 \mathrm{~h}$ consécutives au repas puis, graduellement, s'installe pour quelques $5 \mathrm{~h}$ une période de forte acidité (fluctuations de grande amplitude) entre 8 et 1$)$; enfin, s'installe pour la période interdigestive une alcalinité persistante (entre 7 et 8,3 ). Mais cette description ne laisse pas apparaître de fluctuations particulières du $\mathrm{pH}$ intraduodénal du chien à jeun (période interdigestive), malgré les variations cycliques des sécrétions pancréatiques et biliaires signalées ci-dessus. Néanmoins, la sécrétion pancréatique est surtout importante lors des épisodes cycliques d'activité gastrique associés à des déflections très acides du $\mathrm{pH}$ duodénal, et elle est suspendue lors des phases quiescentes de l'estomac (Itoh et al., 1981). De plus, en période interdigestive (situation de jeûne ; $\mathrm{pH}$ alcalin persistant dans le duodénum), la sécrétion basale est extrêmement faible mais une certaine augmentation existe lors de chaque bouffée d'activité gastrique, ce qui correspond à la période d'A.I. sur le duodénum. Aussi, la composante sécrétoire semble bien réelle chez le chien à jeun, mais elle s'exerce à un niveau très faible qui n'affecte guère le $\mathrm{pH}$ duodénal.

Parallèlement, on constate que la concentration plasmatique du polypeptide pancréatique présente une variation cyclique avec un pic lors de la transition entre A.I. et A.R. (Keane et al., 1980b). Les contractions de la vésicule biliaire s'avèrent étroitement associées avec le déroulement de l'A.l. sur le duodénum du chien (Itoh et Takahashi, 1981). On note également que la perfusion endoveineuse de motiline, qui induit des A.R. surnuméraires sur le duodénum, entraîne également, au début de la réponse, des contractions de la vésicule biliaire (Itoh et Takahashi, 1981). Cet effet de la motiline sur la contractilité vésiculaire est aboli par la vagotomie et après atropine, hexaméthonium ou tétrodotoxine ; à l'opposé, il est renforcé lors de stimulation vagale à une fréquence faible n'affectant pas la motricité ; enfin la contraction de la vésicule produite par une forte stimulation vagale est renforcée par la motiline (Nakayama et al., 1981). La motiline endogène pourrait ainsi contrôler, chez le chien à jeun, une vidange partielle périodique de la vésicule, dans la mesure où les pics périodiques de motilinémie coïncident avec les moments de plus forte concentration de bilirubine dans la vésicule ; le relâchement qui survient ensuite (motilinémie faible) autoriserait une aspiration de bile hépatique vers la vésicule et relancerait le processus de concentration progressive jusqu'à l'évacuation vésiculaire suivante (ltoh et al., 1982). Ce contrôle, possible chez le sujet à jeun, ne préjuge en rien de l'existence d'autres mécanismes mis en jeu dans une vidange vésiculaire plus ou moins complète à la suite du repas.

Au-delà des phénomènes sécrétoires qui présentent une grande analogie chez le Chien et l'Homme quant à leur relation avec les C.M.M., il existe aussi une périodicité des reflux duodéno-gastriques. En effet, le reflux le plus important 
de sécrétions pancréatico-biliaires vers l'estomac survient, chez l'Homme à jeun, à la fin de la phase d'A.I., alors qu'il est le plus faible après le déroulement de l'A.R. (Keane, Dimagno et Malagelada, 1981). Un phénomène analogue existe chez le chien à jeun, avec alcalinisation d'environ 5 unités pH durant 15 à $30 \mathrm{~min}$ au niveau de l'antre au repos alors qu'une A.R. débute sur le duodénum proximal (Bueno, Fioramonti et Ruckebusch, 1981). Cette alcalinisation périodique disparaît lorsque le pylore est obturé par deux ballons solidaires (l'un antral, l'autre duodénal), introduits par une canule gastrique ou duodénale, et dont le gonflage interdit le reflux de contenus duodénaux. Dans la mesure où la motricité gastroduodénale ne semble pas affectée par une réduction de la sécrétion acide gastrique (Bueno et Garcia-Villar, 1979), un rôle essentiel dans I'alcalinisation périodique du milieu antro-duodénal doit être reconnu aux sécrétions biliaire et pancréatique, ce qui contribue d'autant à l'alcalinité duodénale qui s'instaure au moment de I'A.R. duodénale.

Par rapport à ces informations concernant l'Homme et le Chien (C.M.M. à jeun seulement), il est intéressant de savoir ce qu'il en est dans une espèce dont les C.M.M. persistent chez le sujet alimenté. Chez le Porc, des variations cycliques du $\mathrm{pH}$ intraduodénal, de l'ordre de 3 unités $\mathrm{pH}$, peuvent être enregistrées parallèlement aux C.M.M. dès 2 à $3 \mathrm{~h}$ après le repas (Bueno et Fioramonti, 1982). L'amplitude des variations du pH est supérieure à 2,5 unités entre 8 et $14 \mathrm{~h}$ après le repas, chez le Porc comme chez le Chien ; mais elle n'excède pas 1 unité après $24 \mathrm{~h}$ de jeûne, comme chez l'Homme ou le chien à jeun. La superposition des périodes acides aux épisodes de débit de digesta durant l'A.I. duodénale, et l'alcalinisation du milieu duodénal dès l'A.R. et durant toute la quiescence, ont conduit Bueno et Fioramonti (1982) à rendre le débit de digesta gastriques acides, et son interruption lors de l'A.R. duodénale, seuls responsables des variations cycliques du $\mathrm{pH}$. Mais telle qu'elle a été réalisée par ces auteurs, la dérivation extracorporelle des contenus duodénaux en amont du site de mesure du $\mathrm{pH}$ conduit à enregistrer un pH neutre stable qui n'est autre que celui des sécrétions duodénales, dans la mesure où les sécrétions biliaire et pancréatique sont dérivées avec les émissions gastriques. Cette expérience ne permet donc nullement de conclure à l'absence, chez le Porc, d'une composante sécrétoire des C.M.M., ni de préjuger du rôle des sécrétions biliaire et pancréatique à l'égard du $\mathrm{pH}$ endoluminal.

L'enregistrement simultané du $\mathrm{pH}$ intraduodénal, du débit biliaire (cathétérisme chronique du canal cholédoque) et du débit pancréatique (cathétérisme chronique du canal pancréatique) d'une part, et l'étude des relations entre C.M.M. et ces deux sécrétions enregistrées (et restituées automatiquement à l'animal) dans les mêmes conditions d'autre part, permettent de confirmer leur rôle effectif chez le Porc dans la neutralisation du contenu duodénal, et la fluctuation périodique de leur débit. Ainsi, chez le Porc à jeun dont le $\mathrm{pH}$ duodénal est normalement supérieur à 6 durant plus de $70 \%$ du temps, la dérivation totale de la seule sécrétion biliaire réduit de près de $30 \%$ le temps pendant lequel le $\mathrm{pH}$ est supérieur à 6 , mais augmente de $15 \%$ le temps durant lequel est enregistré un $\mathrm{pH}$ inférieur à 4 (Abello, Corring et Laplace, 1984). Cette influence est très importante lors des périodes alcalines survenant périodiquement lors de I'A.R. et de la quiescence duodénales. Alors qu'un pH supérieur à 6 est enregistré durant $77 \%$ 
de la durée des A.R. et $85 \%$ de celle des phases de quiescence, la dérivation de la bile réduit ces valeurs à 45 et $67 \%$ respectivement. Ce rôle de la sécrétion biliaire dans l'alcalinisation périodique du contenu duodénal correspond à la fluctuation cyclique de son débit qui passe par un maximum à la fin de I'A.I., chute lors de l'A.R., et est minimale pendant la quiescence (Abello, Laplace et Corring, 1984).

En définitive, Homme, Chien et Porc présentent une composante sécrétoire des C.M.M. tout à fait semblable. Les fluctuations du $\mathrm{pH}$ duodénal résultant de celles des apports gastriques (acides) et pancréatico-biliaires (pouvoir de neutralisation) sont également analogues, quoique d'une amplitude plus grande par exemple chez le Porc à jeun. La relation temporelle constamment observée entre ces fluctuations de $\mathrm{pH}$ et les C.M.M., conduit donc à envisager le rôle potentiel du $\mathrm{pH}$ (et en particulier du $\mathrm{pH}$ acide durant l'A.I.) comme facteur de libération de peptides tels que la motiline, dont le pic survient précisément en fin d'A.I. La motiline est effectivement libérée par l'acidification duodénale chez l'Homme (Hellemans, Vantrappen et Bloom, 1976 ; Mitznegg et al., 1976 ; Boerger et al., 1978 ; Collins et al., 1981). II s'avère pourtant que, chez l'Homme, les C.M.M. peuvent survenir en l'absence d'acide dans le bulbe duodénal et même lors de neutralisation par du bicarbonate de sodium (Daniel et al., 1981). La motiline est aussi libérée par l'acidification chez le Porc (Modlin, Mitznegg et Bloom, 1978). Par contre, chez le Chien, I'alcalinisation (Brown, Mutt et Dryburgh, 1971 ; Fox, Track et Daniel, 1981) ou l'acidification (Brown et Dryburgh, 1978 ; Lee et al., 1978) pourraient induire une libération de motiline. Enfin, s'il est possible d'induire chez le Mouton des C.M.M. par acidification duodénale, les C.M.M. spontanés ne sont pas affectés par la perfusion de bicarbonate de sodium dans le duodénum (Gregory, 1982).

Ces observations conduisent à admettre que, même si l'acidification duodénale est susceptible d'induire une libération de motiline, il est peu vraisemblable que ce soit le facteur responsable des fluctuations périodiques de la motilinémie dans les conditions normales. Tout au plus pourrait-on concevoir que l'acidité, par le biais de chémorécepteurs acido-sensibles relayés au niveau intrapariétal, intervienne dans l'une des boucles de régulation évoquées plus haut. Le système nerveux serait donc essentiel pour le déroulement des C.M.M. (horloges intrinsèques) ; les peptides (motiline et polypeptide pancréatique) seraient, sous un contrôle principalement nerveux impliquant le système vagal, les instruments d'une coordination avec les sécrétions ; il en résulterait la variation cyclique du débit de celles-ci et les fluctuations corrélatives du pH duodénal. Mais tous ces éléments seraient à la fois acteurs et cibles au sein de boucles de régulation dont l'effet final est d'évidence l'admirable coordination de toutes ces fonctions pour un bon déroulement de la digestion.

\section{c) Peptides et système nerveux central.}

Un autre aspect très différent de l'intégration fonctionnelle neuro-humorale tient à l'observation de la présence dans les centres nerveux de nombreux peptides dits gastro-intestinaux, et à l'hypothèse selon laquelle les peptides libérés dans la circulation à partir de l'intestin pourraient également agir sur des structu- 
res nerveuses centrales. La réalité d'une modulation par des peptides de la représentation centrale des effets de la distension gastrique a été établie par l'étude des effets de l'application locale microiontophorétique de leu-enképhaline ou de I'octopeptide de cholécystokinine sur les activités unitaires des neurones du noyau dorsal du vague chez le rat anesthésié (Ewart et Wingate, 1983a et b). L'influence exercée par la voie vagale extrinsèque sur le tube digestif peut donc faire l'objet d'une modulation centrale.

Or la perfusion de somatostatine dans les ventricules cérébraux chez le Rat est capable d'augmenter la fréquence des C.M.M. de l'intestin, tandis que la cholécystokinine (octopeptide), dans les mêmes conditions, réduit la fréquence des C.M.M. voire suspend leur déroulement au profit d'une A.I. continue (Bueno et Ferré, 1982 ; Bueno et Fioramonti, 1983). Chez le rat alimenté, l'administration intra-cérébro-ventriculaire de neurotensine et celle de calcitonine restaurent l'organisation en C.M.M. caractéristique d'un état de jeûne, et ces effets sont abolis par la vagotomie, cependant que la substance $P$ ne fait qu'abréger la durée de l'activité postprandiale sans influence de la vagotomie (Bueno et al., 1983). Ceci étant, les résultats encore très fragmentaires de l'étude des effets centraux de divers peptides n'autorisent pas à conclure quant à la nature d'un contrôle central de la motricité intestinale. L'ubiquité d'un grand nombre de ces peptides fait que plusieurs hypothèses sont envisageables telles que : (i) action centrale ou modulation de l'activité de centres supérieurs par des peptides circulants libérés au niveau du tube digestif, sous la réserve d'un franchissement de la barrière hémato-méningée ; (ii) rĉle fonctionnel physiologique de peptides présents dans le tissu nerveux en tant que médiateurs de circuits centraux dont le fonctionnement serait modifié par les injections intracérébro-ventriculaires de peptides exogènes et éventuellement par les peptides circulants endogènes. II n'est pas possible à l'heure actuelle de porter un jugement sur l'importance potentielle de tels mécanismes.

\section{Signification fonctionnelle des C.M.M.}

L'intégration manifeste des C.M.M. dans un ensemble parfaitement coordonné de phénomènes physiologiques conduit à s'interroger sur la signification fonctionnelle de cette organisation de la motricıté de l'intestin grêle dont les contrôles nerveux et humoraux s'avèrent très complexes.

\section{a) Formulation des hypothèses.}

Dès la première description de la migration d'une bande d'A.R., celle-ci a été considérée comme jouant le rôle de balayeur interdigestif, chargé de propulser les matériaux résiduels dans la lumière, $d$ 'origine tant exogène qu'endogène (Szurszewski, 1969). Une telle conception paraît effectivement plausible dans une espèce telle que le Chien chez lequel les C.M.M. ne sont observés qu'en situation de jeûne. De fait l'étude du rôle respectif des 3 phases des C.M.M., réalisée chez le Chien par Code et Schlegel (1973), a montré qu'il n'y a pas de propulsion de digesta au cours de la phase de quiescence, alors que I'A.I. comporte des con- 
tractions plus ou moins localisées assurant le brassage des contenus, et des contractions progressivement plus puissantes et propulsives qui en assurent le transit. L'A.R. semble correspondre soit à des contractions rythmiques loca sées (Grivel et Ruckebusch, 1972), soit à une série de contractions péristaltiques (Code et Schlegel, 1973) assurant le nettoyage de l'intestin. Ainsi, on a d'abord reconnu à cette séquence de récurrence cyclique un double rôle de nettoyage de l'intestin grêle du sujet à jeun en anticipation du repas à venir, et d'entretien de la condition musculaire de l'organe par une séquence répétitive programmée d'exercice et de repos (Code et Schlegel, 1973).

Cependant une telle conception n'est guère compatible avec la présence permanente des C.M.M. chez l'animal régulièrement alimenté, comme c'est le cas chez les Ruminants par exemple. Aussi a-t-il été suggéré que, chez le Chien comme chez le Mouton, les C.M.M. contrôleraient un gradient de pression responsable de l'écoulement des digesta en direction aborale (Bueno, Fioramonti et Ruckebusch, 1975). Dans cette perspective, le transit des contenus serait principalement assuré par l'A.I., alors que l'A.R. consécutive, considérée comme non propulsive en elle-même, créerait une barrière de pression évitant le reflux intempestif des matériaux alimentaires vers le territoire plus proximal qui est, à ce moment-là, en état de quiescence. Ceci revient à accorder un rôle essentiel à I'A.I. pour assurer la propulsion des digesta, et à accepter le rôle possible de balayage de l'A.R. On peut indiquer d'emblée que cette interprétation des phénomènes a été confirmée par le travail de Dardillat (1977) qui a démontré l'existence d'un transit par péristaltisme durant I'A.I., suivi d'un brassage par segmentation durant I'A.R. L'intérêt de cette conception est de fournir une image de la signification fonctionnelle des C.M.M. indépendante de l'espèce animale. Du reste, I'A.I. postprandiale continue chez le Chien, comme I'A.I. continue induite par la 5-hydroxytryptamine chez le Mouton, conduisent à une augmentation du débit et à une diminution du temps de transit dans l'intestin grêle (Bueno, Fioramonti et Ruckebusch, 1975). La fonction essentielle des C.M.M. serait donc de contrôler la vitesse du transit des digesta dans le tractus digestif.

Par ailleurs, la fonction de nettoyage des C.M.M. est loin d'être négligeable à l'égard de la flore digestive. En effet, les C.M.M. sont absents chez l'Homme lors de prolifération bactérienne excessive (Vantrappen et al., 1977). Dans le même sens, la suppression des C.M.M. chez le rat par la morphine ou la phénylephrine conduit à une augmentation significative des concentrations de microorganismes en l'espace de $15 \mathrm{~h}$ (Scott et Cahall, 1982). Par conséquent, les C.M.M. sont aussi un important facteur de contrôle de la croissance des populations bactériennes dans l'intestin grêle.

Notons enfin que l'hypothèse d'un rôle des C.M.M. dans le contrôle du déclenchement des repas a été récemment écartée chez le Chien (Crenner et al., 1984).

\section{b) Transit digestif, rôle des C.M.M.}

A l'appui du rôle essentiel des C.M.M. à l'égard du transit digestif, on note que la vitesse de déplacement d'un embol de marqueur (phénolsulfonephtaléine), 
chez le Mouton ou le Chien, dépend de l'état de motricité (phase des C.M.M.) du segment dans lequel il est injecté (Bueno, Fioramonti et Ruckebusch, 1975). Pour les 2 espèces, la vitesse est environ 3 fois plus grande lors d'injection en fin d'A.l. juste avant l'arrivée de I'A.R., que lorsque la même manceuvre est effectuée après le passage de l'A.R., donc dans un segment au repos. Des observations analogues ont été réalisées pour le passage d'un embol de traceur radioactif $\left(\mathrm{Na}^{51} \mathrm{C}_{\mathrm{r}} \mathrm{O}_{4}\right)$ dans une anse de Biebl chez le Chien (Summers, Helm et Christensen, 1976) : le traceur progresse immédiatement en avant, i.e. en aval, de I'A.R. II en va de même chez le Rat (Ruckebusch et Fioramonti, 1975a). Ces observations tendent à montrer que le transit intervient bien durant I'A.I., et tout particulièrement à la fin de cette phase dans les instants qui précèdent l'arrivée de l'A.R., comme si cette dernière imposait l'exigence du déplacement des contenus encore présents par les contractions propulsives de I'A.I. Cette contrainte apparente fait que la durée nécessaire au transit, chez le veau fistulé, depuis un site d'injection duodénal jusqu'à un site de collecte iléal, correspond étroitement à la somme du temps total de migration proximodistale d'une A.R. et du temps écoulé entre le moment de l'injection et celui de l'arrivée sur le site d'une première A.R. (Dardillat et Marrero, 1977). Chez le porc alimenté, on note aussi la coïncidence globale entre le temps total de migration proximo-distale des C.M.M. et le temps écoulé avant l'arrivée à la jonction iléo-caco-colique des premiers matériaux évacués par l'estomac à la suite d'un repas d'épreuve, coïncidence vérifiée pour des régimes dont les caractéristiques physico-chimiques très différentes conduisent à des vitesses de migration différentes des C.M.M. (Laplace, 1978a, 1981).

Au-delà de ces correspondances temporelles globales, l'étude réalisée chez le Veau par l'enregistrement simultané chez l'animal éveillé des activités E.M.G. intestinales et du débit de digesta par débitmétrie électromagnétique in situ (Dardillat, 1977) permet une approche plus fine. II apparaît que les débits de chyme enregistrés au cours des périodes d'A.I. coïncident avec de fortes bouffées de potentiels propagées sur des distances supérieures à $10 \mathrm{~cm}$, telles qu'observées sur le duodénum consécutivement à de fortes contractions antrales avec émission de contenus gastriques. De semblables activités sont retrouvées au niveau jéjunoiléal, en particulier lors de la phase terminale d'une A.I. immédiatement en aval d'une A.R. II survient également au cours d'une A.I. des bouffées de potentiels, peu ou pas propagées, mais celles-ci sont observées lorsque la lumière intestinale sous-jacente est vide (Dardillat, 1977). Ces éléments, établis chez le Veau, concordent avec l'analyse de la migration des bouffées de potentiels au cours des diverses phases des C.M.M. sur l'intestin grêle du Chien (Summers et Dusdieker, 1981). Cette étude conforte la conception du rôle déterminant de la migration d'anneaux de contraction pour assurer le déplacement des digesta dans la lumière du segment affecté par une A.I. Le fait que I'A.R. ne correspond pas à une activité complètement stationnaire mais comporte des séries d'anneaux de contraction faisant également l'objet d'une migration (Summers et Dusdieker, 1981) vient à l'appui d'un rôle de nettoyage par "ramassage " des digesta étalés sur la muqueuse, tel qu'envisagé par Code et Schlegel (1973). Par la même, le rôle de barrière de pression de l'A.R. (Bueno, Fioramonti et Ruckebusch, 1975) se trouve minimisé.

Reproduction, Nutrition, Développement $n^{\circ} 5$ B 1984. -6 . 
Si l'on tente d'analyser de façon plus fine encore les relations entre motricité et mouvements des contenus digestifs, on peut s'interroger sur la fonction précise des divers types de contractions (autres que péristaltiques) qui surviennent au cours d'ıne phase d'A.I. (Laplace, 1981 ; Weisbrodt, 1981). Une telle approche bénéficie aujourd'hui de techniques d'analyse automatique élaborées (Summers, Cramer et Flatt, 1982). Néanmoins, des années d'études appropriées restent nécessaiı as avant de pouvoir formuler une théorie intégrant mouvements de la paroi, propulsion authentique et mouvements des fluides (Weems, 1982). En fait, toute variation quantitative et/ou qualitative des contractions intestinales peut entraîner des modifications du transit des digesta (Scott et Summers, 1976). L'étendue d'intestin affecté par la propagation d'une contraction est certainement un facteur important, mais cette étendue varie selon la nature des constituants du repas comme l'ont montré Schemann et Ehrlein (1983) chez le Chien. L'étude analytique des effets respectifs des mouvements pariétaux transverses et longitudinaux est difficile. Les mouvements longitudinaux, sous réserve qu'ils entraînent un raccourcissement du volume tubulaire, assureraient des échanges entre la veine centrale et la périphérie de la lumière digestive, donc un brassage (Melville, Macagno et Christensen, 1975). Les mouvements transverses (contraction annulaire localisée) ou combinés (contraction annulaire propagée) sont capables de produire à la fois un mouvement net de fluide au long du tube et un brassage ; de plus le couplage hydraulique au sein d'une veine liquide implique que toute contraction en un site a une répercussion sur les territoires environnants dont la section tend à augmenter (Weems, 1982). Il est donc nécessaire pour l'heure de se limiter aux relations entre A.I., A.R. et passage net de digesta, telles que les a mises en évidence Dardillat (1977).

Nous avons noté plus haut l'influence de la nature du régime qui entraîne des variations corrélatives de la vitesse de migration des C.M.M. et de la vitesse de transit. Cette dernière, selon la phase des C.M.M. considérée, varie également en fonction des caractéristiques physiques des digesta (Sarr et Kelly, 1980). Ces phénomènes répondent aux modifications précédemment décrites des caractéristiques des C.M.M. lors de changement important, quantitatif et qualitatif, des digesta déversés dans l'intestin grêle ; ils rendent compte de la capacité de ce viscère à traiter des quantités très variables de digesta selon les rythmes et modes d'alimentation (Bueno, Fioramonti et Ruckebusch, 1977). Il faut en outre souligner que les variations du temps de transit dans l'intestin grêle sont indépendantes des changements du rythme d'évacuation gastrique (Read et al., 1982). A l'inverse, ce sont les C.M.M. qui contrôlent l'évacuation gastrique dans la mesure où l'activité antrale cesse lorsque débute une A.R. sur le duodénum, comme en témoignent les débits de sortie de la caillette chez le Veau (Sissons, 1983).

En définitive, le rôle des C.M.M. à l'égard du transit digestif peut être résumé de la façon suivante: des coulées de contenus sont propulsées par les ondes péristaltiques qui constituent une part de l'activité E.M.G. des A.I. Au terme du déplacement de l'onde péristaltique, ces contenus s'étalent à la surface de la muqueuse, à la façon de la vague sur la grève, mais sans atteindre le segment qui, plus en aval, se trouve au repos. Lorsqu'arrive une A.R., ce qui subsiste de digesta à la surface de la muqueuse est rassemblé pour constituer un bol de con- 
tenus, propulsé juste au devant du front $d^{\prime} A . R$. De telles modalités rendent bien compte du rôle des C.M.M. dans le cas des espèces animales dont l'intestin est en permanence le siège des C.M.M. Elles sont également valables pour les espèces dont les C.M.M. sont suspendus par la prise de nourriture. Ainsi chez l'Homme à jeun, le transit est à tous les niveaux intermittent, et la fonction de ramassage de l'A.R. est particulièrement importante puisque environ la moitié du débit global est assurée de cette façon (Kerlin, Zinsmeister et Phillips, 1982). Par conséquent, à l'exception des épisodes d'A.I. postprandiale continue, le transit des digesta survient toujours sous forme de trains successifs distants les uns des autres, comme le confirme la cinéradiographie (Rayner et al., 1980). Globalement la vitesse de transit au long de l'intestin grêle dépend de la vitesse de migration des C.M.M. qui indique en somme la vitesse de croisière du déplacement des digesta (Lap/ace, 1981).

\section{c) Les C.M.M. et l'absorption intestinale.}

Les effets exercés sur l'absorption des nutriments par l'intermittence du passage des digesta du fait des C.M.M., n'ont pas été explorés de façon aussi détaillée. Néanmoins, les mesures de disparition au cours du franchissement d'un segment jéjunal $(75 \mathrm{~cm})$ isolé, perfusé par une solution salée et glucosée isotonique, montrent que, chez le chien à jeun, l'absorption est la plus importante au cours de la quiescence et la plus faible au cours de I'A.R. (Sarr, Kelly et Phillips, 1980). Par contre chez le sujet alimenté, l'absorption est plus intense qu'au cours des diverses phases des C.M.M. chez le chien à jeun. On notera pourtant que le temps de transit dans l'anse perfusée, mesuré à l'aide d'un marqueur (polyéthylèneglycol marqué, ${ }^{14} \mathrm{C}-\mathrm{PEG}$ ), est analogue durant I'A.I. des C.M.M. et I'A.I. continue postprandiale. Les observations réalisées chez le chien à jeun coïncident bien avec les résultats obtenus chez le Mouton au niveau d'un segment jéjunal de $2 \mathrm{~m}$ (Fioramonti et Ruckebusch, 1977). Lorsque ce segment, vide de digesta, est perfusé par une solution de glucose, l'absorption de celui-ci est maximale durant la quiescence et minimale durant I'A.R. Toutefois lorsque des digesta, dont la teneur en glucose vrai est négligeable, traversent le segment, l'absorption du glucose perfusé est d'environ $30 \%$ au cours de l'A.R. et de la quiescence, et de $10 \%$ seulement au cours de I'A.I.

Chez le porc alimenté, il existe des variations de la glycémie et de l'insulinémie, apparemment liées au déroulement des C.M.M. et au passage des vagues de digesta (Rayner et al., 1980). L'existence d'oscillations périodiques de la glycémie chez le Porc est bien connue (Rérat et al., 1977), et il a été confirmé que ces fluctuations surviennent à une fréquence analogue à celle de la récurrence des C.M.M. sur le duodénum (Fioramonti, Bueno et Ruckebusch, 1982). La relation entre le déroulement des C.M.M. au long de l'intestin grêle lélectromyographie et cinéradiographie) et l'absorption quantitative du glucose mesurée selon un principe développé par Rérat, Vaugelade et Villiers (1980), a été examinée chez le Porc par Rayner et al. (1980). L'absorption est très intense dès les 30 premières minutes postprandiales; lors du premier C.M.M. postprandial, il apparaît que l'absorption nette du glucose passe par un maximum durant le déroulement de 
I'A.l. sur le jéjunum et par un minimum lors du passage de l'A.R. sur ce même territoire. Cependant, dans ce travail, l'absorption est évaluée à partir de différences de concentrations porto-artérielles, c'est-à-dire qu'il s'agit d'un bilan net pour l'ensemble du tractus digestif drainé par la veine porte. Ce caractère très global interdit toute conclusion quant aux relations entre C.M.M. et absorption en un site précis de la paroi intestinale. Ceci étant, il semblerait que l'intestin in situ dans son ensemble assure une absorption globalement la plus importante lors du passage de la vague de digesta transportée par l'A.I. Ce résultat est très différent des conclusions obtenues soit sous perfusion glucosée d'un segment jéjunal vide chez le Chien, soit chez le Mouton lors de perfusion en présence d'un passage de digesta. Bien des questions se posent donc encore pour clarifier la relation motricité-absorption, mais la modélisation des effets des contractions intestinales sur l'absorption s'avère encore plus complexe que celle de l'exacte relation motricité-transit (Macagno, Christensen et Lee, 1982).

\section{d) C.M.M. et physio-pathologie digestive.}

Les C.M.M. sont de toute évidence une organisation complexe, et comme telle relativement fragile en dépit des facultés d'adaptation précédemment mentionnées. Nous ne ferons que suggérer, dans ce paragraphe, l'importance et la complexité des désordres susceptibles de survenir, dans de nombreuses situations concernant directement ou non le tube digestif. En effet, cet aspect de la physiopathologie digestive mériterait à lui seul de longs développements.

Les frontières entre l'organisation "normale", l'anomalie transitoire et le désordre installé peuvent être franchies très rapidement. Ainsi des augmentations importantes du volume des contenus peuvent, selon leur brutalité, conduire à la suspension des C.M.M., à un renforcement ou à une désorganisation complète de cette structuration spatiotemporelle de la motricité. La suspension des C.M.M. peut être considérée comme normale, chez le chien alimenté, au cours de I'A.I. postprandiale continue, alors que le débit d'entrée des digesta dans le duodénum est multiplié par 3. Par contre, cette même suspension des C.M.M., qui peut être induite chez le Mouton par des débits supérieurs à $500 \mathrm{ml} . \mathrm{h}^{-1}$, constitue déjà, pour l'espèce animale considérée, une anomalie. Les situations de renforcement correspondent, lors d'accroissement de la prise d'aliment et de la quantité des digesta, au fait que tous les C.M.M. migrent jusqu'à l'iléon et que des A.R. surnuméraires peuvent s'y ajouter au niveau du jéjunum. Mais au-delà d'une certaine limite, l'accroissement excessif des contenus endoluminaux conduit à une véritable désorganisation des C.M.M. auxquels se substituent sur l'ensemble du viscère des fortes bouffées de potentiels échappant à toute systématisation. Ces diverses modifications de la motricité de l'intestin grêle peuvent être observées ou induites aussi bien chez le Mouton et le Chien (Bueno et Ruckebusch, 1977) que chez le Porc (Laplace, 1980).

Par ailleurs, tous les phénomènes d'ordre physio-pathologique ou relevant d'une pathologie infectieuse (Burns et al., 1980 ; Weisberg, Carlson et Cohen, 1978) voire parasitaire (Ruckebusch, 1981) peuvent conduire à la disparition de l'organisation en C.M.M. Une situation banale est celle de la diarrhée nutrition- 
nelle (Dardillat et Marrero, 1977 ; Ruckebusch, 1981), ou des désordres liés à l'ingestion de tourteau de soja cuit (Sissons et Smith, 1979). La seule distension de l'intestin grêle par un volume important de liquides constitue souvent un facteur essentiel de désorganisation. Les effets de sécrétagogues, tels que sels biliaires (chénodeoxycholate) et acide ricinoléique, sont ainsi assimilables à ceux d'une distension modérée, et il s'agit là d'un effet local qui tend à substituer une activité de pointes irrégulière à l'organisation en C.M.M. (Da Cunha Melo et al., 1981). Mais pour une distension plus importante, c'est à l'inverse une inhibition complète de l'activité E.M.G. qui est constatée du fait de la mise en jeu, au-delà d'un certain seuil, du réflexe inhibiteur intestino-intestinal. Ainsi, divers degrés de désordre peuvent être observés. Une désorganisation plus ou moins prononcée des C.M.M. est constatée chez le Porc lors d'ingestion de lactose en quantité importante, qui crée un appel d'eau vers la lumière par effet osmotique (Laplace, 1978b). De même sur une anse iléale ligaturée chez le lapin, il n'y a stimulation de l'activité E.M.G. que lorsque survient une accumulation de liquides, induite par exemple par la toxine cholérique, avec apparition d'activités propagées particulières qui sont une réponse non spécifique à la distension (Sjögren, Wardlow et Charles, 1984).

L'existence d'activités E.M.G. particulières associées aux états diarrhéiques, sous forme de longues bouffées propagées et de bouffées répétitives plus brèves, est bien établie, notamment lors d'action de toxines de Vibrio cholera et d'Escherichia coli (Mathias et al., 1976 ; Burns et al., 1980). L'administration endoveineuse ou intrapéritonéale du surnageant d'une culture d' $E$. coli traitée par la chaleur entraîne une désorganisation complète des C.M.M. chez le Rat (Gustavsson et al., 1984). II est particulièrement intéressant de noter que l'injection endoveineuse des lipopolysaccharides purifiés d'E. coli induit les activités E.M.G. typiques de l'état diarrhéique, mais que cet effet est partiellement bloqué par injection intracérébroventriculaire de naloxone (Fioramonti, Bueno et $\mathrm{Du}, 1984$ ). Ceci suggère donc que l'action de l'endotoxine d'E. coli sur la motricité intestinale implique des récepteurs centraux aux opiacés. Mais on note aussi que la perfusion de VIP (peptide intestinal vasoactif), endoveineuse ou endoluminale, entraîne les mêmes désordres de la motricité, associés à une sécrétion nette d'eau et d'électrolytes vers la lumière (Sninsky et al., 1983). II n'est pas possible de relier très précisément ces faits et les désordres observés. Mais ces derniers constituent un phénomène banal, présent lors de toute prolifération bactérienne excessive. En fait, si l'arrêt des C.M.M. permet une telle prolifération, il s'avère aussi que celleci, telle qu'observée dans un syndrome d'anse aveugle, peut entraîner la désorganisation de la motricité et contribuer par là même à la diarrhée (Justus et al., 1983).

Les désordres du système neuro-musculaire peuvent être également responsables d'anomalies fonctionnelles. Ainsi, lors de dystrophie myotonique, myopathie qui peut affecter l'appareil digestif, une raréfaction des A.R., dont la durée et la vitesse de propagation sont réduites, est observée (Couturier et al., 1984). Dans la maladie de Chagas, caractérisée par des lésions importantes des plexus myentériques, la vitesse de migration des C.M.M. est considérablement réduite (Oliveira et al., 1983). On connaît aussi des anomalies de l'activité postprandiale chez 
l'enfant, lors d'un syndrome d'irritabilité connu sous le nom de diarrhée de Toddler : les C.M.M. restent normaux chez les sujets à jeun, mais la perfusion de lait ou de sucres dans le duodénum ne peut induire l'A.I. continue postprandiale (Fenton, Harries et Milla, 1983). Mais dans ce cas on ne sait s'il s'agit d'un désordre au niveau périphérique ou d'une anomalie de maturation de la motricité.

D'autres observations concernent les peptides. Chez des sujets atteints de sclérose systémique (Rees et al., 1982), l'organisation normale en C.M.M. reste présente, en situation de jeûne, lorsqu'il n'y a pas d'atteinte digestive cliniquement décelable. Par contre, chez les patients pour lesquels l'affection comporte une atteinte digestive, les C.M.M. sont absents dans la moitié des cas $(3$ malades sur 6 ). Chez tous les sujets pourtant, les variations cycliques des concentrations plasmatiques de motiline et de polypeptide pancréatique sont présentes ; toutefois chez les patients atteints de sclérose systémique, avec ou sans atteinte digestive, la motilinémie est nettement plus élevée que chez les sujets sains quelle que soit la phase des C.M.M. considérée (Rees et al., 1982). L'hypermotilinémie est également observée chez les sujets diabétiques, mais il n'y a aucun lien entre les modifications de la motilinémie et le temps de transit dans l'intestin grêle (Nakanome et al., 1983). Enfin, lors d'insuffisance pancréatique exocrine, la motilinémie basale est plus élevée que chez les sujets sains. Mais à la différence de ces derniers, la perfusion de cholécystokinine ne provoque aucune élévation de la motilinémie, alors que la perfusion intra-duodénale de sécrétion pancréatico-biliaire induit chez les 2 catégories de sujets une forte élévation de la motilinémie (Owyang, Funakoshi et Vinik, 1983).

Les conséquences fonctionnelles de l'anesthésie et des procédures chirurgicales ont également été envisagées (Dauchel et al., 1976 ; Bueno, Fioramonti et Ruckebusch, 1978 ; Bueno, Ferré et Ruckebusch, 1978). La récupération s'effectue de façon variable selon les espèces, mais on notera surtout que l'inhibition (ileus postopératoire) peut être évitée par la splanchnicectomie (Bueno, Fioramonti et Ruckebusch, 1978). L'ulcération gastrique est aussi capable de faire disparaître les C.M.M., chez le Rat et le Chien (Fioramonti et Bueno, 1980). Cet inventaire sommaire n'est pas limitatif, mais les C.M.M. peuvent être considérés comme un indicateur très sensible de la qualité de l'état clinique, tant chez l'animal que chez l'Homme, et il n'est pas exclu que les informations fournies par la pathologie apportent des éléments de compréhension du fonctionnement moteur de l'intestin grêle.

\section{Conclusions}

L'inventaire qui vient d'être dressé des connaissances accumulées au cours des 15 dernières années concernant les fonctions motrices de l'intestin grêle, témoigne de progrès considérables dus à la fois à la généralisation de techniques nouvelles utilisables chez le sujet éveillé, et à l'apport irremplaçable de la physiologie comparée. II est évident que l'intestin grêle n'est pas un viscère inerte chez l'individu à jeun. Il existe en fait, même dans cette situation, et chez un bon nombre d'espèces animales, une activité organisée sous la forme de séquences de 
récurrence cyclique, soumises à une migration proximo-distale. En dépit d'une apparente diversité, cette organisation constitue un système univoque, c'est-àdire commun à toutes ces espèces. Elle est cependant susceptible d'ajustements aux variations quantitatives et qualitatives des matériaux arrivant dans la lumière, selon les habitudes alimentaires de chaque espèce animale. Comme pour toute faculté d'adaptation d'une fonction organique, la frontière entre la modification adaptative dans les limites du fonctionnement normal, et la dysfonction, est très ténue. Mais d'évidence encore, ce système revêt une importance fonctionnelle capitale dans la mesure où il assure un contrôle temporel du passage des digesta dans l'intestin, et par là même, la régularité de l'approvisionnement de l'organisme en nutriments. II est également remarquable que cette organisation soit couplée avec l'activité motrice gastrique d'une part, et les sécrétions gastrique, pancréatique et biliaire d'autre part. Cependant, en dépit de l'importance des travaux réalisés à ce jour, les mécanismes responsables de l'existence de cette organisation, de sa faculté d'adaptation et de sa coordination avec d'autres fonctions du tube digestif, ne sont pas complètement élucidés. II semble bien acquis que, pour l'essentiel, cette structuration spatio-temporelle repose sur l'organisation sous-jacente des plexus nerveux intrinsèques, responsables de l'initiation et de la migration des séquences. Mais de multiples influences humorales et nerveuses extrinsèques semblent intervenir pour " moduler » cette organisation fondamentale. Sans aucun doute, il reste encore un travail important à réaliser pour parvenir à une compréhension complète des interrelations neuro-humorales qui concourent au bon fonctionnement de l'intestin grêle.

Journées Ingestion, Digestion, Absorption de l'Association française de Nutrition, Strasbourg, 20-21 octobre 1983.

\section{Références}

ABELLO J., CORRING T., LAPLACE J. P., 1984. Evolution du pH duodénal chez le Porc à jeun et alimenté ; rôle de la sécrétion biliaire. Reprod. Nutr. Dévelop., 24, 702.

ABELLO J., LAPLACE J. P., CORRING T., 1984. Composante sécrétoire des complexes myoélectriques chez le Porc ; observations préliminaires sur le débit de bile. Reprod. Nutr. Dévelop., 24, 770 .

AEBERHARD P. F., MAGNENAT L. D., ZIMMERMANN W. A., 1980. Nervous control of migratory myoelectric complex of the small bowel. Am. J. Physiol., 238, G102-G108.

AL-SAFFAR A., ROSELL S., 1981. Effects of neurotensin and neurotensin analogues on the migrating myoelectrical complexes in the small intestine of rats. Acta physiol. scand., 112, 203-208.

AL-SAFFAR A., TATEMOTO K., 1984. Effects of peptide $Y Y(P Y Y)$ and porcine pancreatic polypeptide (PP) on migrating myoelectric complexes (MMC) in the small intestine of the rat, 215222. In ROMAN C., Gastrointestinal motility. MTP Press Ltd., Lancaster.

ALTAPARMAKOV I., WIENBECK M., 1983. Alpha-adrenergic control of the interdigestive migrating electrical complex (IDMEC), 3-7. In LABO G., BORTOLOTTI M., Gastrointestinal motility. Cortina International Ed., Verona.

BALDI F., FERRARINI F., SALERA M., GIACOMONI P., TOVOLI S., BARBARA L., $1984 . \quad$ Nocturnal motor activity of the upper gastrointestinal tract, and plasma levels of entero-pancreatic hormones and primary bile acids in man, 257-264. In ROMAN C., Gastrointestinal motility. MTP Press Ltd., Lancaster. 
BAYLISS W. M., STARLING E. H., 1899. The movement and innervation of the small intestine. J. Physiol. (London), 24, 99-143.

BECKER J. M., DUFF W. M., MOODY F. G., 1981. Myoelectric control of gastrointestinal and biliary motility: A review. Surgery, 89, 466-477.

BIANCHI G., FERRETTI P., RECCHIA M., ROCCHETTI M., TAVANI A., MANARA L., 1983. Morphine tissue levels and reduction of gastrointestinal transit in rats. Correlation supports primary action site in the gut. Gastroenterology, 85, 852-858.

BLOOM S. R., CHRISTOFIDES N. D., BESTERMAN H. S., ADRIAN T. E., GHATEI M. A., 1978. Release of motilin in man by oral and intravenous nutriments. Scand. J. Gastroenterol., 13 (suppl. 49), 26 (abstr.).

BLOOM S. R., CHRISTOFIDES N. D., GOODALL E. D., RAYNER V., 1982. Motilin and the migrating myoelectric complex in pigs. J. Physiol. (London), 322, 54P.

BOERGER H. W., SCHAFMAYER A., WERNER M., BECKER H. D., 1978. Motilin mucosal content and release after intraduodenal acid, fat and peptone in man. Scand. J. Gastroenterol., 13 (suppl. 49), 29 (abstr.).

BORMANS V., PEARCE D., PEETERS T. L., VANTRAPPEN G. R., 1983. Smooth muscle motilin receptors in rabbit stomach and duodenum, 33-36. In LABO G., BORTOLOTTI M., Gastrointestinal motility, Cortina International Ed., Verona.

BORODY T. J., BYRNES D. J., SLOWIACZEK J. G., TITCHEN D. A., 1981. Motilin and migrating myoelectric complexes in pigs. J. Physiol. (London), 310, 37P-38P.

BORTOFF A., 1976. Myogenic control of intestinal motility. Physiol. Rev., 56, 418-434.

BORTOLOTTI M., BERSANI G., LONGANESI A., CALLETTI T., FOSCHI S., LABO G., 1983. Modification of the interdigestive migrating motor complex (IMMC) in patients with partial gastrectomy and gastrojejunostomy. Gastroenterol. clin. biol., 7, 722 (abstr.).

BROWN J. C., DRYBURGH J. R., 1978. Isolation of motilin, 327-331. In BLOOM S. R., Gut hormones. Churchill Livingstone, Edinburgh.

BROWN J. C., MUTT V., DRYBURGH J. R., 1971. The further purification of motilin, a gastric motor activity stimulating polypeptide from the mucosa of the small intestine of hogs. Can. J. Physiol. Pharmacol., 49, 399-405.

BUENO L., FERRÉ J. P., 1982. Central regulation of intestinal motility by somatostatin and cholecystokinin octapeptide. Science, 216, 1427-1429.

BUENO L., FERRE J. P., FIORAMONTI J., HONDE C., 1983. Effects of intracerebroventricular administration of neurotensin, substance $P$, and calcitonin on gastrointestinal motility in normal and vagotomized rats. Regul. Peptides, 6, 197-205.

BUENO L., FERRÉ J. P., RUCKEBUSCH Y., 1978. Effects of anesthesia and surgical procedures on intestinal myoelectric activity in rats. Am. J. Dig. Dis., 23, 690-695.

BUENO L., FIORAMONTI J., 1982. Origin of the cyclical variations of the duodenal pH in pig, 169173. In WIENBECK M., Motility of the digestive tract. Raven Press, New York.

BUENO L., FIORAMONTI J., 1983. Central regulation of intestinal motility by somatostatin and cholecystokinin octapeptide, 181-183. In LABO G., BORTOLOTTI M., Gastrointestinal motility, Cortina International, Ed., Verona.

BUENO L., FIORAMONTI J., RAYNER V., RUCKEBUSCH Y., 1982. Effects of motilin, somatostatin, and pancreatic polypeptide on the migrating myoelectric complex in pig and dog. Gastroenterology, 82, 1395-1402.

BUENO L., FIORAMONTI J., RUCKEBUSCH Y., 1975. Rate of flow of digesta and electrical activity of the small intestine in dogs and sheep. J. Physiol. (London), 249, 69-85.

BUENO L., FIORAMONTI J., RUCKEBUSCH Y., 1977. Mechanisms of propulsion in the small intestine. Ann. Rech. vét., 8, 293-301.

BUENO L., FIORAMONTI J., RUCKEBUSCH Y., 1978. Post-operative intestinal motility in dogs and sheep. Am. J. Dig. Dis., 23, 682-689.

BUENO L., FIORAMONTI J., RUCKEBUSCH Y., 1981. Gastric $\mathrm{pH}$ changes associated with duodenal motility in fasted dogs. J. Physiol. (London), 316, 319-325.

BUENO L., GARCIA-VILLAR R., 1979. Secretory and motor activities at the gastroduodenal junction in dogs. Vet. sci. Comm., 3, 249-256.

BUENO L., PRADDAUDE F., FIORAMONTI J., RUCKEBUSCH Y., 1981. Effect of dietary fiber on gastrointestinal motility and jejunal transit time in dogs. Gastroenterologv, 80, 701-707. 
BUENO L., PRADDAUDE F., RUCKEBUSCH Y., 1979. Propagation of electrical spiking activity along the small intestine : intrinsic versus extrinsic neural influences. J. Physiol. (London), 292, $15-26$.

BUENO L., RAYNER V., RUCKEBUSCH Y., 1981. Initiation of the migrating myoelectric complex in dogs. J. Physiol. (London), 316, 309-318.

BUENO L., RUCKEBUSCH M., 1976. Insulin and jejunal electrical activity in dogs and sheep. Am. J. Physiol., 230, 1538-1544.

BUENO L., RUCKEBUSCH Y., 1975. Effets de l'insuline sur l'activité électrique du jéjunum chez le Mouton. C.R. Soc. Biol., 169, 430-434.

BUENO L., RUCKEBUSCH Y., 1977. Migrating myoelectrical complexes : disruption, enhancement and disorganization, 83-90. In DUTHIE H. L., Gastrointestinal motility in health and disease. MTP Press Ltd, Lancaster.

BUENO L., RUCKEBUSCH Y., 1979. Perinatal development of intestinal myoelectrical activity in dogs and sheep. Am. J. Physiol., 237, E61-E67.

BUENO L., WEEKES T. E. C., RUCKEBUSCH Y., 1977. Effects of diet on the motility of the small intestine and plasma insulin levels in sheep. Ann. Rech. vét., 8, 95-104.

BURKS T. F., HIRNING L. D., GALLIGAN J. J., DAVIS T. P., 1982. Motility effects of opioid peptides in dog intestine. Life Sci., 31, 2231-2240.

BURNS T. W., MATHIAS J. R., MARTIN J. L., CARLSON G. M., SHIELDS R. P., $1980 . \quad$ Alteration of myoelectric activity of small intestine by invasive Escherichia Coli. Am. J. Physiol., 238, G57-G62.

CARLSON G. M., BEDI B. S., CODE C. F., 1972. Mechanism of propagation of intestinal interdigestive myoelectric complex. Am. J. Physiol., 222, 1027-1030.

CHRISTOFIDES N. D., BLOOM S. R., BESTERMAN H. S., ADRIAN T. E., GHATEI M. A., 1979. Release of motilin by oral and intravenous nutrients in man. Gut, 20, 102-106.

CHRISTOFIDES N. D., BLOOM S. R., VANTRAPPEN G., JANSSENS J., PEETERS T. L., HELLEMANS J., 1981. Postprandial release of motilin in relation to the interdigestive motor complex in man. Biomed. Res. (Tokyo), 2, 67-68.

CODE C. F., MARLETT J. A., 1975. The interdigestive myoelectric complex of the stomach and small bowel of dogs. J. Physiol. (London), 246, 289-309.

CODE C. F., SCHLEGEL J. F., 1973. The gastrointestinal interdigestive housekeeper : motor correlates of the interdigestive myoelectric complex of the dog, 631-633. In Proc. 4th int. Symp. Gastrointest. Motility. Mitchell Press, Vancouver.

COLLINS S. M., LEWIS T. D., FOX J. E. T., TRACK N. S., MEGHJI M. M., DANIEL E. E., 1981. Changes in plasma motilin concentration in response to manipulation of intragastric and intraduodenal contents in man. Can. J. Physiol. Pharmacol., 59, 188-194.

COUTURIER D., GRANDJOUAN S., ELOUAER-BLANC L., VERDURON A., TRAVERS B., TURPIN J. C., BOUCHE P., GUERRE J., 1984. Jejunal motility in dystrophia myotonica, a manometric study of migrating motor complex, 287-295. In ROMAN C., Gastrointestinal motility. MTP Press Ltd., Lancaster.

CRENNER F., FELDER G., LAMBERT A., GRENIER J. F., 1984. Feeding behaviour and the migrating myoelectric complex, 271-275. In ROMAN C., Gastrointestinal motility. MTP Press Ltd., Lancaster.

CRENNER F., FELDER G., SCHANG J. C., GRENIER J. F., 1983. Continuous enteral nutrition in dogs : Influence of the caloric load on the intestinal migrating myoelectric complex, 19-21. In LABO G., BORTOLOTTI M., Gastrointestinal motility. Cortina International Ed., Verona.

CUBER J. C., LAPLACE J. P., CHAYVIALLE J. A., 1984. Motilin and myoelectric complexes in the pig, 231-237. In ROMAN C., Gastrointestinal motility. MTP Press Ltd., Lancaster.

DA CUNHA MELO J., SUMMERS R. W., THOMPSON H. H., WINGATE D. L., YANDA R., 1981. Effects of intestinal secretagogues and distension on small bowel myoelectric activity in fasted and fed conscious dogs. J. Physiol. (London), 321, 483-494.

DANIEL E. E., FOX J. E. T., COLLINS S. M., LEWIS T. D., MEGHJI M., TRACK N. S., 1981. tiation of migrating myoelectric complexes in human subjects : Role of duodenal acidification and plasma motilin. Can. J. Physiol. Pharmacol., 59, 173-179.

DARDILLAT C., 1977. Analyse électromyographique et débitmétrique du transit alimentaire chez le veau nouveau-né. J. Physiol. (Paris), 73, 925-944.

DARDILLAT C., MARRERO E., 1977. Etude de I'électromyogramme global chronique de la paroi 
intestinale du veau pré-ruminant : migration des phases d'activité régulière et relation avec le transit. Ann. Biol. anim. Bioch. Biophys., 17, 523-530.

DAUCHEL J., SCHANG J. C., KACHELHOFFER J., ELOY R., GRENIER J. F., 1976. Gastrointestinal myoelectrical activity during the postoperative period in man. Digestion, 14, 293303.

DEFILIPPI C., VALENZUELA J. E., 1981. Sham feeding disrupts the interdigestive motility complex in man. Scand. J. Gastroenterol., 16, 977-979.

DE WEVER I., EECKHOUT C., VANTRAPPEN G., HELLEMANS J., 1978. Disruptive effect of test meals on interdigestive motor complex in dogs. Am. J. Physiol., 235, E661-E665.

DE WEVER I., EECKHOUT C., VANTRAPPEN G., HELLEMANS J., 1980. How does oil disrupt the interdigestive myoelectric complex ? 295-297. In CHRISTENSEN J., Gastrointestinal motility. Raven Press, New York.

DIAMANT N. E., HALL K., MUI H., EL SHARKAWY T. Y., 1980. Vagal control of the feeding motor pattern in the lower oesophageal sphincter, stomach and small intestine of dog, 365370. In CHRISTENSEN J., Gastrointestinal motility. Raven Press, New York.

DIMAGNO E. P., HENDRICKS J. C., DOZOIS R. R., GO V. L. W., 1981. Effect of secretin on pancreatic duct pressure, resistance to pancreatic flow and duodenal motor activity in the dog. Dig. Dis. Sci, 26, 1-6.

DIMAGNO E. P., HENDRICKS J. C., GO V. L. W., DOZOIS R. R., 1979. Relationships among canine fasting pancreatic and biliary secretions, pancreatic duct pressure, and duodenal phase III motor activity. Boldyreff revisited. Dig. Dis. Sci., 24, 689-693.

DOCKRAY G. J., GREGORY R. A., 1980. Relations between neuropeptides and gut hormones. Proc, roy. Soc. Lond., B210, 151-164.

DUKE G. E., KOSTUCH T. E., EVANSON O. A., 1975a. Gastroduodenal electrical activity in turkeys. Am. J. Dig. Dis., 20, 1047-1057.

DUKE G. E., KOSTUCH T. E., EVANSON O. A., 1975b. Electrical activity and intraluminal pressures in the lower small intestine of turkeys. Am. J. Dig. Dis., 20, 1040-1046.

DUTTA S. K., RUSSELL R. M., IBER F. L., 1979a. Influence of exocrine pancreatic insufficiency on the intraluminal pH of the proximal small intestine. Dig. Dis. Sci., 24, 529-534.

DUTTA S. K., RUSSELL R. M., IBER F. L., 1979b. Impaired acid neutralization in the duodenum in pancreatic insufficiency. Dig. Dis. Sci., 24, 775-780.

EECKHOUT C., DE WEVER I., PEETERS T., HELLEMANS J., VANTRAPPEN G., 1978. Role of gastrin and insulin in post-prandial disruption of migrating complex in dogs. Am. J. Physiol., 235, E666-E669.

EECKHOUT C., DE WEVER I., VANTRAPPEN G., JANSSENS J., 1980. Local disorganization of interdigestive migrating complex by perfusion of a Thiry-Vella loop. Am. J. Physiol., 238, G509-G513.

El-SHARKAWY T. Y., MARKUS H., DIAMANT N. E., 1982. Neural control of the intestinal migrating myoelectric complex. A pharmacological analysis. Can. J. Physiol. Pharmacol., 60. 794-804.

EVANS D. F., FOSTER G. E., HARDCASTLE J. D., 1984. Does exercise affect the migrating motor complex in man ?, 277-284. In ROMAN C., Gastrointestinal motility. MTP Press Ltd., Lancaster.

EWART W. R., WINGATE D. L., 1983a. Central representation and opioid modulation of gastric mechanoreceptor activity in the rat. Am. J. Physiol., 7, G27-G32.

EWART W. R., WINGATE D. L., 1983b. The brain-gut axis : a role for cholecystokinin-octapeptide, 177-180. In LABO G., BORTOLOTTI M., Gastrointestinal motility. Cortina International, Ed., Verona.

FAHRENKRUG J., 1979. Vasoactive intestinal polypeptide : Measurement, distribution, and putative neurotransmitter function. Digestion, 19, 149-169.

FENTON T. R., HARRIES J. T., MILLA P. J., 1983. Abnormalities of postprandial small intestinal motor activity in childhood : their role in the pathogenesis of the irritable bowel syndrome, 207-213. In LABO G., BORTOLOTTI M., Gastrointestinal motility. Cortina International Ed., Verona.

FINCH P. M., INGRAM D. M., HENSTRIDGE J. D., CATCHPOLE B. N., 1982. Relationship of fasting gastroduodenal motility to the sleep cycle. Gastroenterology, 83, 605-612. 
FIOCCHI R., BIANCHI G., PETRILLO P., TAVANI A., MANARA L., 1982. Morphine inhibits gastrointestinal transit in the rat primarily by impairing propulsive activity of the small intestine. Life Sci., 31, 2221-2223.

FIORAMONTI J., BUENO L., 1980. Gastrointestinal myoelectric activity disturbances in gastric ulcer disease in rats and dogs. Dig. Dis. Sci., 25, 575-580.

FIORAMONTI J., BUENO L., DU C., 1984. Alterations of digestive motility by Escherichia coli endotoxin in rabbits mediated through central opiate receptors, 549-556. In ROMAN C., Gastrointestinal motility. MTP Press Ltd., Lancaster.

FIORAMONTI J., BUENO L., RUCKEBUSCH, 1982. Blood sugar oscillations and duodenal migrating myoelectric complexes. Am. J. Physiol., 242, G15-G20.

FIORAMONTI J., RUCKEBUSCH M., 1977. Motricité et absorption du glucose au niveau de I'intestin grêle chez le Mouton. C.R. Soc. Biol., 171, 964-969.

FLECKENSTEIN P., 1978. Migrating electrical spike activity in the fasting human small intestine. Am. J. Dig. Dis., 23, 769-775.

FLECKENSTEIN P., OIGAARD A., 1977. The interdigestive myoelectrical complex and other migrating electrical phenomena in the human small intestine, 19-27. In : DUTHIE H. L., Gastrointestinal motility in health and disease. NITP Press Ltd, Lancaster.

FOX D. A., EPSTEIN M. L., BASS P., 1984. Electrical activity of an intrinsically denervated jejunum of the unanesthetized rat, 319-325. In ROMANC., Gastrointestinal motility, MTP Press Ltd., Lancaster.

FOX J. E. T., DANIEL E. E., JURY J., TRACK N. S., CHIU S., 1983. Cholinergic control mechanisms for immunoreactive motilin release and motility in the canine duodenum. Can. J. Physiol. Pharmacol., 61, 1042-1049.

FOX J. E. T., TRACK N. S., DANIEL E. E., 1981. Relationship of plasma motilin concentration to fat ingestion, duodenal acidification and alkalinization and migrating motor complexes in dogs. Can. J. Physiol. Pharmacol., 59, 180-187.

GAGINELLA T. S., O'DORISIO T. M., HUBEL K. A., 1981. Release of vasoactive intestinal polypeptide by electrical field stimulation of rabbit ileum. Regul. Peptides, 2, 165-174.

GREEN W. E. R., RUPPIN H., WINGATE D. L., DOMSCHKE W., WÜNSCH E., DEMLING L., RITCHIE H. D., 1976. Effects of 13-nle-motilin on the electrical and mechanical activity of the isolated perfused canine stomach and duodenum. Gut, 17, 362-370.

GREENBERG G. R., HALL K. E., MUI H., EL-SHARKAWY T. Y., DIAMANT N. E., 1980. Pancreatic polypeptide and migrating motor complexes in the dog : effect of vagal blockade. Regul. Peptides, Suppl. 1, S 44 (abstr.).

GREGORY P. C., 1982. Acid induction of migrating myoelectric complex in sheep, J. Physiol. (London), 332, 99P

GRIVEL M. L., RUCKEBUSCH Y., 1972. The propagation of segmental contractions along the small intestine. J. Physiol. (London), 227, 611-625.

GUSTAVSSON S., RÖNNBERG B., STÄHLE E., WADSTRÖM T., 1984. Disorganisation of the interdigestive small bowel motility by $E$. coli endotoxin in the rat, 299-304. In ROMAN C., Gastrointestinal motility. MTP Press Ltd, Lancaster.

HALL K. E., DIAMANT N. E., EL-SHARKAWY T. Y., GREENBERG G. R., 1983. Effect of pancreatic polypeptide on canine migrating motor complex and plasma motilin. Am. J. Physiol., 245, G178-G185.

HALL K. E., DIAMANT N. E., GREENBERG G. R., 1983. Motilin induced motor complexes are mediated by non-vagal cholinergic pathways. Regul. Peptides, Suppl. 2, S 83 (abstr.).

HALL K. E., EL-SHARKAWY T. Y., DIAMANT N. E., 1982. Vagal control of migrating motor complex in the dog. Am. J. Physiol., 243, G276-G284.

HELLEMANS J., VANTRAPPEN G., BLOOM S. R., 1976. Endogenous motilin and the LES pressure. Scand. J. Gastroenterol., 11 (suppl. 39), 67-73.

HELLEMANS J., VANTRAPPEN G., JANSSENS J., PEETERS T., 1977. Effect of feeding and of gastrin on the interdigestive myoelectrical complex in man, 29-30. In DUTHIE H. L., Gastrointestinal motility in health and disease. MTP Press Ltd., Lancaster.

HEPPELL J., BECKER J. M., KELLY K. A., ZINSMEISTER A. R., 1983. Postprandial inhibition of canine enteric interdigestive myoelectric complex. Am. J. Physiol., 244, G160-G164. 
HEPPELL J., KELLY K. A., SARR M. G., 1983. Neural control of canine small intestinal interdigestive myoelectric complexes. Am. J. Physiol., 244, G95-G100.

HUTTON M. R. E., DEAN P., WINGATE D. L., 1983. The effect of morphine on small bowel transit and electric spiking activity in conscious rats, 157-159. In LABO G., BORTOLOTTI M., Gastrointestinal motility. Cortina International Ed., Verona.

HUTTON M. R. E., WINGATE D. L., 1984. Modulation of rat small bowel motor activity by food and peptides, 349-353. In ROMAN C., Gastrointestinal motility. MTP Press Ltd., Lancaster.

ITOH Z., AIZAWA I., TAKEUCHI S., 1981. Neural regulation of interdigestive motor activity in canine jejunum. Am. J. Physiol., 240, G324-G330.

ITOH Z., HONDA R., AIZAWA I., 1980. Diurnal pH changes in duodenum of conscious dogs. Am. J. Physiol., 238, G91-G96.

ITOH Z., HONDA R., AIZAWA I., TAKEUCHI S., HIWATASHI K., COUCH E. F., 1978a. Interdigestive motor activity of the lower esophageal sphincter in the conscious dog. Am. J. Dig. Dis., 23, 239-247.

ITOH Z., HONDA R., HIWATASHI K., TAKEUCHI S., AIZAWA I., TAKAYANAGI R., COUCH E. F., 1976. Motilin induced mechanical activity in the canine alimentary tract. Scand. J. Gastroent., 11 (suppl. 39), 93-110.

ITOH Z., TAKAHASHI I., 1981. Periodic contractions of the canine gall bladder during the interdigestive state. Am. J. Physiol., 240, G183-G189.

ITOH Z., TAKAHASHI I., NAKAYA M., SUZUKI T., 1981. Variation in canine exocrine pancreatic secretory activity during the interdigestive state. Am. J. Physiol., 241, G98-G103.

ITOH Z., TAKAHASHI I., NAKAYA M., SUZUKI T., ARAI H., WAKABAYASHI K., 1982. Interdigestive gallbladder bile concentration in relation to periodic contraction of gallbladder in the dog. Gastroenterology, 83, 645-651.

ITOH Z., TAKAYANAGI R., TAKEUCHI S., ISSHIKI S., 1978b. Interdigestive motor activity of Heidenhain pouches in relation to main stomach in conscious dogs. Am. J. Physiol., 234, E333-E338.

ITOH Z., TAKEUCHI S., AIZAWA I., MORI K., TAMINATO T., SEINO Y., IMURA H., YANAIHARA N., 1978c. Changes in plasma motilin concentration and gastrointestinal contractile activity in conscious dogs. Am. J. Dig. Dis., 23, 929-935.

ITOH Z., TAKEUCHI S., AIZAWA I., TAKAYANAGI R., 1978d. Characteristic motor activity of the gastrointestinal tract in fasted conscious dogs measured by implanted force transducers. Am. J. Dig. Dis., 23, 229-238.

JANSSENS J., HELLEMANS J., ADRIAN T. E., BLOOM S. R., PEETERS T. L., CHRISTOFIDES N., VANTRAPPEN G., 1982. Pancreatic polypeptide is not involved in the regulation of the migrating motor complex in man. Regul. Peptides, 3, 41-49.

JANSSENS J., VANTRAPPEN G., PEETERS T. L., 1983. The activity front of the migrating motor complex of the human stomach but not of the small intestine is motilin-dependent. Regul. Peptides, 6, 363-369.

JUSTUS P. G., FERNANDEZ A., MARTIN J. L., KING C. E., TOSKES P. P., MATHIAS J. R., 1983. Altered myoelectric activity in the experimental blind loop syndrome. J. clin. Invest. 72, 10641071.

KEANE F. B., DIMAGNO E. P., DOZOIS R. R., GO V. L. W., 1980a. Relationships among canine interdigestive exocrine pancreatic and biliary flow, duodenal motor activity, plasma pancreatic polypeptide, and motilin. Gastroenterology, 78, 310-316.

KEANE F. B., DIMAGNO E. P., DOZOIS R. R., GO V. L. W., 1980b. Canine pancreatic exocrine secretion and levels of pancreatic polypeptide related to fasting duodenal motility, 319-321. In CHRISTENSEN J., Gastrointestinal motility. Raven Press, New York.

KEANE F. B., DIMAGNO E. P., MALAGELADA J. R., 1981. Duodenogastric reflux in humans ; its relationship to fasting antroduodenal motility and gastric, pancreatic and biliary secretion. Gastroenterology, 81, 726-731.

KERLIN P., PHILLIPS S. G., 1982. Variability of motility of the ileum and jejunum in healthy humans. Gastroenterology, 82, 694-700.

KERLIN P., ZINSMEISTER A., PHILLIPS S., 1982. Relationship of motility to flow of contents in the human small intestine. Gastroenterology, 82, 701-706. 
KONTUREK S. J., 1984. Gastrointestinal hormones and intestinal motility, 593-612. In ROMAN C., Gastrointestinal motility. MTP Press Ltd., Lancaster.

KÖRNER M. M., ALTAPARMAKOV I., WIENBECK M., 1983. Slow wave and spike activity in the feline gut after prolonged fasting, 203-206. In : LABO G., BORTOLOTTI M., Gastrointestinal motility. Cortina International Ed., Verona.

KRAGLUND K., HJERMIND J., JENSEN F. T., JORGENSEN E. O., PEDERSEN S. A., 1983. The relationship between gastro intestinal cyclic motor activity and gallbladder emptying in humans. Gastroenterol, clin. biol,, 7, 702 (abstr.).

LAPLACE J. P., 1968. Sur les phénomènes mécaniques et électriques du tractus digestif chez le mouton. 200 pp. Th. Doct. Sci. biol. (Physiol. anim.), Univ. Lyon.

LAPLACE J. P., 1978a. Organisation de la motricité de l'intestin grêle chez le porc et influence de I'alimentation. Ann. Zootech., 27, 377-408.

LAPLACE J. P., 1978b. Observations préliminaires sur quelques effets du lactose chez le Porc: Complexes myoélectriques de l'intestin grêle, motricité caecale et diarrhée. Ann. Zootech., 27, 495-517.

LAPLACE J. P., 1980. Stomach and small intestine motility in the pig: electromyography in nutritional studies, 24-47. In LOW A. G., PARTRIDGE I. G., Current concepts of digestion and absorption in pigs. N.I.R.D. Press, Reading.

LAPLACE J. P., 1981. The transit of digesta in the different parts of the digestive tract of the pig, 847-872. In HARPER A. E., DAVIS G. K., Nutrition in health and disease and international development. Alan Liss Ed., New York.

LAPLACE J. P., ROMAN C., 1979. Activités de la musculature gastrointestinale et mouvements des contenus digestifs. Ann. Biol, anim. Bioch. Biophys., 19, 849-879.

LAWSON M., EVERSON G. T., KLINGENSMITH W., KERN F., 1983. Coordination of gastric and gallbladder emptying after ingestion of a regular meal. Gastroenterology, 85, 866-870.

LEE K. Y., CHEY W. Y., TAI H. H., YAJIMA H., 1978. Radio immunoassay of motilin. Validation and studies on the relationship between plasma motilin and interdigestive myoelectric activity of the duodenum of dog. Am. J. Dig. Dis., 23, 789-795.

LEE K. Y., CHEY W. Y., TAI H. H., WAGNER D., YAJIMA H., 1977. Cyclic changes in plasma motilin levels and interdigestive myoelectric activity of canine antrum and duodenum. Gastroenterology, 72, 1162 (abstr.).

LEE K. Y., KIM M. S., CHEY W. Y., 1980. Effects of a meal and gut hormones on plasma motilin and duodenal motility in dog. Am. J. Physiol., 238, G280-G283.

LUX G., FEMPPEL J., LEDERER P., ADRIAN T., ROSCH W., BLOOM S. R., DOMSCHKE W., 1980a. Pancreatic polypeptide, motilin and somatostatin levels during interdigestive motility in man. Gastroenterology, 78, 1212 (abstr.).

LUX G., FEMPPEL J., LEDERER P., ROSCH W., DOMSCHKE W., 1980b. Somatostatin induces interdigestive intestinal motor and secretory complex-like activity in man. Gastroenterology, 78, 1212 (abstr.).

LUX G., LEDERER P., FEMPPEL J., SCHMACK B., RÖSCH W., DOMSCHKE W., 1980c. Motor and secretory activity of the duodenal interdigestive complex : an integrated function, 311318. In CHRISTENSEN J., Gastrointestinal motility. Raven Press, New York.

LUX G., STRUNZ U., DOMSCHKE S., FEMPPEL J., MITZNEGG P., RÖSCH W., DOMSCHKE W., 1978. Motilin and interdigestive myoelectric and motor activity of small intestine in man : Lack of causal relationship. Scand. J. Gastroenterol., 13 (suppl. 49), 118 (abstr.).

MACAGNO E. O., CHRISTENSEN J., LEE C. L., 1982. Modeling the effect of wall movement on absorption in the intestine. Am. J. Physiol., 243, G541-G550.

MARIK F., CODE C. F., 1975. Control of the interdigestive myoelectric activity in dogs by the vagus nerves and pentagastrin. Gastroenterology, 69, 387-395.

MARLETT J. A., CODE C. F., 1979. Effects of celiac and superior mesenteric ganglionectomy on interdigestive myoelectric complex in dogs. Am. J. Physiol., 237, E432-E436.

MATHIAS J. R., CARLSON G. M., DI MARINO A. J., BERTIGER G., MORTON H. E., COHEN S., 1976. Intestinal myoelectric activity in response to live Vibrio cholera and cholera enterotoxin. J. clin. Invest., 58, 91-96.

McRAE S. M., YOUNGER K., THOMPSON D. G., WINGATE D. L., 1982. Sustained mental stress alters human jejunal motor activity. Gut, 23, 404-409. 
MELVILLE J., MACAGNO E., CHRISTENSEN J., 1975. Longitudinal contractions in the duodenum : their fluid-mechanical function. Am. J. Physiol., 228, 1887-1892.

MIOLAN J. P., ROMAN C., 1978. Discharge of efferent vagal fibers supplying gastric antrum : indirect study by nerve suture technique. Am. J. Physiol., 235, E366-E373.

MITZNEGG P., BLOOM S. R., CHRISTOFIDES N., BESTERMAN H., DOMSCHKE W., DOMSCHKE S., WÜNSCH E., DEMLING L., 1976. Release of motilin in man. Scand. J. Gastroenterol., 11 (suppl. 39), 53-56.

MODLIN I. M., MITZNEGG P., BLOOM S. R., 1978. Motilin release in the pig. Gut, 19, 399-402.

MORGAN K. G., SCHMALZ P. F., SZURSZEWSKI J. H., 1978. The inhibitory effects of vasoactive intestinal polypeptide on the mechanical and electrical activity of canine antral smooth muscle. J. Physiol. (London), 282, 437-450.

MORI K., SEINO Y., ITOH Z., YANAIHARA N., IMURA H., 1981. Motilin release by intravenous infusion of nutrients and somatostatin in conscious dogs. Regul. Peptides, 1, 265-270.

MUKHOPADHYAY A. K., THOR P. J., COPELAND E. M., JOHNSON L. R., WEISBRODT N. W. 1977. Effect of cholecystokinin on myoelectric activity of small bowel of the dog. Am. J. Physiol., 232, E44-E47.

NAKANOME C., AKAI H., HONGO M., IMAI N., TOYOTA T., GOTO Y., OKUGUCHI F., KOMATSU K., 1983. Disturbances of the alimentary tract motility and hypermotilinemia in the patients with diabetes mellitus. Tohoku J. exp. Med, 139, 205-215.

NAKAYAMA S., MIZUTANI M., NEYA T., TAKAKI M., 1981. Effect of motilin on gallbladder and gastroduodenal motility in dogs. Ital. J. Gastroenterol, 13, 6-9.

OLIVEIRA R. B., MENEGHELli U. G., DE GODOY R. A., DANTAS R. O., PADOVAN W., 1983. Abnormalities of interdigestive motility of the small intestine in patients with Chagas' disease. Dig. Dis. Sci, 28, 294-299.

ORMSBEE H. S., KOEHLER S. L., TELFORD G. L., 1978. Somatostatin inhibits motilin induced interdigestive contractile activity in the dog. Am. J. Dig. Dis., 23, 781-788.

ORMSBEE H. S., TELFORD G. L., MASON G. R., 1979. Required neural involvement in control of canine migrating motor complex. Am. J. Physiol., 237, E451-E456.

ORMSBEE H. S., TELFORD G. L., SUTER C. M., WILSON P. D., MASON G. R., 1981. Mechanism of propagation of canine migrating motor complex - a reappraisal. Am. J. Physiol., 240, G141-G146.

OWYANG C., ACHEM-KARAM S. R., VINIK A. I., 1983. Pancreatic polypeptide and intestinal migrating motor complex in humans. Effect of pancreatico biliary secretion. Gastroenterology, 84, 10-17.

OWYANG C., FUNAKOSHI A., VINIK A. I., 1983. Evidence for modulation of motilin secretion by pancreatic biliary juice in health and in chronic pancreatitis. J. clin. Endocrinol. Metab., 57, 1015-1020.

PASCAUD X., FERRE J. P., GENTON M., ROGER A., RUCKEBUSCH M., BUENO L., $1982 . \quad$ Intestinal motility responses to insulin and glucagon in streptozotocin diabetic rats. Can. J. Physiol. Pharmacol., 60, 960-967.

PEARCE E. A. N., WINGATE D., 1980. Myoelectric and absorptive activity in the transected canine small bowel. J. Physiol. (London), 302, 11-12P.

PEETERS T. L., JANSSENS J., VANTRAPPEN G., 1983. Somatostatin and the interdigestive migrating motor complex in man. Regul. Peptides, 5, 209-217.

PEETERS T. L., VANTRAPPEN G., JANSSENS J., 1980a. Bile acid output and the interdigestive migrating motor complex in normals and cholecystectomy patients. Gastroenterology, 79, 678-681.

PEETERS T. L., VANTRAPPEN G., JANSSENS J., 1980b. Fasting plasma motilin levels are related to the interdigestive motility complex. Gastroenterology, 79, 716-719.

PEETERS T. L., VANTRAPPEN G., JANSSENS J., 1983a. Somatostatin has a physiological role in the regulation of the migrating motor complex (MMC) in man, 9-10. In LABO G., BORTOLOTTI M., Gastrointestinal motility. Cortina International Ed., Verona.

PEETERS T. L., VANTRAPPEN G., JANSSENS J., 1983b. Sham-feeding amplifies the secretory component of interdigestive activity. Gastroenterol. clin. biol., 7, 722 (abstr.).

PINNINGTON J., WINGATE D. L., 1983. The effects of motilin on periodic myoelectric spike activity in intact and transected canine small intestine. J. Physiol. (London), 337, 471-478. 
POITRAS P., STEINBACH J. H., VAN DEVENTER G., CODE C. F., WALSH J. H., 1980. Motilinindependent ectopic-fronts of the interdigestive myoelectric complex in dogs. Am. J. Physiol., 239, G215-G220.

RAYNER V., WEEKES T. E. C., 1978. Feeding disrupts the migrating myoelectric complex : is insulin the cause ? J. Physiol. (London), 276, 61P-62P.

RAYNER V., WEEKES T. E. C., BRUCE J. B., 1981. Insulin and myoelectric activity of the small intestine of the pig. Dig. Dis. Sci, 26, 33-41.

RAYNER V., WENHAM G., WHITE F., RHIND S. M., BRUCE J. B., 1980. Digesta transit by X-ray screening, glucose absorption, insulin secretion, and the migrating myoelectric complex in the pig, 253-260. In CHRISTENSEN J., Gastrointestinal motility. Raven Press, New York.

READ N. W., CAMMACK J., EDWARDS C., HOLGATE A. M., CANN P. A., BROWN C., 1982. Is the transit time of a meal through the small intestine related to the rate at which it leaves the stomach ? Gut, 23, 824-828.

REES W. D. W., LEIGH R. J., CHRISTOFIDES N. D., BLOOM S. R., TURNBERG L. A., 1982. Interdigestive motor activity in patients with systemic sclerosis. Gastroenterology, 83. 575-580.

RÉRAT A., AUMAITRE A., VAISSADE P., VAUGELADE P., 1977. Etude expérimentale qualitative de l'absorption des glucides après ingestion d'un repas à base de lactose chez le Porc. Ann. Biol. anim. Bioch. Biophys., 17, 589-596.

RÉRAT A., VAUGELADE P., VILLIERS P., 1980. A new method for measuring the absorption of nutrients in the pig : critical examination, 177-214. In LOW A. G., PARTRIDGE I. G., Current concepts of digestion and absorption in pigs. N:I.R.D. Press, Reading.

REVERDIN N., HUTTON M. R., LING A., THOMPSON H. H., WINGATE D. L., CHRISTOFIDES N., ADRIAN T. E., BLOOM S. R., 1980. Vagotomy and the motor response to feeding, 359-364. In CHRISTENSEN J., Gastrointestinal motility. Raven Press, New York.

RICHARDSON K. C., WYBURN R. S., 1983. Electromyographic events in the stomach and small intestine of a small kangaroo, the tammar wallaby (Macropus eugenii), J. Physiol. (Lond.), 342, 453-463.

ROCHE M., 1974. Motricité gastrointestinale chez le poulet. Ann. Rech. vét., 5, 295-309.

ROCHE M., BUENO L., VAGNE M., BLOURDE C., 1982. Patterns of electrical activity in the digestive tract of the conscious cat. Br. J. Nutr., 48, 129-135.

ROCHE M., DECERPRIT J., 1977. Contrôle hormonal et nerveux de la motricité du tractus digestif de la poule. Ann. Rech. vét., 8, 25-40.

ROCHE M., RUCKEBUSCH Y., ACHARD F., 1983. Effects of mash diet and pellets upon digestive motor functions in domestic hens and guinea hens. Can. J. anim. Sci., 63, 663-669.

ROZÉ C., DUBRASOUET M., 1983. Endorphines, enképhalines et tube digestif. Gastroenterol. clin. biol., 7, 177-188.

RUCKEBUSCH M., FERRÉ J. P., 1973. Origine alimentaire des variations nycthémérales de l'activité électrique de l'intestin grêle chez le rat. C. R. Soc. Biol., 167, 2005-2009.

RUCKEBUSCH M., FIORAMONTI J., 1975a. Electrical spiking activity and propulsion in small intestine in fed and fasted rats. Gastroenterology, 68, 1500-1508.

RUCKEBUSCH M., FIORAMONTI J., 1975b. Insulino sécrétion et motricité intestinale. $C$. $R$. Soc. Biol., 169, 435-439.

RUCKEBUSCH M., WEEKES T. E. C., 1976. Insulin resistance and related electrical activity of the small intestine. Experientia, 32, 1163-1165.

RUCKEBUSCH Y., 1973. Les particularités motrices du jéjuno-iléon chez le cheval. Cah. Méd. vét., 42, 128-143.

RUCKEBUSCH Y., 1976. Interaction of duodenal and antral activity in sheep and dogs. J. Physiol. (London), 254, 79P.

RUCKEBUSCH Y., 1981. Motor functions of the intestine. Adv. vet. Sci. comp. Med., 25, 345-369.

RUCKEBUSCH Y., BUENO L., 1973. The effect of weaning on the motility of the small intestine in the calf. Br. J. Nutr., 30, 491-499.

RUCKEBUSCH Y., BUENO L., 1975. Electrical activity of the ovine jejunum and changes due to disturbances. Am. J. Dig. Dis., 20, 1027-1033.

RUCKEBUSCH Y., BUENO L., 1976. The effect of feeding on the motility of the stomach and small intestine in the pig. Br. J. Nutr., 35, 397-405. 
RUCKEBUSCH Y., BUENO L., 1977a. Origin of migrating myoelectric complex in sheep. Am. J. Physiol., 233, E483-E487.

RUCKEBUSCH Y., BUENO L., 1977b. Migrating myoelectrical compiex of the small intestine. An intrinsic activity mediated by the vagus. Gastroenterology, 73, 1309-1314.

RUCKEBUSCH Y., BUENO L., FIORAMONTI J., 1981. La mécanique digestive chez les mammifères. Actualités Scientifiques et Agronomiques, $n^{\circ} 7$, Masson Ed., Paris.

RUCKEBUSCH Y., DARDILLAT C., HATEY F., 1972. La motricité intestinale chez le veau nouveauné. Influence du repas. C. R. Soc. Biol., 166, 1547-1551.

RUCKEBUSCH Y., LAPLACE J. P., 1967. La motricité intestinale chez le mouton éveillé : phénomènes mécaniques et électriques. C. R. Soc. Biol., 161, 2517-2523.

SARNA S., CHEY W. Y., CONDON R. E., DODDS W. J., MYERS T., CHANG T. M., 1983. Causeand-effect relationship between motilin and migrating myoelectric complexes. Am. J. Physiol., 245, G277-G284.

SARNA S., CONDON R. E., COWLES V., 1983a. Enteric mechanisms of initiation of migrating myoelectric complexes in dogs. Gastroenterology, 84, 814-822.

SARNA S., CONDON R. E., COWLES V., 1983b. Morphine versus motilin in the initiation of migrating myoelectric complexes. Am. J. Physiol., 245, G217-G220.

SARNA S., NORTHCOTT P., BELBECK L., 1982. Mechanism of cycling of migrating myoelectric complexes : effect of morphine. Am. J. Physiol., 242, G588-G595.

SARNA S., STODDARD Ch., BELBECK L., McWADE D., 1981. Intrinsic nervous control of migrating myoelectric complexes. Am. J. Physiol, 241, G16-G23.

SARR M. G., KELLY K. A., 1980. Patterns of movement of liquids and solids through canine jejunum. Am. J. Physiol., 239, G497-G503.

SARR M. G., KELLY K. A., 1981. Myoelectric activity of the autotransplanted canine jejuno ileum. Gastroenterology, 81, 303-310.

SARR M. G., KELLY K. A., GO V. L. W., 1983. Motilin regulation of canine interdigestive intestinal motility. Dig. Dis. Sci, 28, 249-256.

SARR M. G., KELLY K. A., PHILLIPS S. F., 1980. Canine jejunal absorption and transit during interdigestive and digestive motor states. Am. J. Physiol., 239, G167-G172.

SCHAFFALITZKY DE MUCKADELL O. B., FAHRENKRUG J., HOLST J. J., 1977. Release of vasoactive intestinal polypeptide (V.I.P.) by electric stimulation of the vagal nerves. Gastroenterology, 72, 373-375.

SCHAFFALITZKY DE MUCKADELL O. B., FAHRENKRUG J., HOLST J. J., LAURITSEN K. B., 1977. Release of vasoactive intestinal polypeptide (V.I.P.) by intraduodenal stimuli. Scand. J. Gastroent., 12, 793-799.

SCHANG J. C., ANGEL F., LAMBERT A., CRENNER F., APRAHAMIAN M., GRENIER J. F., 1981a. Inhibition of canine duodenal interdigestive myoelectric complex by nutrient perfusion of jejunal and ileal Thiry-Vella loops. Gut, 22, 738-743.

SCHANG J. C., DAUCHEL J., SAVA P., ANGEL F., BOUCHET P., LAMBERT A., GRENIER J. F., 1978. Specific effects of different food components on intestinal motility. Eur. Surg. Res., 10, 425-432.

SCHANG J. C., SAVA P., ANGEL F., BOUCHET P., GRENIER J. F., 1980. Fat induced postprandial intestinal motility; relation between its duration and lipidic ileal output in the dog, 353-357. In : CHRISTENSEN J., Gastrointestinal motility, Raven Press, New York.

SCHANG J. C., SAVA P., ANGEL F., LAMBERT A., MARESCAUX J., GRENIER J. F., 1981b. Influence de l'absorption intestinale sur la motricité de l'intestin grêle. Etude électromyographique chez le Chien. Gastroenterol. clin. biol., 5, 490-496.

SCHEMANN M., EHRLEIN H. J., 1983. Motility patterns of the canine jejunum, 196-200. In LABO G., BORTOLOTTI M., Gastrointestinal motility. Cortina International Ed., Verona.

SCHWARTZ T. W., HOLST J. J., FAHRENKRUG J., LINDKAER-JENSEN S., NIELSEN O. V., REHFELD J. F., SCHAFFALITZKY DE MUCKADELL O. B., STADIL F., 1978. Vagal cholinergic regulation of pancreatic polypeptide secretion. J. clin. Invest., 61, 781-789.

SCOTT L. D., CAHALL D. L., 1982. Influence of the interdigestive myoelectric complex on enteric flora in the rat. Gastroenterology, 82, 737-745.

SCOTT L. D., LESTER R., VANTHIEL D. H., WALD A., 1983a. Pregnancy-related changes in small intestinal myoelectric activity in the rat. Gastroenterologv, 84, 301-305. 
SCOTT L. D., SUMMERS R. W., 1976. Correlation of contractions and transit in rat small intestine. Am. J. Physiol., 230, 132-137.

SCOTT R. B., EL-SHARKAWY T. Y., DIAMANT N. E., 1983. Propagation of the canine migrating myoelectric complex - a mathematical model. Am. J. Physiol., 244, G13-G19.

SCOTT R. B., STRASBERG S. M., EL-SHARKAWY T. Y., DIAMANT N. E., 1983b. Fasting biliary secretion and the sphincter of Oddi. Gastroenterol. clin. biol., 7, 713 (abstr.).

SISSONS J. W., 1983. Effect of feed intake on digesta flow and myoelectric activity in the gastrointestinal tract of the preruminant calf. J. Dairy Res., 50, 387-395.

SISSONS J. W., SMITH R. H., 1979. Digesta movement and gut motility in the preruminant calf. Ann. Rech. vét., 10, 176-178.

SJÖGREN R. W., WARDLOW M., CHARLES L. G., 1984. Stimulation of action potential complexes by fluid distension of rabbit small intestine. Evidence that migrating action potential complexes are a non-specific myoelectric response, 311-318. In ROMAN C., Gastrointestinal motility, MTP Press Ltd., Lancaster.

SNINSKY C. A., WOLFE M. M., MARTIN J. L., HOWE B. A., O'DORISIO T. M., McGUIGAN J. E., MATHIAS J.R., 1983. Myoelectric effects of vasoactive intestinal peptide on rabbit small intestine. Am. J. Physiol., 244, G46-G51.

STODDARD C. J., SMALLWOOD R. H., DUTHIE H. L., 1978. Migrating myoelectrical complexes in man, 9-15. In DUTHIE H. L., Gastrointestinal motility in health and disease. MTP Press Ltd, Lancaster.

SUMMERS R. W., CRAMER J., FLATT A. J., 1982. Computerized analysis of spike burst activity in the small intestine. IEEE Trans. Biomed. Eng., 29, 309-314.

SUMMERS R. W., DUSDIEKER N. S., 1981. Patterns of spike burst spread and flow in the canine small intestine. Gastroenterology, 81, 742-750.

SUMMERS R. W., HELM J., CHRISTENSEN J., 1976. Intestinal propulsion in the dog. Its relation to food intake and the migratory complex. Gastroenterology, 70, 753-758.

SVENBERG T., CHRISTOFIDES N. D., FITZPATRICK M. L., AREOLA-ORTIZ F., BLOOM S. R., WELBOURN R. B., 1982. Interdigestive biliary output in man : Relationship to fluctuations in plasma motilin and effect of atropine. Gut, 23, 1024-1028.

SZURSZEWSKI J. H., 1969. A migrating electric complex of the canine small intestine. Am. J. Physiol., 217, 1757-1763.

SZURSZEWSKI J. H., CODE C. F., 1968. Activity fronts of the canine small intestine. Gastroenterology, 54, 1304 (abstr.).

TAKEUCHI S., AIZAWA I., TAKAYANAGI R., ITOH Z., 1980. Interdigestive migrating contractions in short bowel dogs. Gastroenterol. Jpn., 15, 199-206.

TELFORD G. L., SZURSZEWSKI J. H., 1983. Blockade of migrating myoelectric complexes by naloxone. Gastroenterol. clin. biol., 7, 717-718 (abstr.).

THOMPSON D. G., ARCHER L., GREEN W. J., WINGATE D. L., 1981. Fasting motor activity occurs during a day of normal meals in healthy subjects. Gut. 22, 489-492.

THOMPSON D. G., RICHELSON E., MALAGELADA J. R., 1982. Perturbation of gastric emptying and duodenal motility through the central nervous system. Gastroenterology, 83, 1200-1206.

THOMPSON D. G., WINGATE D. L., ARCHER L., BENSON M. J., GREEN W. J., HARDY R. J., 1980. Normal patterns of human upper small bowel motor activity recorded by prolonged radiotelemetry. Gut, 21, 500-506.

THOR P. J., KONTUREK J. W., SENDUR R., KONTUREK S. J., 1984. Comparison of neurotensin and fat on myoelectric activity pattern of the small bowel, 343-348. In ROMAN C., Gastrointestinal motility, MTP Press Ltd., Lancaster.

THOR P., KROL R., KONTUREK S. J., COY D. H., SCHALLY A. V., 1978. Effect of somatostatin on myoelectrical activity of small bowel. Am. J. Physiol., 235, E249-E254.

THOR K., ROSELL S., ROKAEUS A., KAGER L., $1982 . \quad\left(\mathrm{Gln}^{4}\right.$ )-neurotensin changes the motility pattern of the duodenum and proximal jejunum from a fasting-type to a fed-type. Gastroenterology, 83, 569-574.

THOR P. J., SENDUR R., KONTUREK S. J., 1982. Influence of substance $P$ on myoelectric activity of the small bowel. Am. J. Physiol., 243, G493-G496.

VALORI R. M., WINGATE D. L., PATRICK M. P. H., RAIMAN A., PARNHAM A. P., 1983. The inhibition of the human fasting motor complex (MC) by prolonged but intermittent mental

Reproduction, Nutrition, Développement $n^{\circ} 5$ B 1984. -7. 
stress, 13-14. In LABO G., BORTOLOTTI M., Gastrointestinal motility. Cortina International Ed., Verona.

VANTRAPPEN G., JANSSENS J., HELLEMANS J., CHRISTOFIDES N., BLOOM S. R., 1978a. Studies on the interdigestive (migrating) motor complex in man, 3-6. In DUTHIE H. L., Gastrointestinal motility in health and disease, MTP Press Ltd, Lancaster.

VANTRAPPEN G., JANSSENS J., HELLEMANS J., GHOOS Y., 1977. The interdigestive motor complex of normal subjects and patients with bacterial overgrowth of the small intestine. $J$. clin. Invest., 59, 1158-1166.

VANTRAPPEN G., JANSSENS J., PEETERS T. L., BLOOM S. R., CHRISTOFIDES N. D., HeLLEMANS J., 1979. Motilin and the interdigestive migrating motor complex in man. Dig. Dis. Sci., 24, 497-500.

VANTRAPPEN G., JANSSENS J., PEETERS T. L., BLOOM S., VANTONGEREN J., HELLEMANS J., 1978b. Does motilin have a role in eliciting the interdigestive migrating motor complex (MMC) in man ? Gastroenterology, 74, 1149 (abstr.).

VANTRAPPEN G., PEETERS T. L., JANSSENS J., 1979a. The interdigestive complexes of man have both secretory and motor components. Gastroenterology, 76, 1264 (abstr.).

VANTRAPPEN G., PEETERS T. L., JANSSENS J., 1979b. The secretory component of the interdigestive migrating motor complex in man. Scand. J. Gastroent., 14, 663-667.

WATERFALL W. E., 1983. Electrical patterns in the human jejunum with and without vagotomy : Migrating myoelectrical complexes and the influence of morphine. Surgery, 94, 186-190.

WEEMS W. A., 1982. Intestinal wall motion, propulsion and fluid movement: Trends toward a unified theory. Am. J. Physiol., 243, G177-G188.

WEISBERG P. B., CARLSON G. M., COHEN S., 1978. Effect of Salmonella typhimurium on myoelectrical activity in the rabbit ileum. Gastroenterology, 74, 47-51.

WEISBRODT N. W., 1981. Patterns of intestinal motility. Ann. Rev. Physiol., 43, 21-31.

WEISBRODT N. W., CHRISTENSEN J., 1972. Electrical activity of the cat duodenum in fasting and vomiting. Gastroenterology, 63, 1004-1010.

WEISBRODT N. W., COPELAND E. M., KEARLEY R. W., MOORE E. P., JOHNSON L. R., 1974. Effects of pentagastrin on electrical activity of small intestine of the dog. Am. J. Physiol., 227, 425-429.

WEISBRODT N. W., COPELAND E. M., MOORE E. P., KEARLEY R. W., JOHNSON L. R., 1975a. Effect of vagotomy on electrical activity of the small intestine of the dog. Am. J. Physiol., 228, 650-654.

WEISBRODT N. W., COPELAND E. M., THOR P. J., DUDRICK S. J., 1976. The myoelectric activity of the small intestine of the dog during total parenteral nutrition. Proc. Soc. exp. Biol. Med., 153, 121-124.

WEISBRODT N. W., COPELAND E. M., THOR P. J., MUKHOPADHYAY A. K., JOHNSON L. R., 1975b. Nervous and humoral factors which influence the fasted and fed patterns of intestinal myoelectric activity, 82-87. In VANTRAPPEN G., Proc. 5th int. Symp. G.I. Motility. Typoff-Press, Leuven.

WILEN T., GUSTAVSSON S., JUNG B., 1982. Effects of neurotensin on small bowel propulsion in intact and vagotomized rats. Regul. Peptides, 4, 191-201.

WINGATE D. L., 1981. Backwards and forewards with the migrating complex. Dig. Dis. Sci, 26. 641-666.

WINGATE D. L., PEARCE E. A., HUTTON M., DAND A., THOMPSON H. H., WÜNSCH E., 1978. Quantitative comparison of the effects of cholecystokinin, secretin, and pentagastrin on gastrointestinal myoelectric activity in the conscious fasted dog. Gut, 19, 593-601.

WINGATE D. L., RUPPIN H., GREEN W. E. R., THOMPSON H. H., DOMSCHKE W., WÜNSCH E., DEMLING L., RITCHIE H. D., 1976. Motilin induced electrical activity in the canine gastrointestinal tract. Scand. J. Gastroenterologv, 11 (suppl. 39), 111-118.

WINGATE D. L., RUPPIN H., THOMPSON H. H., GREEN W. E. R., DOMSCHKE W., WÜNSCH E., DEMLING L., RITCHIE H. D., 1975. 13-Norleucine motilin versus pentagastrin : contrasting and competitive effects on gastrointestinal myoelectrical activity in the conscious dog. Acta hepatogastroenterol., 22, 409-410.

WINGATE D. L., RUPPIN H., THOMPSON H. H., GREEN W. E. R., DOMSCHKE W., WÜNSCH E., DEMLING L., RITCHIE H. D., 1977. The gastrointestinal myoelectric response to 13-Nle- 
Motilin infusion during interdigestive and digestive states in the conscious dog. Acta hepatogastroenterol., 24, 278-287.

WOOD J. D., 1980. Intracellular study of effects of morphine on electrical activity of myenteric neurons in cat small intestine. Gastroenterology, 79. 1222-1230.

WOZNIAK E., FENTON T. R., MILLA P. J., 1984. The development of fasting small intestinal motility in the human neonate, 265-270. In ROMAN C., Gastrointestinal motility. MTP Press Ltd., Lancaster.

YOU C. H., CHEY W. Y., LEE K. Y., 1980. Studies on plasma motilin concentration and interdigestive motility of the duodenum in humans. Gastroenterology, 79, 62-66. 